\title{
Evaluation of object attributes to study speed-accuracy trade-off of gloves using ISO 9241-411 standard
}

\author{
Isha Gaut \\ ig0009@mix.wvu.edu
}

Follow this and additional works at: https://researchrepository.wvu.edu/etd

Part of the Industrial Engineering Commons

\section{Recommended Citation}

Gaut, Isha, "Evaluation of object attributes to study speed-accuracy trade-off of gloves using ISO 9241-411 standard" (2020). Graduate Theses, Dissertations, and Problem Reports. 7971.

https://researchrepository.wvu.edu/etd/7971

This Thesis is protected by copyright and/or related rights. It has been brought to you by the The Research Repository @ WVU with permission from the rights-holder(s). You are free to use this Thesis in any way that is permitted by the copyright and related rights legislation that applies to your use. For other uses you must obtain permission from the rights-holder(s) directly, unless additional rights are indicated by a Creative Commons license in the record and/ or on the work itself. This Thesis has been accepted for inclusion in WVU Graduate Theses, Dissertations, and Problem Reports collection by an authorized administrator of The Research Repository @ WVU. For more information, please contact researchrepository@mail.wvu.edu. 


\title{
Evaluation of object attributes to study speed-accuracy trade-off of gloves using ISO 9241-411 standard
}

\section{Isha Gaut}

Thesis submitted to the

Benjamin M. Statler College of Engineering and Mineral Resources at

West Virginia University

in partial fulfillment of the requirement for the degree of

\author{
Master of Science \\ in \\ Industrial Engineering
}

\author{
Ashish D. Nimbarte, Ph.D., Chair \\ Alan McKendall, Ph.D. \\ Bhaskaran Gopalakrishnan, Ph.D.
}

Department of Industrial and Management Systems Engineering

Morgantown, West Virginia

September 2020

Keywords: Fitts' Law; Speed-Accuracy Trade-off; Gloves; Throughput

Copyright 2020 Isha Gaut 


\title{
Abstract \\ Evaluation of object attributes to study speed-accuracy trade-off of gloves using ISO 9241-411 standard
}

\begin{abstract}
Isha Gaut
Selection of appropriate gloves plays an important role in the overall comfort and productivity of workers. Currently, there are no standards and/or guidelines available to systematically evaluate the glove performance based on speed-accuracy trade-off. The ISO 9241-411 standard which is based on Fitts' Law has been extensively used in the literature to measure speed-accuracy trade-off in terms of throughput in the virtual environments. This study was aimed at developing guidelines for implementing ISO 9241-411 standard in the physical environment so that it can be used to estimate (and compare) throughputs of safety gloves. Specifically, the various physical attributes of objects used in the target transfer tasks (within the ISO 9241-411 standard) were evaluated using an experimental study. Fifteen healthy subjects performed a series of target transfer tasks using three glove conditions (barehand, glove type 1, glove type 2), three object heights (0.28", $0.43 ", 0.88^{\prime \prime)}$, two object materials (nylon, stainless-steel) and two object shapes (circular, hexagonal). The main effect of glove condition was statistically significant. The mean throughput for the barehand was 3.61 $\mathrm{bits} / \mathrm{sec}$, and for glove types 1 and 2, the mean throughputs were $3.36 \mathrm{bits} / \mathrm{sec}$ and $3.31 \mathrm{bits} / \mathrm{sec}$, respectively. The interaction effect of object height with object material was statistically significant. The mean throughput for $0.88^{\prime \prime}$ stainless-steel objects $(2.99 \mathrm{bits} / \mathrm{sec})$ was significantly different from 0.88 " nylon objects $(3.13 \mathrm{bits} / \mathrm{sec})$, but for 0.28 " and 0.43 " objects, there was no difference in the mean throughput due to difference in the material. The main effect of object shape was statistically insignificant. Based on the additional analysis of different statistical measures, the stainless-steel 0.88 " circular object was found to perform better compared to other objects in terms of its ability to distinguish different glove conditions. In summary, this study concludes that it is possible to use ISO 9241-411 standard in a 3-D physical environment to compare barehanded exertions with gloved exertions. However, it cannot be said conclusively that the standard can be used for comparing different gloves.
\end{abstract}




\section{Acknowledgements}

It is my pleasure to acknowledge and say thanks to all the people who have been instrumental in the endeavor of completing my master's thesis. First, I would like to extend my sincere gratitude to my committee chair, Dr. Ashish Nimbarte, for providing me an opportunity to work under him. His constant guidance, encouragement and support has helped me in achieving this milestone.

I owe my deepest gratitude to the other members of my committee, Dr. Alan McKendall and Dr. Bhaskaran Gopalakrishnan, for their assistance and invaluable suggestions.

I am highly indebted to the subjects who extended their help and participated in the experiments. I would like to thank my colleagues and staff of the Industrial Engineering department for offering their kind assistance in many ways.

I am deeply grateful to my family and friends for their moral support and having faith in me. Lastly, I want to thank everyone else who may have helped me directly or indirectly in the completion of my thesis. 


\section{Table of Contents}



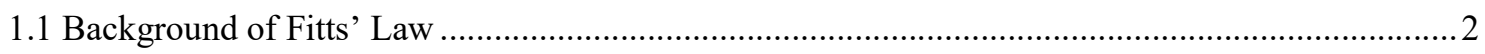

1.2 Application of Fitts’ Law in Human-Computer Interaction .......................................................

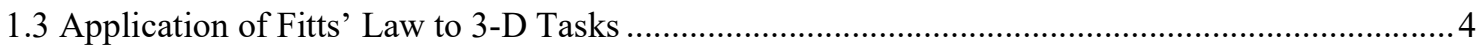

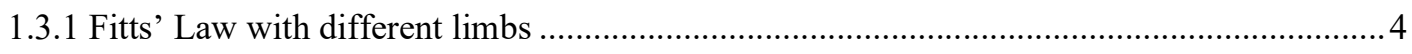

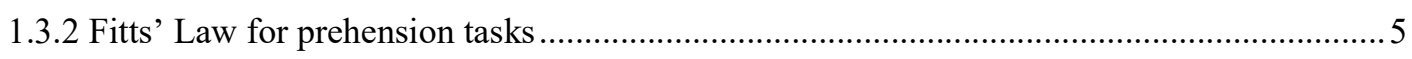

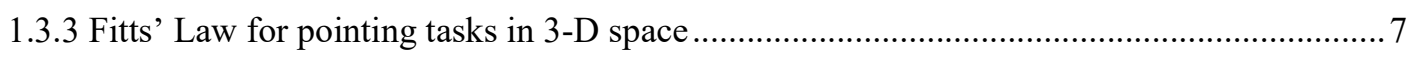

1.4 Effects of Gloves on Hand Performance Capabilities..................................................................

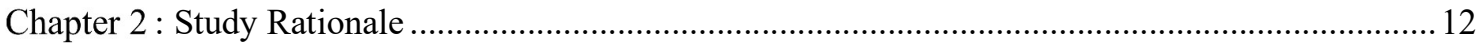

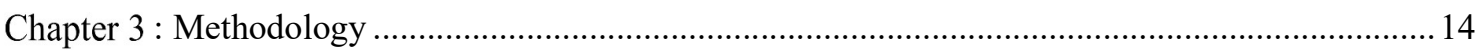

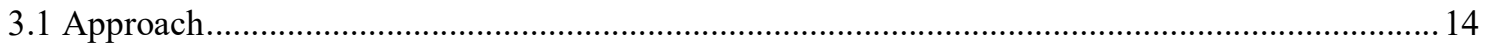

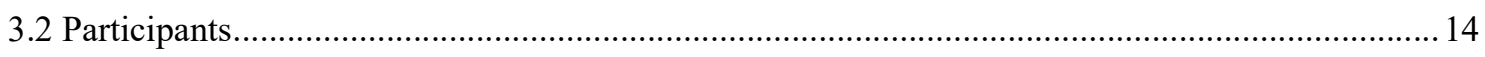

3.2.1 Sample Size Determination and Statistical Power Analysis ............................................. 14

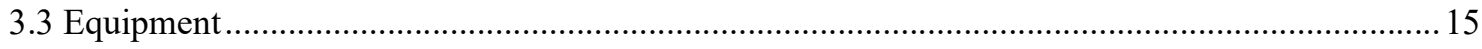

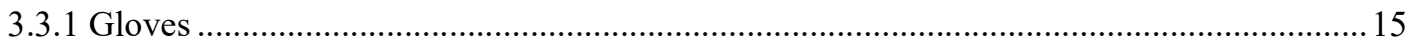

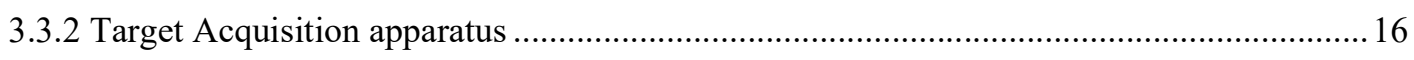

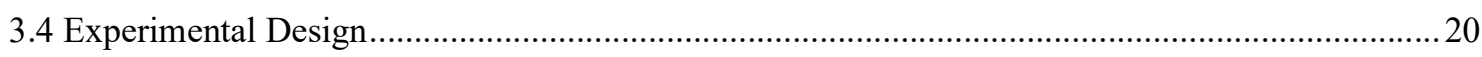

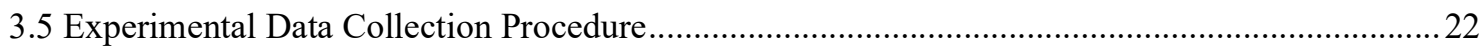

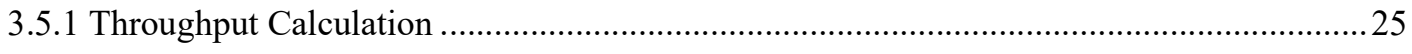

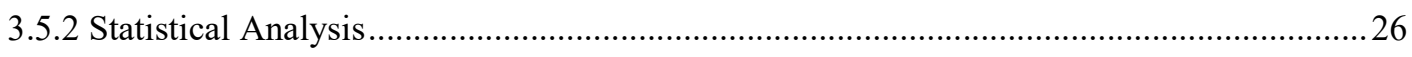

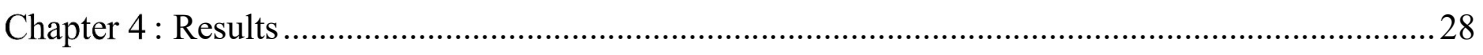

4.1 Relationship between Movement Time and Effective Index of Difficulty ...................................28

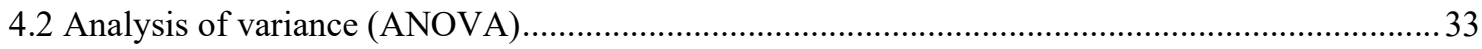

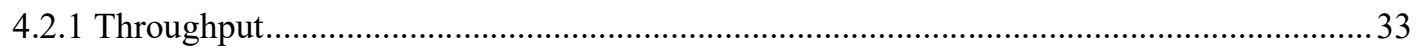

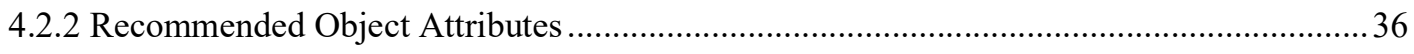

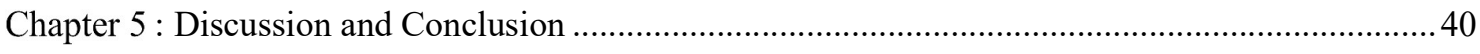

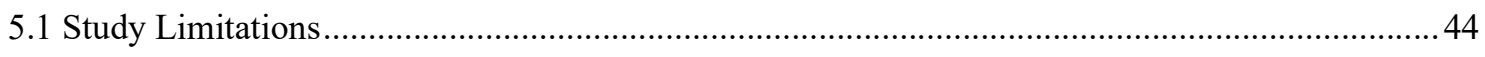

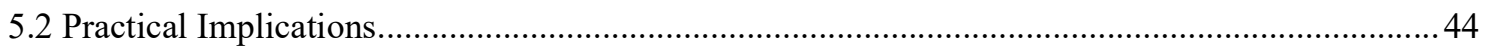

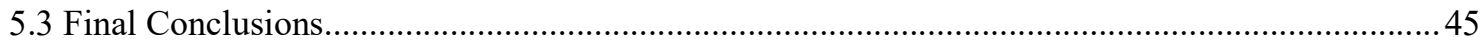

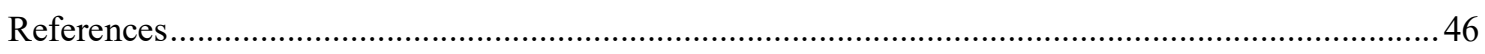


Appendix I: Anthropometric Measurements Of Participants........................................................... A

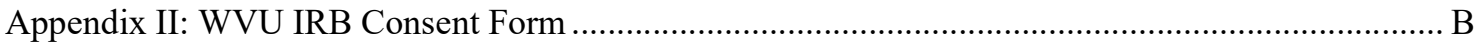

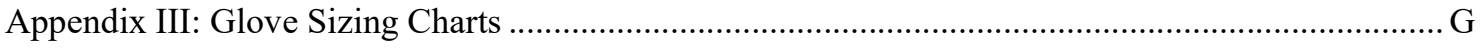

Appendix IV: Test for normality and equality of variance of throughput ........................................

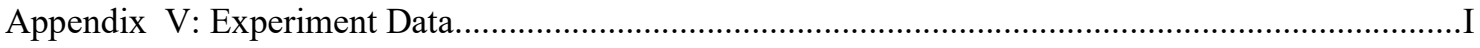




\section{List of Figures}

Figure 1-1: Prediction of movement time using multiple regression model..........................................

Figure 1-2: Angles measured in 3-D space in Cha \& Myung [23] study .......................................... 8

Figure 1-3: Contribution of object dimensions to variance in 1-, 2- and 3-constraint cases ................. 9

Figure 3-1: Gloves tested in this study: Glove type 1 (top), Glove type 2 (bottom)............................ 16

Figure 3-2: Target Acquisition System: (a) Vinyl adhesive mats, (b) Steel plates, (c) Target objects,

(d) Microscribe Digitizer, (e) Tripod, (f) Pan and tilt mount for camera............................................ 17

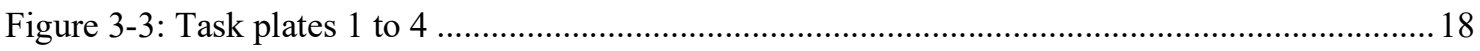

Figure 3-4: Microscribe Digitizer system : (a) Articulating arm unit (b) USB Cable (c) Input device 19

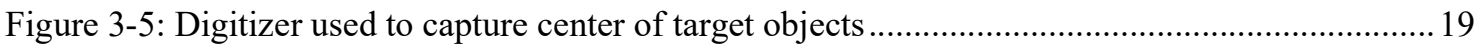

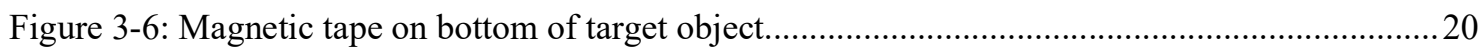

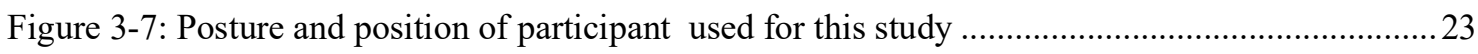

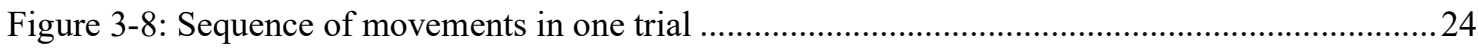

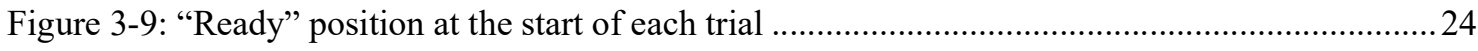

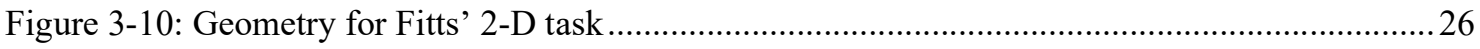

Figure 4-1: MT as a function of $\mathrm{ID}_{\mathrm{e}}$ under different combinations of object attributes .......................30

Figure 4-2: Normalized MT as a function of $\mathrm{ID}_{\mathrm{e}}$ under different combinations of object attributes.... 31

Figure 4-3: Linear fit between IDe and Normalized MT under different combinations of independent

variables

Figure 4-4: Mean and 95\% Confidence Interval of Throughput for all combinations of Object Height

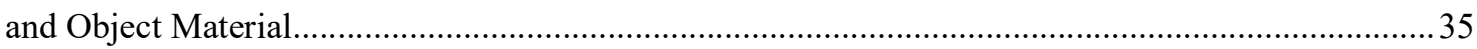

Figure 4-5: Mean and 95\% Confidence Interval of Throughput for all combinations of Object

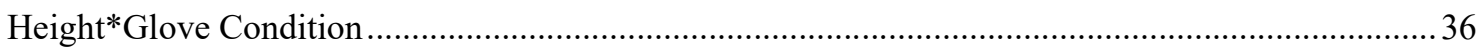

Figure 4-6: Variance of different experimental conditions tested in this study ....................................38

Figure 5-1: Comparison of gloves while lifting smallest 0.28 " objects ............................................. 42 


\section{List of Tables}

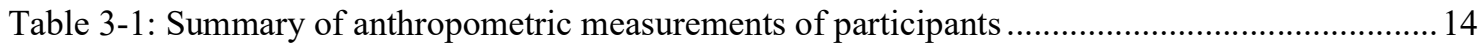

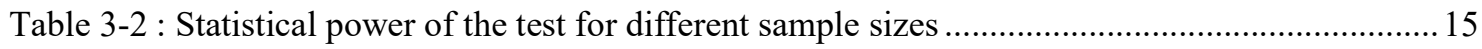

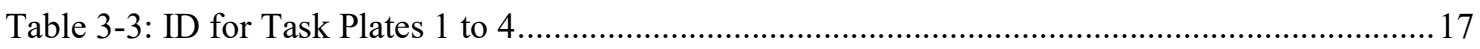

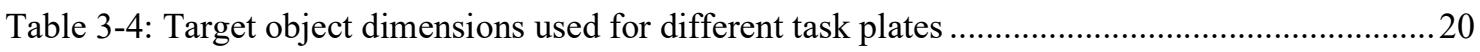

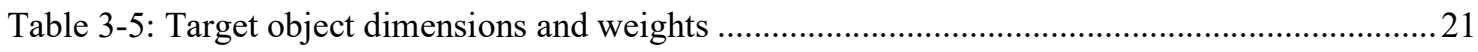

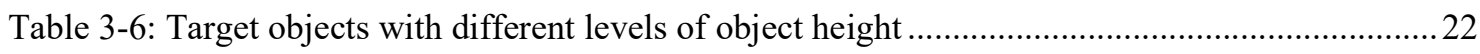

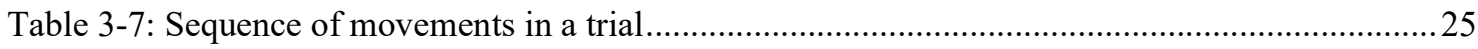

Table 4-1: ANOVA and Mean Pairwise Comparison Result of Throughput ......................................... 34

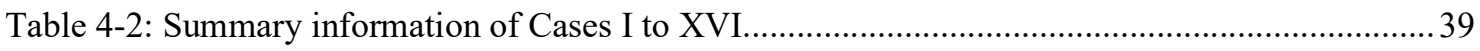

Table 4-3: Cases of experimental conditions sorted according to increasing variance............................39 


\section{Chapter 1 : Introduction}

Gloves provide protection against hand injuries to industrial workers in operations such as material handling, assembly tasks, working with hand-tools, etc. Industrial gloves are made of different types of material depending upon the desired protection against potential hazards in the workplaces. Leather gloves, fabric and coated fabric gloves, chemical resistant gloves and insulating rubber gloves are the broad categories of gloves for industrial applications [1]. Occupational Safety and Health Administration (OSHA) mandates employers to select appropriate hand protective equipment depending on the potential safety hazards in the workplace environment (29 Code of Federal Regulations (CFR) 1910.138(a) , 29 CFR $1910.138(b))$ [2].

Additionally, there are standards published by the American National Standards Institute / International Safety Equipment Association (ANSI/ISEA) to assist the employers with the glove selection process. ANSI / ISEA 138-2019 standard provides guidelines to measure impact performance of gloves [3]. ANSI/ISEA 105-2016 is a voluntary consensus standard which provides guidelines for test methods and classification levels of performance characteristics of hand protection equipment. This standard includes performance characteristics of Cut Resistance, Puncture Resistance, Hypodermic Needle Puncture Resistance, Abrasion Resistance, Chemical Permeation, Chemical Degradation, Heat and Flame Protection, Heat Degradation Resistance, Conductive Heat Resistance, Vibration Reduction and Dexterity. According to this standard, the smallest diameter of pin that can be picked up wearing a glove determines the glove's dexterity. The smaller the pin size, the higher the level of dexterity [4]. While dexterity is an important measure, it may not always correlate with the measure of performance during industrial assembly or maintenance tasks. During such tasks, the workers are not only required to grasp objects of various dimensions, but also to place/locate these objects at specific locations with high accuracy. Many a times these tasks are performed under time pressure, making speed an important factor in addition to the accuracy. To our knowledge, very little research had been done on methods that can simultaneously measure speed and accuracy during manual tasks performed using gloves. Throughput based on Fitts' Law combines speed and accuracy during target acquisition/transfer task into one number and has a potential to be used as a possible measure of gloves performance. 
Throughput is measured in terms of output per unit time or output per person employed. Throughput data is often used to specify performance of an activity and it is useful for future planning or improvement of operations. Accuracy of human tasks is measured in terms of human errors. Human errors which result due to incorrect execution of correct intentions are the ones which are most affected by speed. A higher quality output can be achieved through elimination of errors [5]. According to Fitts' Law, there is an inverse relationship between accuracy demands of a task and the time needed to complete the task. Speed-accuracy tradeoff is a trade-off between how fast a task is performed and the number of errors. Higher speed is associated with higher number of errors and vice-versa. In this study an attempt is made to develop new guidelines for glove selection based on speed-accuracy trade-off in terms of Fitts' throughput.

\subsection{Background of Fitts' Law}

Speed-accuracy trade-off in rapid human movement was first studied by Woodworth. Woodworth studied the impact of movement duration, velocity, amplitude on movement accuracy of voluntary movements [6]. Many theoretical and mathematical models have been proposed to explain speed-accuracy trade-off for both spatially constrained and temporally constrained movements. Fitts' Law is the most popular model for spatially constrained movements when both the amplitude of movement and width of target object is known. This law has been used extensively to model movements for one-dimensional (1-D) to 3dimensional (3-D) environment, underwater movements, using various limbs and most importantly in human-computer interaction [7].

In 1954, Paul M. Fitts' extended the use of information theory to quantify information capacity of the human motor system. Fitts measure of task difficulty was based on the "maximum relative uncertainty" which is ratio of the width of the target object and twice the amplitude of movement [8]. Fitts conducted three experiments: reciprocal tapping between two rectangular metal plates with a stylus, washer transfer task from one pin to another, and pin transfer task from one set of holes to another. Consider one experiment - the washer transfer task, the difference between the inside diameter of the washer and the pin diameter was given the term "tolerance", now called the "target width" (W). The distance between the two pins was called the "amplitude" (A). Here, movement amplitude is analogous to "signals" and target width is analogous to "noise" [9]. These two terms together determine the "Index of difficulty" of a given task. The units of index of difficulty (ID) is bits/response. The time of each transfer 
cycle was measured and was called the "movement time" (MT). The ratio of ID and MT was called "Index of performance", now called "Throughput". The units of throughout is bits/sec. This term is analogous to rate of transmission of information. Original Fitts' Law did not produce a good fit at low values of IDs, where the movements are likely ballistic and not visually-controlled [10]. Over the years, several modifications have been proposed to the ID in the Fitts' Law. However, three forms of Fitts' Law are most relevant:

(1) Original Fitts' Law:

$$
\mathrm{ID}=\log _{2}\left(\frac{2 \mathrm{~A}}{\mathrm{~W}}\right)
$$

(2) Welford formulation:

$$
\mathrm{ID}=\log _{2}\left(\frac{\mathrm{A}}{\mathrm{W}}+0.5\right)
$$

(3) Shannon formulation:

$$
\mathrm{ID}=\log _{2}\left(\frac{\mathrm{A}}{\mathrm{W}}+1\right)
$$

Welford and Shannon formulations provide good results for a wide range of IDs [10]. The variability in the sequence of output responses is used to determine the "Effective target width". The distribution of output responses is a "normal" distribution and the percentage of errors or standard deviation of the output responses can be used to determine the effective target width. "Effective amplitude" determines the distance moved along the task axis [11]. The detailed calculations for ID and Throughput using the effective target width and effective amplitude are given in section 3.5.1. Shannon formulation is widely used for analysis in Human-Computer interaction whereas the original Fitts' Law is widely used by researchers to model human movement [10].

\subsection{Application of Fitts' Law in Human-Computer Interaction}

ISO 9241-411 provides a standardized methodology for application of Fitts' Law to test performance of input devices in Human-Computer Interaction. Multi-part ISO 9241 refers to "Ergonomic requirements for office work with visual display terminals (VDTs)." Part 411

refers to "Evaluation methods for the design of physical input devices". This standard is implemented to 1-D task and two-dimensional (2D) task of the Fitts' paradigm. The standard 
is applicable to serial or reciprocal target selections, and not discrete target selections [11]. There has been extensive use of Fitts' Law in the evaluation of input devices in HCI.

Hassan et al. [12] compared the use of a hands-free input - face tracking software called Camera Mouse with a hands-on input - touchpad. Camera Mouse yielded lower throughput (0.85 bps) compared to touchpad (2.30 bps). List et al. [13] compared the touch performance of varying display sizes. Error rates were higher in smaller display sizes while the larger screens were associated with higher fatigue. The results suggested use of different screen sizes for different applications. Zhuang et al. [14] used Fitts' Law to develop a model which can be used to improve cockpit layout to reduce prevent potential safety problems arising from pilot's errors. Roig-Maimó et al. [15] studied the use of head-tracking interface on mobile phones and found that the throughput by moving the head was higher than the throughput by moving the device. Bachynskyi et al. [16] compared use of different touch surface types like tablet, laptop, tabletop, public display and smartphone using a performance factor - throughput and an ergonomics index - muscle activation. This study gave information about the touch surfaces that should be used and the postures that should be adopted while using them. Laptop had a poor performance but was best for long term use while smartphone was unsuitable for longterm use.

\subsection{Application of Fitts' Law to 3-D Tasks}

Fitts' Law is well established for aiming tasks in virtual environment as discussed above. Originally the law was developed for quantifying human information capacity (throughout) of 3-D tasks. However, calculation of throughput for movements in 3-D physical world are influenced by other factors as well. This section will present some findings showing that object dimensions (in one or more than one axis), location of the object in the 3-D space, the act of grasping object for lifting (prehension) influence throughput results using Fitts' Law.

\subsubsection{Fitts' Law with different limbs}

Drury [17] extended the use of Fitts' Law from hand movements to foot movements. Different IDs were created using different combinations of foot-pedal width and separation between the two pedals in the same plane. A correlation coefficient of 0.97 between MT and ID was obtained. Drury confirmed that this relationship can be used to predict movement time in different foot-pedal configurations. 
Glaser et al. [18] studied the accuracy of Fitts' Law to determine the braking movement time in 3-D space. Movement times for different relative positions of brake with respect to accelerator - in terms of depth, height and lateral position were measured. The results showed that only depth had a significant effect on the movement time. The results were compared with the predictions using Fitts' Law $\left(r^{2}=0.549\right.$ significant at $\left.p<0.0001\right)$. It was found that Fitts' Law gave inaccurate results when the brake pedal was placed behind the frontal plane of the accelerator.

Drury [19] used Fitts' Law to illustrate time savings associated with the order in which tasks are carried out in an assembly task. This study showed that for the items that are assembled or sorted in a limited space, movement times will be the lowest for the increasing order of size (thickness), followed by random order, and then by reverse order. He also showed that the number of items and the variability in their thickness is directly correlated with the increase in total assembly time. The amount of time savings is highly relevant to repetitive operations.

\subsubsection{Fitts' Law for prehension tasks}

Bootsma et al. [20] studied the relevance of Fitts' Law for prehension tasks instead of aiming tasks. Prehension tasks include two components - the transport component of bringing the hand closer to the object to be grasped and the grasp component of enclosing the object with fingers. The experimental results showed that the movement time is positively correlated to the movement amplitude, negatively correlated to object width and independent of object size until the maximum grasping size is reached. Here, object width refers to the extension of the object along the reach axis while object size refers to the extension of the object orthogonal to the reach axis. The movement time was explained in terms of the acceleration phase - from start of movement till the peak velocity is attained, and the deacceleration phase - from the peak velocity till the end of unidirectional movement of hand. Higher movement amplitude caused an increase in both acceleration phase and deacceleration phase. Smaller object widths had a longer deacceleration phase. Peak hand velocity was also found to be positively correlated to movement amplitude, object size and object width. The grasp characteristics Peak hand aperture is positively correlated to object width and object size; Peak finger closing velocity was found to be a function of the difference between the hand aperture and object size.

To apply Fitts' Law to prehension tasks, Bootsma et al. [20] suggested that the object width may be considered analogous to the target width. However, the relationship between the 
movement time and index of difficulty for prehension tasks $\left(r^{2}=0.678\right)$ is not as strong as the aiming tasks. This weakened relationship was attributed to dependency of two concurrent mechanisms - transporting and grasping.

McIntosh et al. [21] and others have tried to fit their test data of grasping objects in three dimensions with the Fitts' model, which was originally developed for one-directional movements. McIntosh has cited three reasons for inefficiency of applicability of Fitts' law to prehension tasks: 1) Prehension tasks are more complex than the unidimensional tasks. Amplitude and target object size may have additive effects on movement time. 2) A two-factor model with amplitude and target size having independent effects will be more fitting than the original Fitts' law. 3) While grasping an object on a table, the path of movement is a curvature and not a straight line. This alters the effective size of the object. Also, when the fingers approach downward and are stopped by the table, the accuracy constraint is no longer parallel to the plane of reach.

McIntosh et al. [21] carried out a sensitivity analysis of the movement time by varying object dimensions and amplitude; and compared the results obtained with the Fitts' singlefactor model (Index of Difficulty) with the two-factor model. Aerial tasks were conducted in this study to overcome the issues mentioned in point number 3 in the paragraph above. Cuboidal target objects were used, the height and width of the object were orthogonal to the direction of reach while the object depth was in the direction of reach. The results showed that movement time has an indirect relationship with object height and object depth; and a direct relationship with the amplitude and object width. Higher object widths decrease the safety margin between the fingers and the object, increasing the movement time. However, this relationship was observed to be significant at higher width values (greater than $40 \mathrm{~mm}$ ).

A multiple regression model using two factors (Figure 1-1) was generated. The predicted response from the regression model provided higher coefficient of determination $\left(r^{2}>0.9\right)$ than using the single-factor Index of Difficulty model $\left(\mathrm{r}^{2}<0.8\right)$. Peak velocity had a positive correlation with amplitude but was independent of object size. Higher amplitude increased time to attain peak speed (TPS) and time after peak speed (TAPS). Larger object size decreased the TAPS only. It was suggested that the changes in movement time due to amplitude and object size are brought about by different reasons and thus a two-factor model will be more appropriate. However, singular dimension (object height or width or depth) of the cuboid against movement time was studied thus, neglecting that the target is a 3-D object. If the log 
term is separated into two terms, the units for ID will not remain bits and thus the information analogy will be lost [11].

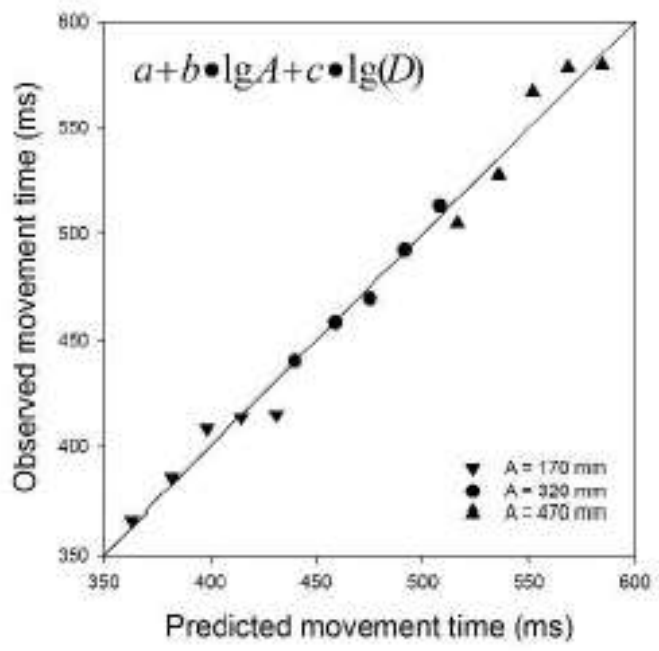

Figure 1-1: Prediction of movement time using multiple regression model

\subsubsection{Fitts' Law for pointing tasks in 3-D space}

Murata \& Iwase [22] gave a modified form of Fitts' Law to explain 3-D pointing tasks. The direction of movement from the starting point to the location of the target $\theta$ was measured. The results showed a significant effect of $\theta$ on the movement time and the following equation was proposed $(\mathrm{c}=0.5)$ :

$$
\mathrm{ID}=\log _{2}\left(\frac{\mathrm{d}}{\mathrm{s}}+1\right)+\mathrm{c}^{*} \sin \theta
$$

This relationship gave a higher value of $r^{2}=0.726$ in contrast to the conventional Fitts' model $\mathrm{r}^{2}=0.561$. The conventional Fitts' model holds good for directional Fitts' 2-D task using mouse having $\mathrm{r}^{2}=0.99$. However, the same is not true in a 3-D pointing task due to variable movement times. This is caused due to involvement of highly complex movement trajectories and involvement of more muscular forces. Thus, it becomes important to determine the relationship between the movement time and the direction of movement.

Cha \& Myung [23] specified location of a target object using two angles in the 3-D space: $\theta_{1}$ - angle between positive $\mathrm{z}$-axis and target location; $\theta_{2}$ - angle between positive y-axis and target location (Figure 1-2). 


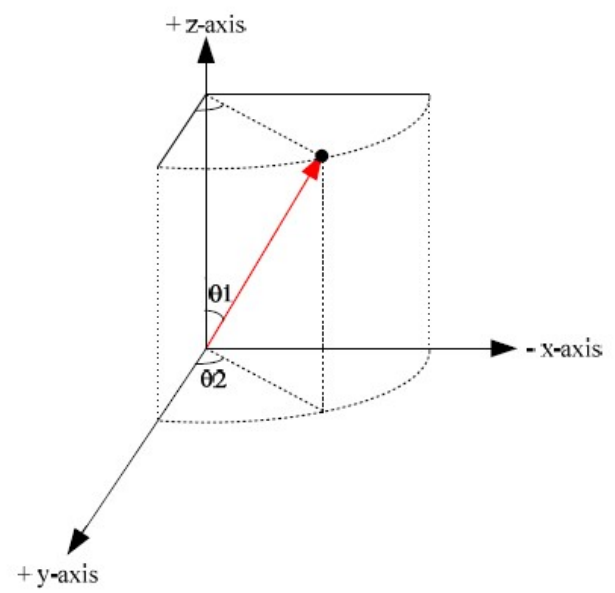

Figure 1-2: Angles measured in 3-D space in Cha \& Myung [23] study

The experiments showed a linear increase in movement time with increase in $\theta_{1}$ and movement time varied as a cosine function of $\theta_{2}$. The modified equation for index of difficulty is given as $(c=0.03$ and $d=0.4)$ :

$$
\mathrm{ID}=\log _{2}\left(\frac{\mathrm{D}}{\mathrm{W}}+1\right)+\mathrm{d} * \cos \theta_{2}+\mathrm{c} * \theta_{1}
$$

The coefficient of determination increased from 0.488 using conventional Fitts' model to 0.756 using extended Fitts' model as described above. Standard error was reduced to almost half using the extended Fitts' model. The increase in movement time due to change in $\theta_{1} \& \theta_{2}$ was explained by increase in physical forces in raising the arm to reach that specific target location.

Index of difficulty for a task increases with an increase in the number of target constraints [10]. Hoffmann, Drury \& Romanowski [10] studied the effect of target constraints in 3-D on movement time. The participants carried out stylus reciprocal tapping tasks on 1-D, 2-D and 3-D targets. The measured movement times were compared using different models developed for multi-dimensional pointing. Crossman equation and weighted Euclidean model equation provided the best fit $[24,25]$. The Crossman equation for movement time is given as:

$$
\text { Movement time }=\mathrm{a}+\mathrm{b} * \log _{2}\left(\frac{\mathrm{A}}{\mathrm{W}_{\mathrm{x}}}\right)+\mathrm{c} * \log _{2}\left(\frac{\mathrm{A}}{\mathrm{W}_{\mathrm{y}}}\right)+\mathrm{d} * \log _{2}\left(\frac{\mathrm{A}}{\mathrm{W}_{\mathrm{z}}}\right)
$$

Here, the weights $b, c$ and $d$ correspond to the rate of information processing in their respective dimensions. The weighted Euclidean model for movement time is given as: 


$$
\text { Movement time }=\mathrm{a}+\mathrm{b}^{*} \log _{2} \sqrt{\left(\frac{\mathrm{A}}{\mathrm{W}_{\mathrm{x}}}\right)^{2}+\alpha^{*}\left(\frac{\mathrm{A}}{\mathrm{W}_{\mathrm{y}}}\right)^{2}+\beta^{*}\left(\frac{\mathrm{A}}{\mathrm{W}_{\mathrm{z}}}\right)^{2}}
$$

Here, $\alpha$ and $\beta$ are weights assigned to the effect of constraints in their respective direction. Their values are obtained with iteration. $\mathrm{X}$-axis is the direction of reach to the target. $\mathrm{Y}$-axis is the target height perpendicular to the direction of movement. Z-axis is the depth of the target perpendicular to the direction of movement. The contributions of the three constraints towards movement time using the Crossman equation were: for the 2-constraint case, $\mathrm{W}_{\mathrm{x}}-70.6 \%, \mathrm{~W}_{\mathrm{y}}$ - 19.4\%; for the 3-constraint case, $\mathrm{W}_{\mathrm{x}}-78 \%, \mathrm{~W}_{\mathrm{y}}-14 \%, \mathrm{~W}_{\mathrm{z}}-3 \%$. Thus, when approaching a target all the three constraints are processed simultaneously with the highest contribution from $\mathrm{W}_{\mathrm{x}}$. If the direction of reach is changed then the contributions of different constraints will adjust accordingly. The times for 2 and 3 constraints cases are almost same as shown in Figure 1-3.

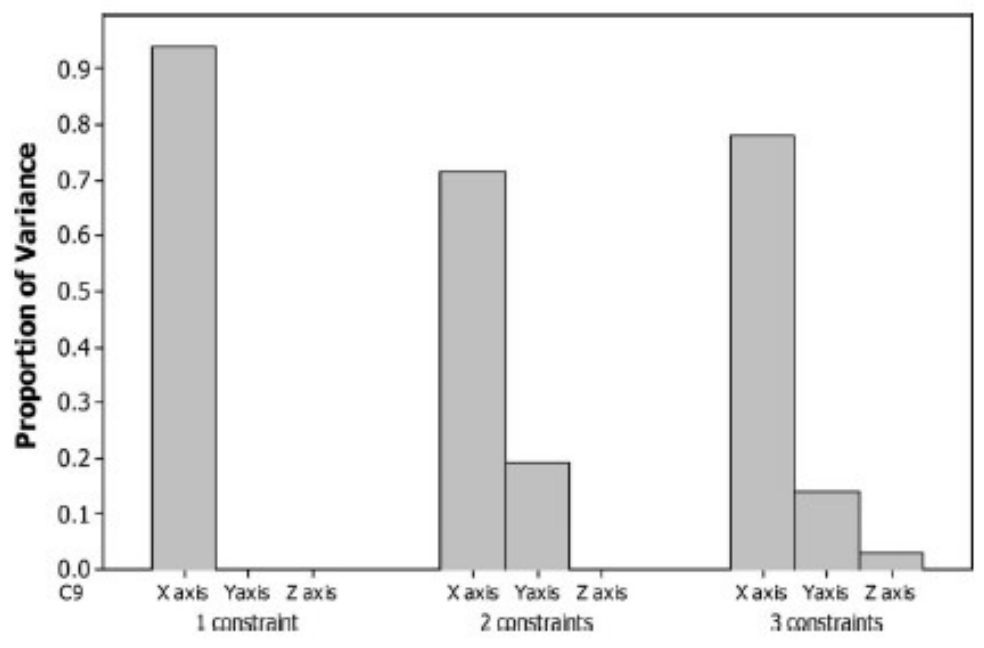

Figure 1-3: Contribution of object dimensions to variance in 1-, 2- and 3-constraint cases

\subsection{Effects of Gloves on Hand Performance Capabilities}

Almost all industrial tasks require workers to wear gloves. Gloves are often associated with reduced dexterity, tactile sensitivity, grip strength, muscle fatigue and discomfort [26]. Reduced dexterity is attributed to low coefficient of friction between glove and surface of object, poor fit of hand causing slippage and poor manipulation of hand/fingers due to stiffness and thickness of the glove material [27]. Reduced tactile sensitivity refers to reduced feedback about the object attributes like shape, texture and size. Dianat et al. [28] has reviewed 85 research papers on the methods used and the results obtained to assess glove effects on hand 
performance capabilities. Glove tenacity or glove adherence determines the amount of gripping force required to hold objects. This is dependent on the coefficient of friction between the surface of object and surface of glove material in contact with the object.

Numerous studies have reported that wearing gloves reduces manipulability of manual tasks, causing an increase in the performance time. Kinoshita [29] studied the effects of different types of gloves with varying thickness on prehensile forces and performance time needed to lift different types of objects. Rubber and cotton gloves were used to lift objects covered with rayon and sandpaper. With barehand, the coefficient of static friction was higher for sandpaper surface than rayon surface. Compared to barehand, rubber gloves were much less slippery for rayon surface. The difference between the two measured forces, static force and slip force, was called the safety margin. Safety margin was the incremental force needed to prevent slippage of the object. Increase in glove thickness increased the safety margin for the gloves. Peak and static forces increased with increase in glove thickness but with a very high variability. Increase in total loading time with increase in glove thickness was insignificant. Kinoshita compared these findings with the previous research and suggested that the performance time can increase significantly if the participants are asked to perform the tasks as quickly as possible, unlike self-determined speed as used in this study. Rubber gloves had a higher coefficient of friction against both surface types than the cotton glove against rayon surface. The cotton glove provided a wider range of coefficient of friction, making them unsuitable for working with slippery surfaces. The pre-loading phase for the rubber glove was significantly shorter than the cotton glove. A survey among participants indicated that using a rubber glove was better than barehand and the cotton glove was the most difficult to use.

Polechoński \& Olex-zarychta [30] studied the effect of tactile impairment on the movement accuracy and speed of carrying out tasks with the upper extremities. Earlier studies indicated that only visual and prioceptive information determines movement and accuracy. The participants performed groove-tracking task with a pen using Vienna Test System using four gloved conditions. There was a significant increase in the number of errors and the total time of errors with gloves. However, wearing gloves did not have any effect on the total movement time. The largest number of errors were made with the thickest glove made of soft animal leather. The influence of tactile impairment on accuracy was more pronounced for short task than for the longer task, which involves more muscles and joints. 
Moore \& Campbell-Kyureghyan [26] obtained glove user fit rating, comfort rating and dexterity rating for three kinds of gloves - knit gloves, leather gloves and oil/gas industry heavy duty gloves. The performance times of bolt disassembly task and rope type tasks were measured. The gloves with shorter performance times had higher user ratings. Thicker gloves have lower hand grip strength due to thicker layers of materials, reduced friction between the glove and the surface of the object and lowered tactile sensitivity.

Bronkema-Orr and Bishu [31] studied the effect of varying loads on the grasping force exerted with gloved hands. The study showed an increase in grasping force with increase in load weight. Similar results were reported by Bishu et al. [32]. 


\section{Chapter 2 : Study Rationale}

Manufacturing and assembly tasks involve gripping, grasping, holding and lifting activities. Workers typically are required to wear gloves while conducting such activities to reduce risks of hand injuries. Our literature review suggested that gloves provide protection but can also influence speed-accuracy trade-off. Fitts' throughput combines speed and accuracy during target transfer/movement tasks into a single performance index. The ISO 9241-411 standard has been extensively used in the literature to quantify speed-accuracy trade-off in terms of throughput. However, the ISO 9241-411 standard is designed to estimate throughput for physical input devices used in human-computer interface and thus majority of existing studies based on this standards were performed in the virtual environments. This study was aimed at examining the possibility of implementing ISO 9241-411 standard in the physical environment so that guidelines can be developed to estimate (and compare) throughputs of safety gloves.

As noted, the ISO 9241-411 standard is widely used in the HCI research area. The standard provides methods to estimate throughput using aiming tasks in virtual environment. The most common application of this standard is in the evaluation of hands-on input devices like mouse, touchpad, joystick and hands-free input using face or head. List et al. [13] used this standard to compare touch performance in screens of different sizes like tablet, desktop and wall screen. Medium screen size of desktop was ranked the best in terms of both performance and fatigue. Another study by Bachynskyi et al. [16] linked muscle activation with throughput performance of different touchscreen devices. Laptop had a poor performance but was best for long-term use while smartphone was unsuitable for long-term use.

The ISO 9241-411 standard in its current format is not suitable to estimate throughput for tasks performed in 3-D physical world. Movements of objects in 3-D space is influenced by various attributes such as location, size, surface and weight which can influence individual's ability to grasp and move objects in 3-D space and all these factors can influence throughput. Bootsma et al. [20] showed that Fitts' Law is applicable to prehension tasks. However, the relationship was weaker than simple aiming tasks due to functional coupling of transport and grasp components while performing 3-D activities. Murata \& Iwase [22] and Cha \& Myung [23] added new variables to the index of difficulty to specify movement to a target location in 3-D space. In another study by Hoffmann, Drury \& Romanowski [10], object dimension in the 
direction of movement had the highest impact on speed-accuracy trade-off, followed by other dimensions.

Gloves are often associated with reduced dexterity, reduced tactile sensitivity, reduced grip strength, muscle fatigue, discomfort and increase in performance times. Increase in glove thickness increases the number of errors. Gloves with lower ratings of dexterity, fit and comfort are associated with longer completion times. Lower coefficient of friction between glove and object and higher glove thickness increase the grasping force. Due to these factors, workers are less likely to wear safety gloves in the workplace. Hand injuries ranks second among workrelated injuries and seventy percent of these hand injuries occur because workers are not wearing safety gloves. Almost a million workers are sent to the emergency room owing to hand injuries. The average cost of medical claim and worker's compensation for hand injury is $\$ 13,000[33]$.

In order to develop guidelines (based on the ISO 9241-411 standard) to estimate throughput for different types of gloves, it is critically important to understand how object attributes of shape, height and material (density) can affect between and within glove variability. Heavier objects will take longer to speed up and speed down than lighter objects, making density an important factor. Similarly, object shape can also influence speed and/or accuracy during the object transfer tasks. Thus, we designed a study to systematically evaluate effect of target/object shape, height and material (density) on throughput. We designed tasks with different index of difficulties to test the effect of target/object attributes on throughput. Furthermore, the glove conditions were carefully selected (increasing thickness) such that average throughput values were different between the gloves.

The following null and alternate hypothesis were used to test main and interaction effects of glove condition, object shape and weight on throughput:

Ho: Glove condition, object attributes (shape, height and material) and their interaction will have no effect on throughput.

$\mathrm{H}_{\mathrm{A}}$ : Glove condition, object attributes (shape, height and material) and their interaction will have an effect on throughput 


\section{Chapter 3 : Methodology}

\subsection{Approach}

Empirical method was used to measure Fitts' throughput. In this study, the participants performed repeated object transfer tasks. The objects were placed along a circle and were transferred from one position to another diametrically opposite position. These tasks were performed using targets of various dimensions under different gloved conditions. Movement time for all the trials were measured and throughput was calculated using the ISO 9241-411 standard.

\subsection{Participants}

A total of 15 participants between the ages of 23 to 34 years were recruited for data collection in this study. Table 3-1 gives a summary of mean and standard deviation (S.D.) of participants' age, weight, height and knuckle width. Data for individual participants is presented in Appendix I. Participants were excluded from the research if they suffered from any type of musculoskeletal, degenerative, or neurological disorder or if they had a history of hand or fingertip pain or were suffering from any current pain. The objective and experimental procedure of this study was explained to them. Then, the participants were asked to read and sign a consent form approved by the local Institutional Review Board (Appendix II).

Table 3-1: Summary of anthropometric measurements of participants

\begin{tabular}{|c|c|c|}
\hline Variable & Mean & S.D. \\
\hline Age (years) & 27.5 & 3.4 \\
\hline Weight (pounds) & 141.3 & 23.7 \\
\hline Height (feet) & 5.6 & 0.3 \\
\hline Knuckles Width (inches) & 3.2 & 0.4 \\
\hline
\end{tabular}

\subsubsection{Sample Size Determination and Statistical Power Analysis}

Operating Characteristic (OC) Curves were used to select the appropriate sample size and determine the statistical power of the test. The following formula was used to perform calculations [34]:

$$
\Phi^{2}=\frac{\mathrm{nD}^{2}}{2 \mathrm{a} \sigma^{2}}
$$


Where,

$\Phi^{2}$ : non-centrality parameter

$\mathrm{n}$ : sample size or number of participants

$\mathrm{D}$ : minimum difference between treatment means beyond which null hypothesis should be rejected

$\mathrm{a}:$ number of levels of treatment factor

$\sigma^{2}:$ variance estimate

Based on the literature review, value of $\mathrm{D}$ equal to $1 \mathrm{bps}$ and value of $\sigma^{2}$ equal to 0.5 was chosen. The significance level of the test was set at $\alpha=0.5$. Table 3-2 shows the statistical power values corresponding to different sample sizes. The results suggest that for sample size of 15 , power of the test will be $93 \%$.

Table 3-2 : Statistical power of the test for different sample sizes

\begin{tabular}{|c|c|c|c|c|c|c|}
\hline $\mathbf{n}$ & $\Phi^{2}$ & $\Phi$ & a-1 & $a(n-1)$ & $\boldsymbol{\beta}$ & Power $=(1-\beta)$ \\
\hline 9 & 3.00 & 1.73 & 2 & 24 & 0.30 & 0.70 \\
\hline 11 & 3.67 & 1.91 & 2 & 30 & 0.19 & 0.81 \\
\hline 13 & 4.33 & 2.08 & 2 & 36 & 0.15 & 0.85 \\
\hline 15 & 5.00 & 2.24 & 2 & 42 & 0.07 & 0.93 \\
\hline
\end{tabular}

\subsection{Equipment}

\subsubsection{Gloves}

The gloves were selected such that they impose different (incremental) levels of constraints during target transfer tasks and thus will produce distinct throughput values. Glove type 1 was made of goatskin leather (Figure 3-1). This glove was described as a cut-resistant work glove used in manufacturing, metal handling, general maintenance, construction, forklift drivers, truck drivers, and yard work. Glove type 2 was a metacarpal glove (Figure 3-1). It was a high-visibility glove that had cut and puncture resistant materials on the dorsal side. It was made of goatskin leather with Thermoplastic Rubber (TPR) material molded on the fingers, thumb and dorsal side of hand. This heavy-duty glove is used in mining, oil and gas and 
construction industries. It was expected that throughput for glove type 2 will be lower than its' less bulky counterpart, i.e., glove type 1 .

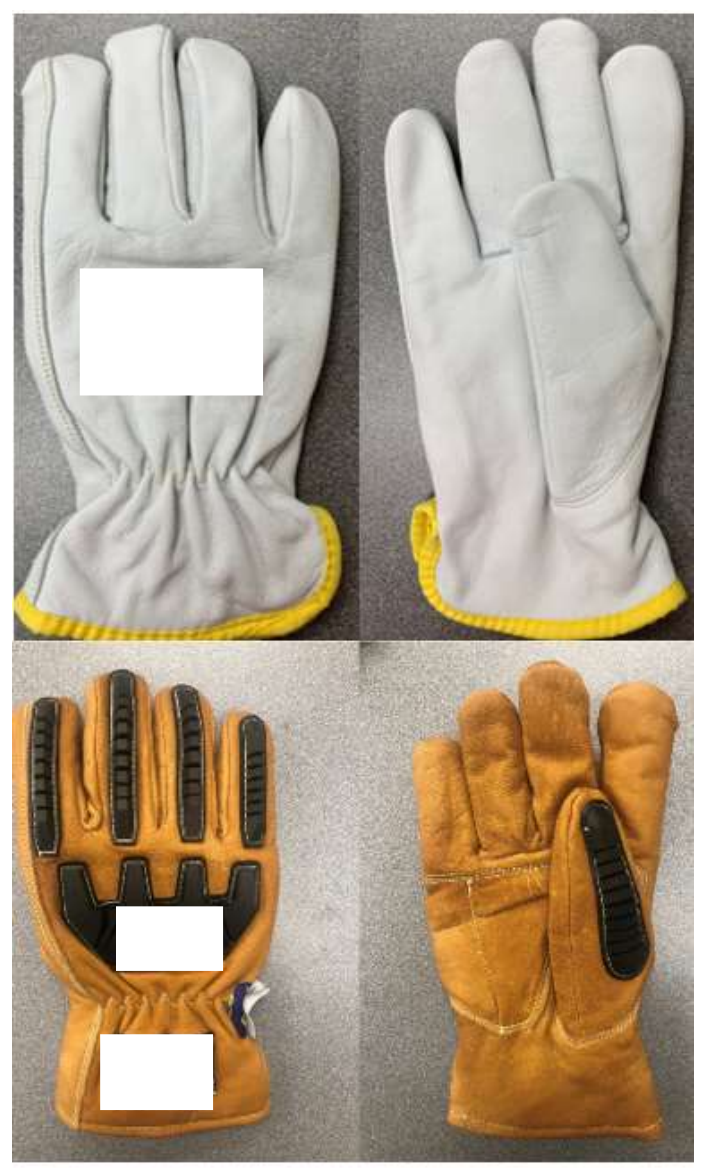

Figure 3-1: Gloves tested in this study: Glove type 1 (top), Glove type 2 (bottom)

\subsubsection{Target Acquisition apparatus}

The position data during target transfer tasks were measured using a custom-built Target Acquisition apparatus (Figure 3-2). It consisted of steel task plates (0.25 cm thickness) of various dimensions, target objects with different features, a Microscribe digitizer and a tripod with pan and tilt mount to hold the camera. The task plates were affixed with opaque vinyl adhesive mats. These mats included a pattern consisting of 12 target positions placed along a big circle. The width of target was referred as Target Width (W) and the diameter of the big circle was referred as Amplitude (A) as shown in Figure 3-2. Based on Fitts's law, the Index of Difficulty (ID) for a plate was estimated using the following equation: 


$$
\mathrm{ID}=\log _{2}\left(\frac{\mathrm{A}}{\mathrm{W}}+1\right)
$$

Four plates with ID's ranging from 3.06 to 5.43 were used in this study (Table 3-3). The IDs are a measure of task difficulty where low ID is associated with an easy task and a high ID is associated with a difficult task. The maximum amplitude in our study was constrained by the length of digitizer arm.

Table 3-3: ID for Task Plates 1 to 4

\begin{tabular}{|c|c|c|c|}
\hline $\begin{array}{c}\text { Task } \\
\text { Plate }\end{array}$ & $\begin{array}{c}\text { Amplitude } \\
\text { (in.) (A) }\end{array}$ & $\begin{array}{c}\text { Target Width (in.) } \\
\text { (W) }\end{array}$ & $\begin{array}{c}\text { Index of Difficulty } \\
\text { (ID) }\end{array}$ \\
\hline 1 & 11 & 1.50 & 3.06 \\
\hline 2 & 16 & 1.50 & 3.54 \\
\hline 3 & 15 & 0.75 & 4.39 \\
\hline 4 & 21 & 0.5 & 5.43 \\
\hline
\end{tabular}



Figure 3-2: Target Acquisition System: (a) Vinyl adhesive mats, (b) Steel plates, (c) Target objects, (d) Microscribe Digitizer, (e) Tripod, (f) Pan and tilt mount for camera 


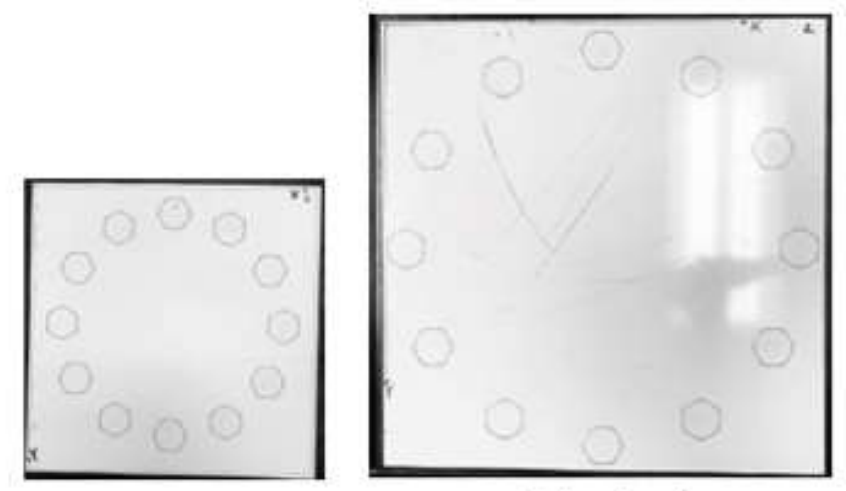

Task plate 1

Task plate 2

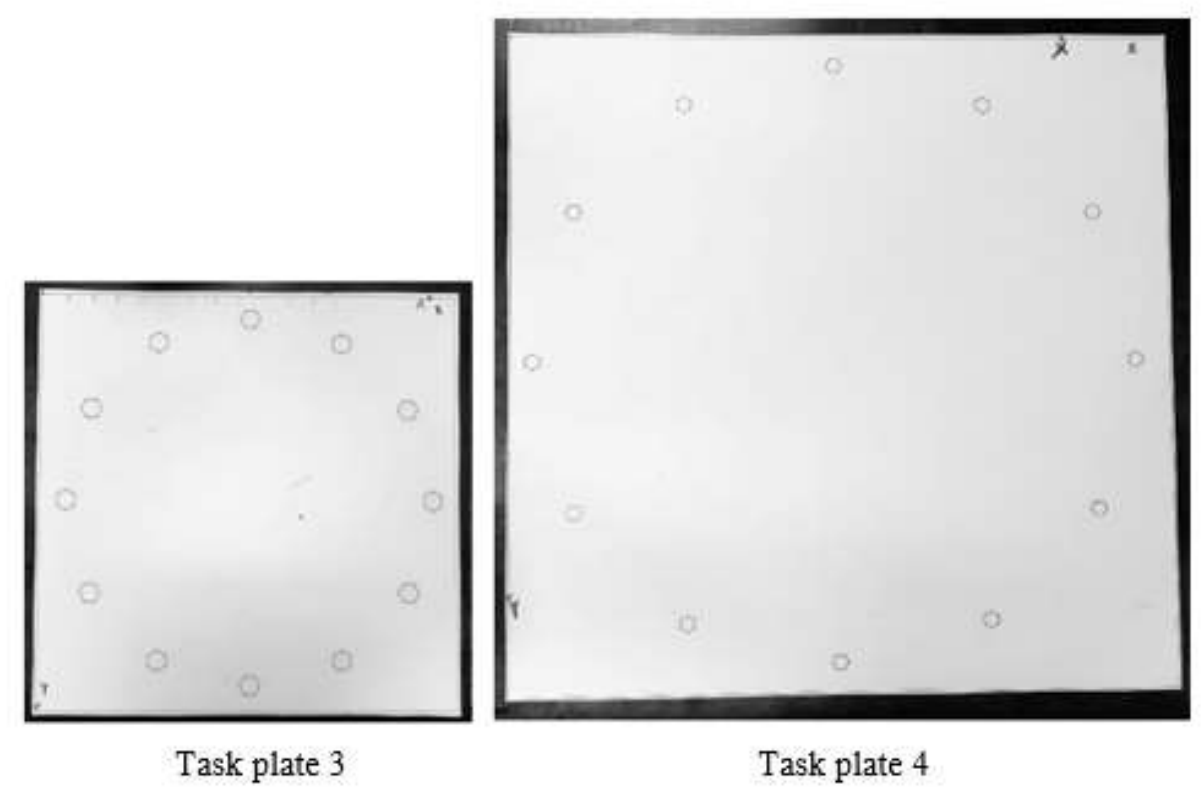

Figure 3-3: Task plates 1 to 4

Microscribe G2LX (Revware Systems, Inc.) digitizer was used to capture the coordinates of the center points of the target objects. This Microscribe system consisted of an articulating arm unit, a USB cable to communicate with a host computer and a hand-input device to trigger input data (Figure 3-4). The articulating arm unit contained a stylus which was used to record coordinate data (Figure 3-5). The coordinate data was recorded using Rhino 6 - a 3D computer-aided graphics and design software. The coordinates were exported from Rhino 6 to a text file. Output results were extracted using MATLAB. The position of the digitizer and the steel plates were marked on the scissor lift to maintain constancy of the reference coordinates.

Tripod with pan and tilt mount was used to hold the phone camera. Videos covering full image of the task plates were recorded. Time for all individual trials were extracted from 
these videos. The adhesive side of magnetic tape was stuck on the bottom side of the target objects to prevent any undesired displacement of objects (Figure 3-6).

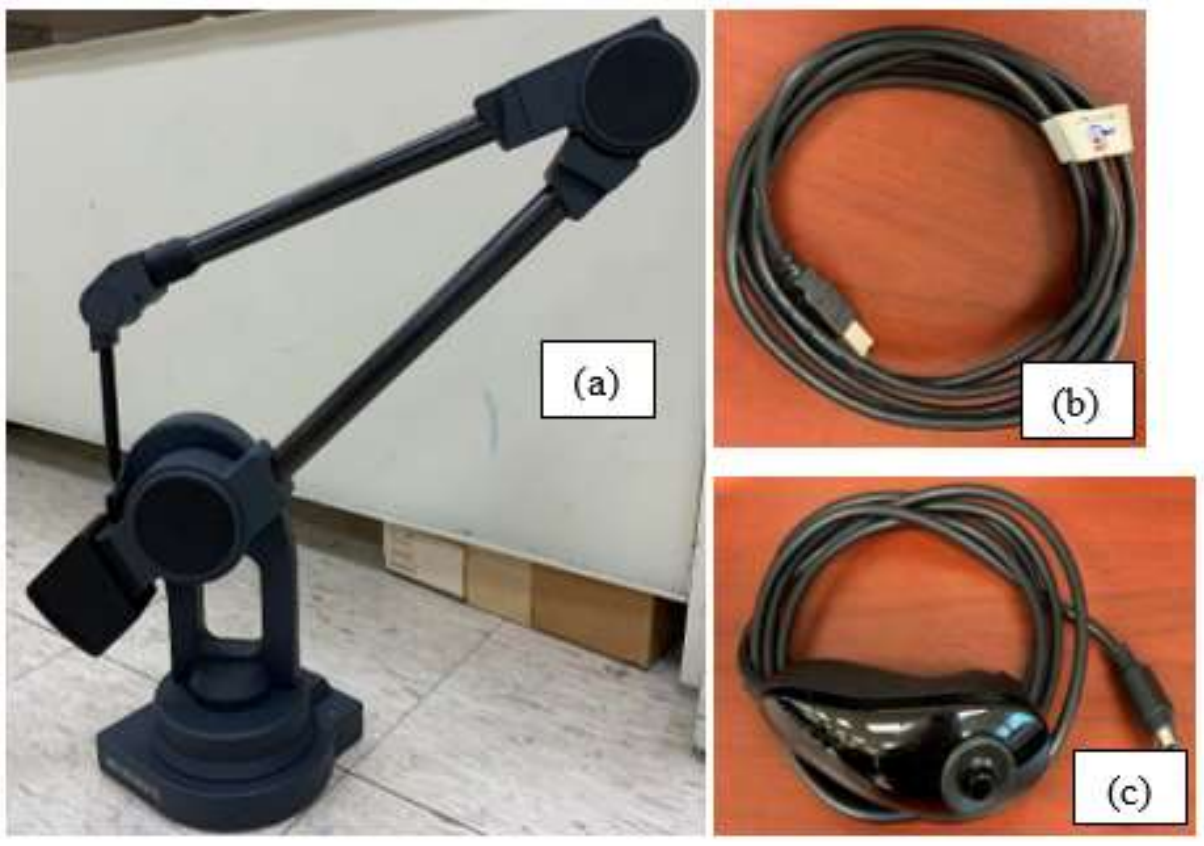

Figure 3-4: Microscribe Digitizer system : (a) Articulating arm unit (b) USB Cable (c) Input device

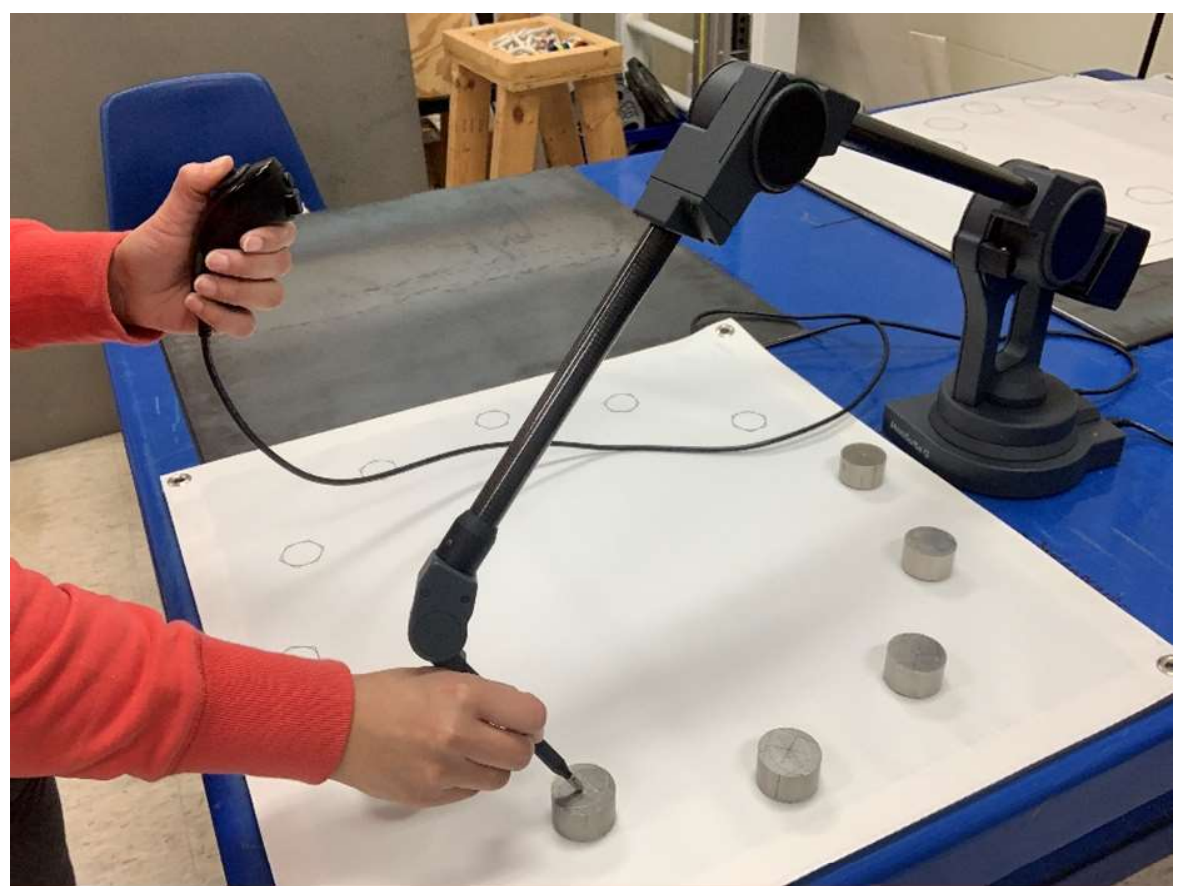

Figure 3-5: Digitizer used to capture center of target objects 


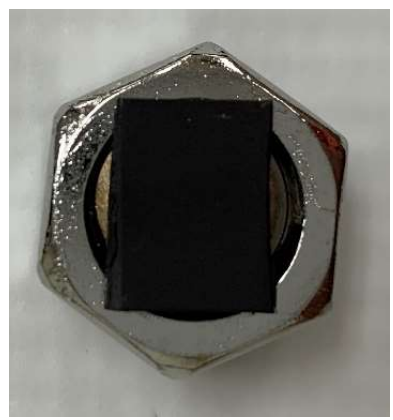

Figure 3-6: Magnetic tape on bottom of target object

\subsection{Experimental Design}

In this study, the dependent variable was Fitts' throughput. It was quantified using effective index of difficulty $\left(\mathrm{ID}_{\mathrm{e}}\right)$ and task completion time. Method used to estimate $\mathrm{ID}_{\mathrm{e}}$ is explained in section 3.5.1. The independent variables in this study are listed below:

I. Glove condition - (1) No glove/ Barehand (2) Glove type 1, (3) Glove type 2

II. Object shape - (1) Hexagonal (Hex Nuts), (2) Circular (Solid Discs)

III. Object material/weight - (1) Stainless-steel / heavy, (2) Nylon/ light. The density of stainless-steel is almost seven times higher than density of nylon.

IV. Object height - (1) 0.28", (2) 0.43", (3) $0.88^{\prime \prime}$

The width of target objects which could be used for a plate depended on the Target Width (W) of that plate. Object height was different for different object widths. Table 3-4 shows the target object dimensions applicable for plates 1 to 4 .

Table 3-4: Target object dimensions used for different task plates

\begin{tabular}{|c|c|c|}
\hline $\begin{array}{c}\text { Task } \\
\text { Plate }\end{array}$ & $\begin{array}{c}\text { Object Width } \\
\text { (in.) }\end{array}$ & $\begin{array}{c}\text { Object Height } \\
\text { (in.) }\end{array}$ \\
\hline 1 & 1.50 & 0.88 \\
\hline 2 & 1.50 & 0.88 \\
\hline 3 & 0.75 & 0.43 \\
\hline 4 & 0.50 & 0.28 \\
\hline
\end{tabular}

The different levels of object attributes (shape, height and material) which were studied are shown in Table 3-5 and Table 3-6. 
Table 3-5: Target object dimensions and weights

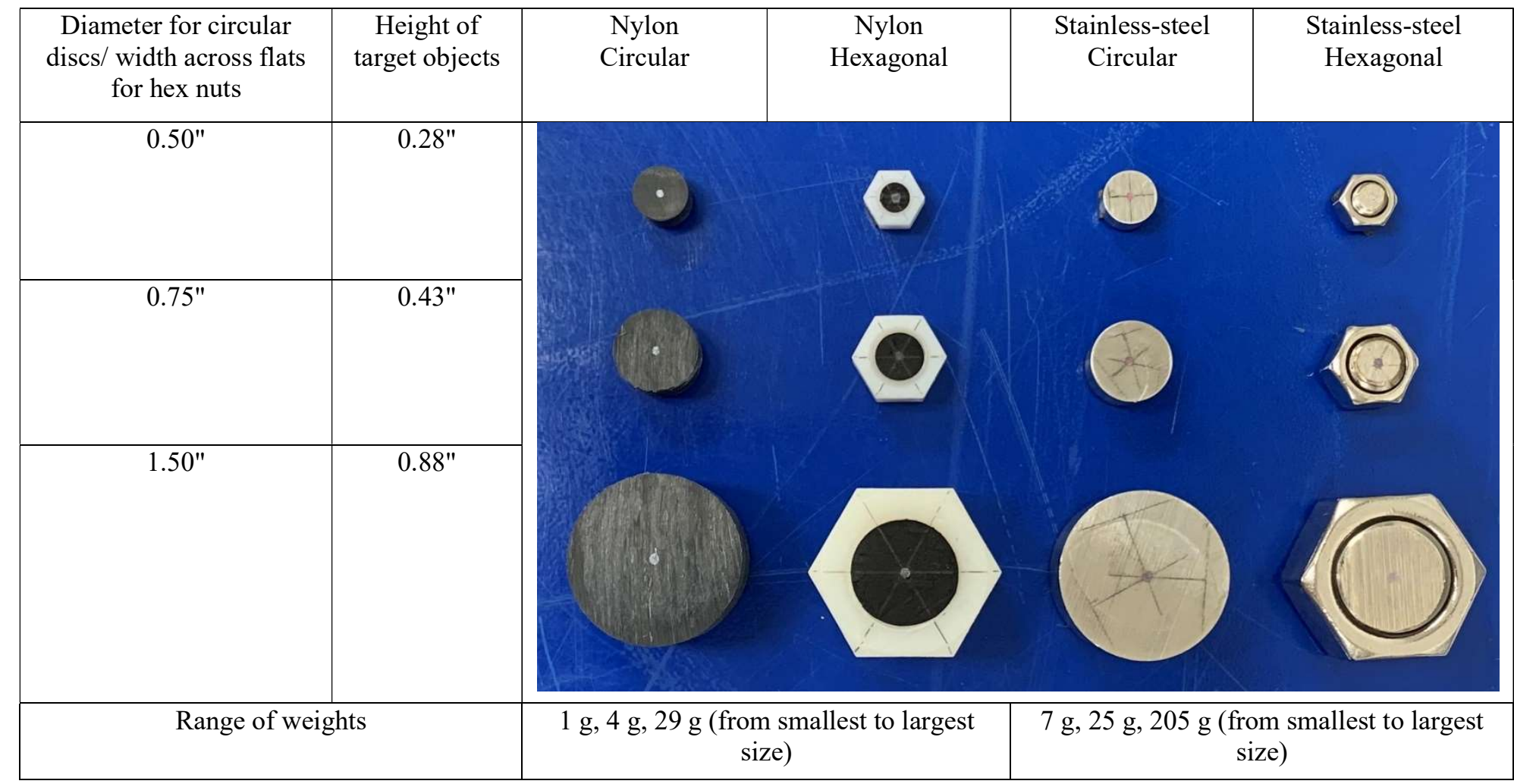


Table 3-6: Target objects with different levels of object height

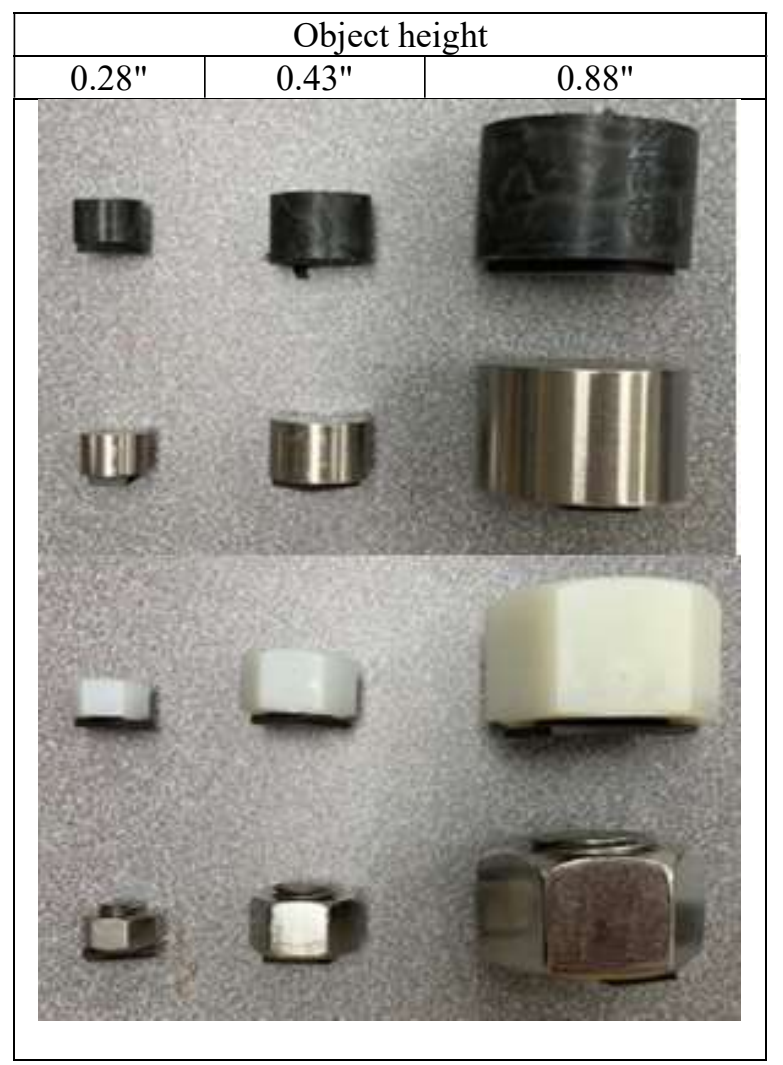

Each participant performed 144 experimental trials (4 IDs $\times 2$ object shapes $\times 2$ object material $\times 3$ gloves conditions $\times 3$ repetitions). Rest periods of 2 minutes after every twelve trials and 5 minutes after each plate were given to overcome fatigue. The trial order was randomized within plates and the plate order was also randomized.

\subsection{Experimental Data Collection Procedure}

Upon arrival at the laboratory, the participants were given a detailed explanation of the study objectives, experimental procedure and the equipment used. Then, the participants were asked to read and sign the consent form. Then, their anthropometric data including age, height, body weight and knuckle width was recorded. Hand measurement - knuckle width was taken to provide appropriate glove size for the participant. If the glove obtained from the sizing chart did not fit properly, then the participants could pick up the size which was the most comfortable to them. Glove Sizing chart for the gloves is included in Appendix III.

The participants were instructed to stand along the drawn line of the floor to maintain a constant distance from the edge of the plate. The center of their body had to be aligned with 
the center of the task plate. The height of the task plate could be adjusted to the hip height of the participant with the help of a scissor lift. The participant were asked to carry out the experimental tasks using thumb, index finger and middle finger of the dominant hand. They were advised to keep the non-dominant hand parallel to the body (Figure 3-7). The participants were given some time to familiarize themselves with the equipment and data collection procedure. Participants were allowed to practice for some time before beginning with the actual data collection.

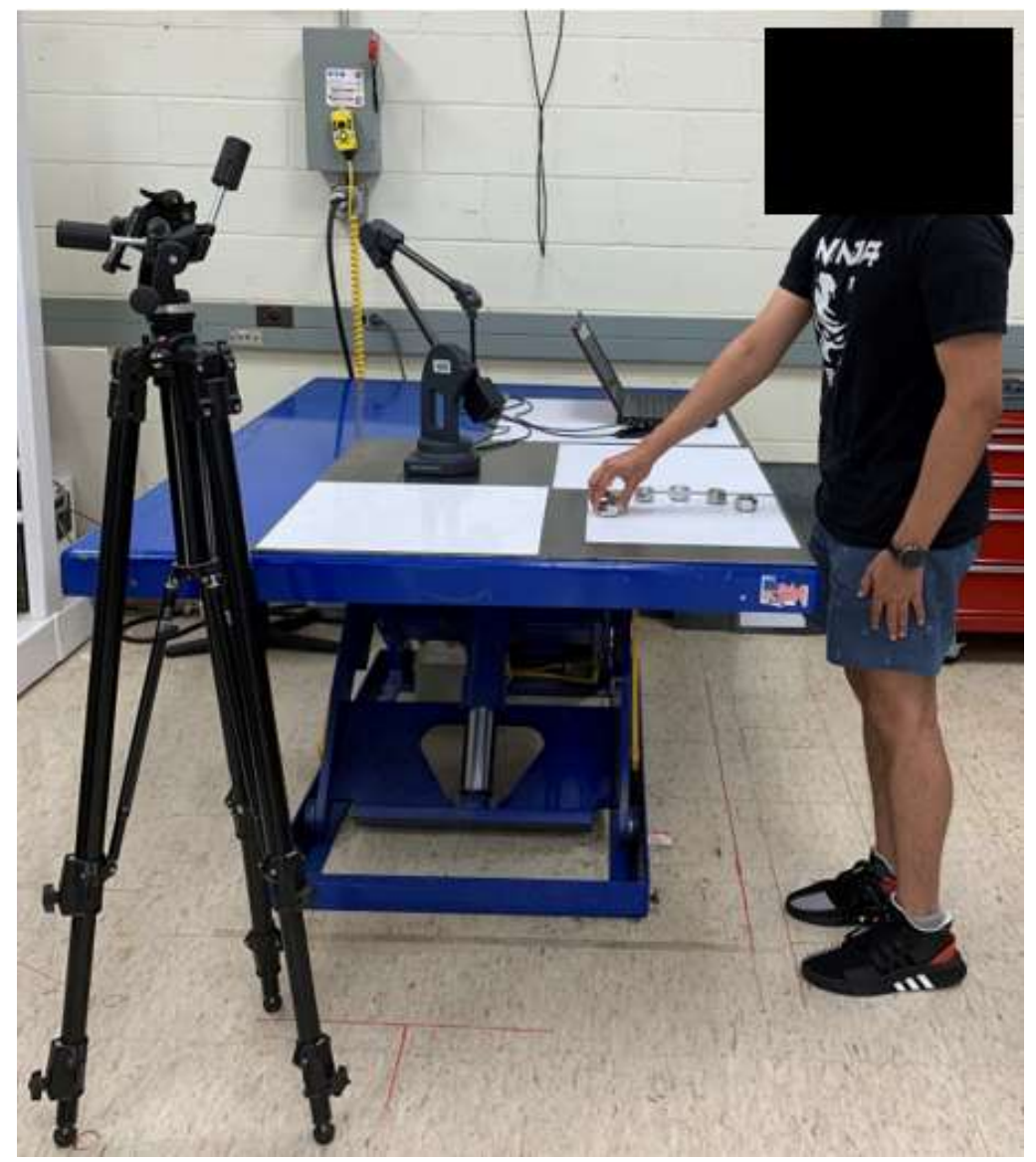

Figure 3-7: Posture and position of participant used for this study

Six objects were placed at positions "1" to "6" (Figure 3-8). The participant was asked to keep the dominant hand in "Ready" position (Figure 3-9). Then, participant was signaled to start the experimental trial. The trial began with the participant lifting the object at position " 1 " and moving it along a straight line to position "7" and so on (Table 3-7). The participants were asked to perform the task as fast as possible while maintaining accuracy of the task. Each trial lasted for about 6 to 10 seconds. After every trial, Microscribe 3D Digitizer was used to record 
the coordinates of the center of the object at the "Select" position. "Select" position represented the final position (position where the object was actually placed). "From" and "To" coordinates remained fixed thus eliminating the need of measuring them in every trial. The movement time for all trials were video recorded.

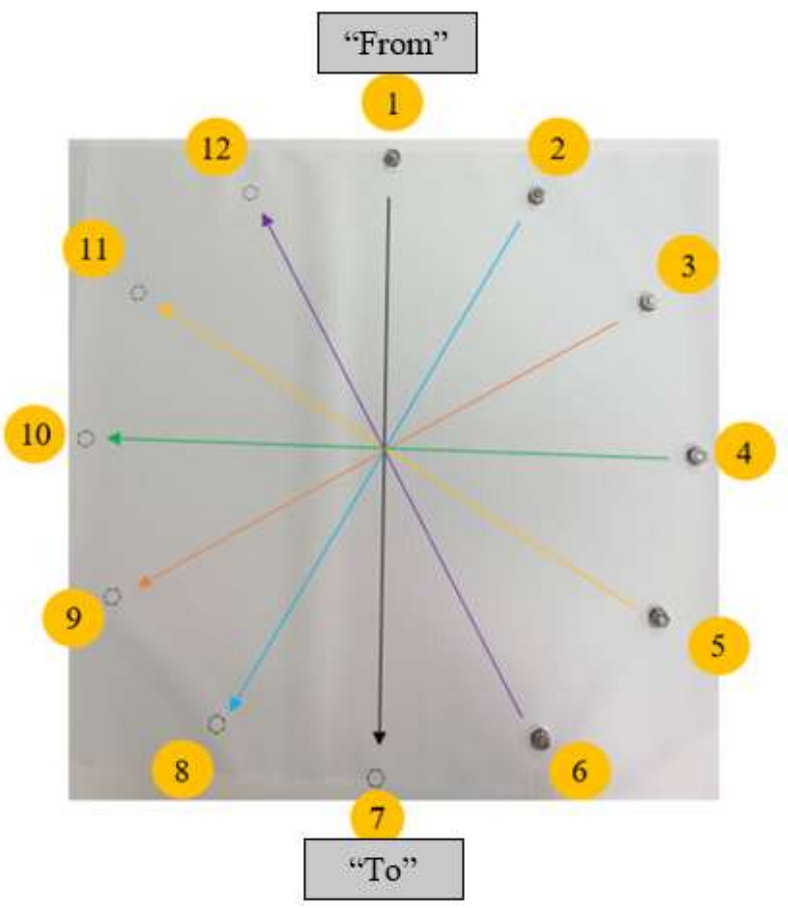

Figure 3-8: Sequence of movements in one trial

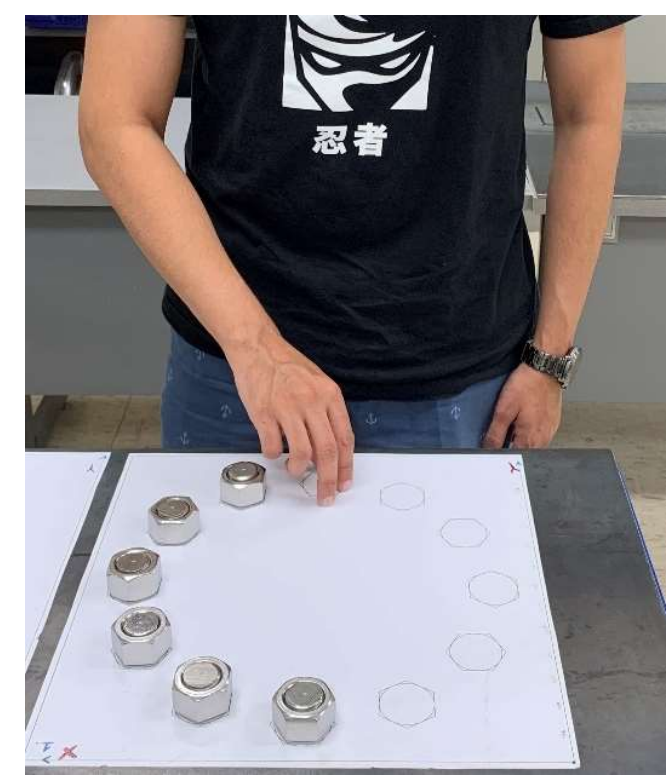

Figure 3-9: "Ready" position at the start of each trial 
Table 3-7: Sequence of movements in a trial

\begin{tabular}{|c|c|c|}
\hline $\begin{array}{c}\text { Steps in a } \\
\text { trial }\end{array}$ & "From" & "To" \\
\hline 1 & 1 & 7 \\
\hline 2 & 2 & 8 \\
\hline 3 & 3 & 9 \\
\hline 4 & 4 & 10 \\
\hline 5 & 5 & 11 \\
\hline 6 & 6 & 12 \\
\hline
\end{tabular}

\subsubsection{Throughput Calculation}

ISO Standard 9241-411 was used to calculate throughput. MacKenzie [11] provides the guidelines for calculating Fitts' throughput. The throughput for a given experimental trial was calculated using the following equation:

$$
\mathrm{TP}_{\mathrm{i}}=\frac{\mathrm{ID}_{\mathrm{ei}}}{\mathrm{MT}_{\mathrm{i}}}
$$

Here,

$\mathrm{ID}_{\mathrm{ei}}-$ effective index of difficulty for the $\mathrm{i}^{\text {th }}$ trial

$$
\mathrm{ID}_{\mathrm{ei}}=\log _{2}\left(\frac{\mathrm{A}_{\mathrm{ei}}}{\mathrm{W}}+1\right)
$$

$\mathrm{MT}_{\mathrm{i}}$ - average time for a single movement in the $\mathrm{i}^{\text {th }}$ trial

$A_{e i}$ - effective amplitude for the $i^{\text {th }}$ trial

$\mathrm{W}$ - width of the target object

The calculation process is illustrated below:

Consider one of the six movements in a trial. Let $\left(\mathrm{x}_{1}, \mathrm{y}_{1}\right),\left(\mathrm{x}_{2}, \mathrm{y}_{2}\right)$, and $(\mathrm{x}, \mathrm{y})$ be the coordinate position of the "From", "To", and "Select" point respectively (Figure 3-10). Here, the "from" point represents starting position (original/starting position of an object), and "to" point represents target position (position where the object is expected to be placed) and "select" point represents the final position (position where the object is actually placed). Image 


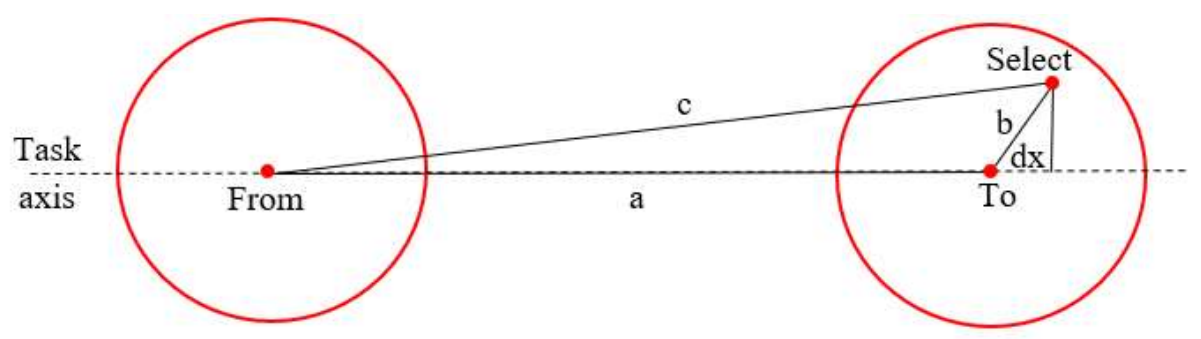

Figure 3-10: Geometry for Fitts' 2-D task

Processing Toolbox Rhino6 was used to obtain the cartesian coordinates for these three points using digitizer. The lengths of $\mathrm{a}, \mathrm{b}$ and $\mathrm{c}$ were estimated from these points as follows:

$$
\begin{gathered}
a=\sqrt{\left(x_{1}-x_{2}\right)^{2}+\left(y_{1}-y_{2}\right)^{2}} \\
b=\sqrt{\left(x-x_{2}\right)^{2}+\left(y-y_{2}\right)^{2}} \\
c=\sqrt{\left(x_{1}-x\right)^{2}+\left(y_{1}-y\right)^{2}}
\end{gathered}
$$

Next, $d_{x}$ was calculated to determine $a_{e}$ as:

$$
\begin{gathered}
d_{x}=\left(c^{2}-b^{2}-a^{2}\right) / 2 a \\
a_{e}=a+d_{x}
\end{gathered}
$$

Here, $a_{e}$ is effective target amplitude for a single movement. The effective target amplitude $\left(\mathrm{A}_{\mathrm{ei}}\right)$ for the $\mathrm{i}^{\text {th }}$ trial is the average of all $\mathrm{a}_{\mathrm{e}}$ values in that trial, i.e., average of 6 movements. $\mathrm{MT}_{\mathrm{i}}$ is the average time for a single movement in the $\mathrm{i}^{\text {th }}$ trial.

$$
\mathrm{MT}_{\mathrm{i}}=\text { Total movement time for } \mathrm{i}^{\text {th }} \text { trial / Number of movements (= } 6 \text { in this study) }
$$

Effective index of difficulty and throughput for all 144 trials were computed.

\subsubsection{Statistical Analysis}

To investigate the effect of the independent variable on the dependent variables, General Linear analysis of variance (ANOVA) models were used. Glove condition, object height, object material and object shape and their interactions were treated as fixed factors and participant was treated as a random factor. The throughput data met the normality and equality of variance assumptions of ANOVA (test findings and data are presented in Appendix IV and 
Appendix V, respectively). The main effects of independent variables on throughput were tested using a statistical significance level of $\alpha=0.05$. Two- and three-way interaction effects on throughput were also tested. Significant main and interaction effects were further evaluated by conducting a comparison between means using Tukey's Honestly Significant Difference (HSD) all-pairwise comparison test. JMP Pro 14 (SAS Institute Inc., USA) was used to perform the statistical analysis. 


\section{Chapter 4 : Results}

\subsection{Relationship between Movement Time and Effective Index of Difficulty}

According to Fitts' Law, a linear relationship is expected between the Index of Difficulty (ID) and the movement time (MT), meaning higher the accuracy constraints of carrying out a task, lower is the speed. This is referred to as the speed-accuracy trade-off. ID is a logarithmic function of ratio of amplitude and target width.

Figure 4-1 shows the relationship between Effective Index of Difficulty $\left(\mathrm{ID}_{\mathrm{e}}\right)$ and $\mathrm{MT}$ for the following combinations of object attributes: Nylon-Circular, Nylon-Hexagonal, SSCircular and SS-Hexagonal. When the data was fitted with linear model, the correlation coefficients were low and ranged from 0.21 to 0.30 . Possible reasons for the poor linear fit could be the huge spread in MT data due to between-subject differences. Furthermore, the ID of plates 1 and 2 were quite close to each other (3.06 and 3.54 respectively). Thus, these two plates were not sufficiently different to distinguish the participants from each other. The data for $\mathrm{ID}_{\mathrm{e}}$ and MT is given in Appendix V (Columns 8 and 9).

To improve the fit between $\mathrm{ID}_{\mathrm{e}}$ and $\mathrm{MT}$, the $\mathrm{MT}$ for individual participants was normalized with respect to their maximum movement time to obtained Normalized MT. Also, plate 2 was eliminated. The resulting plots between ID $_{\mathrm{e}}$ and MT for plates 1, 3, and 4 (with IDs of 3.06, 4.39 and 5.43 respectively) are shown in Figure 4-2. The correlation coefficients were improved with strength of the relationship being the highest for Nylon-Circular objects $\left(\mathrm{r}^{2}=\right.$ $0.55)$ followed by Nylon-Hexagonal objects $\left(r^{2}=0.50\right)$. These graphs suggest that the movement time increases as a linear function of $\mathrm{ID}_{\mathrm{e}}$ and so, Fitts' Law is applicable to the data collected in this study.

Figure 4-3 shows the relationship between $\mathrm{ID}_{\mathrm{e}}$ and Normalized MT for different combinations of Object Material (Nylon/ SS), Object Shape (Circular/ Hexagonal), Glove condition (Barehand/ Glove Type 1/ Glove Type 2). For barehand, the strongest relationship was found for Nylon Hexagonal objects $\left(r^{2}=0.42\right)$, followed by Nylon Circular objects $\left(r^{2}=\right.$ 0.40). For Glove Type 1, the strongest relationship was found for Nylon Circular objects $\left(\mathrm{r}^{2}=\right.$ 0.67), followed by Nylon Hexagonal objects $\left(r^{2}=0.64\right)$. For Glove Type 2, the strongest relationship was found for Nylon Circular objects $\left(r^{2}=0.67\right)$, followed by SS Circular objects $\left(\mathrm{r}^{2}=0.65\right)$. On average, the relationship between $\mathrm{ID}_{\mathrm{e}}$ and MT holds best for NylonCircular objects. Figure 4-3 also suggests that the effect of increase in MT with higher $\mathrm{ID}_{\mathrm{e}}$ is 
more prominent in glove types 1 and 2 than barehand. This emphasizes the importance of evaluating and comparing glove performance based on Fitts' law. 


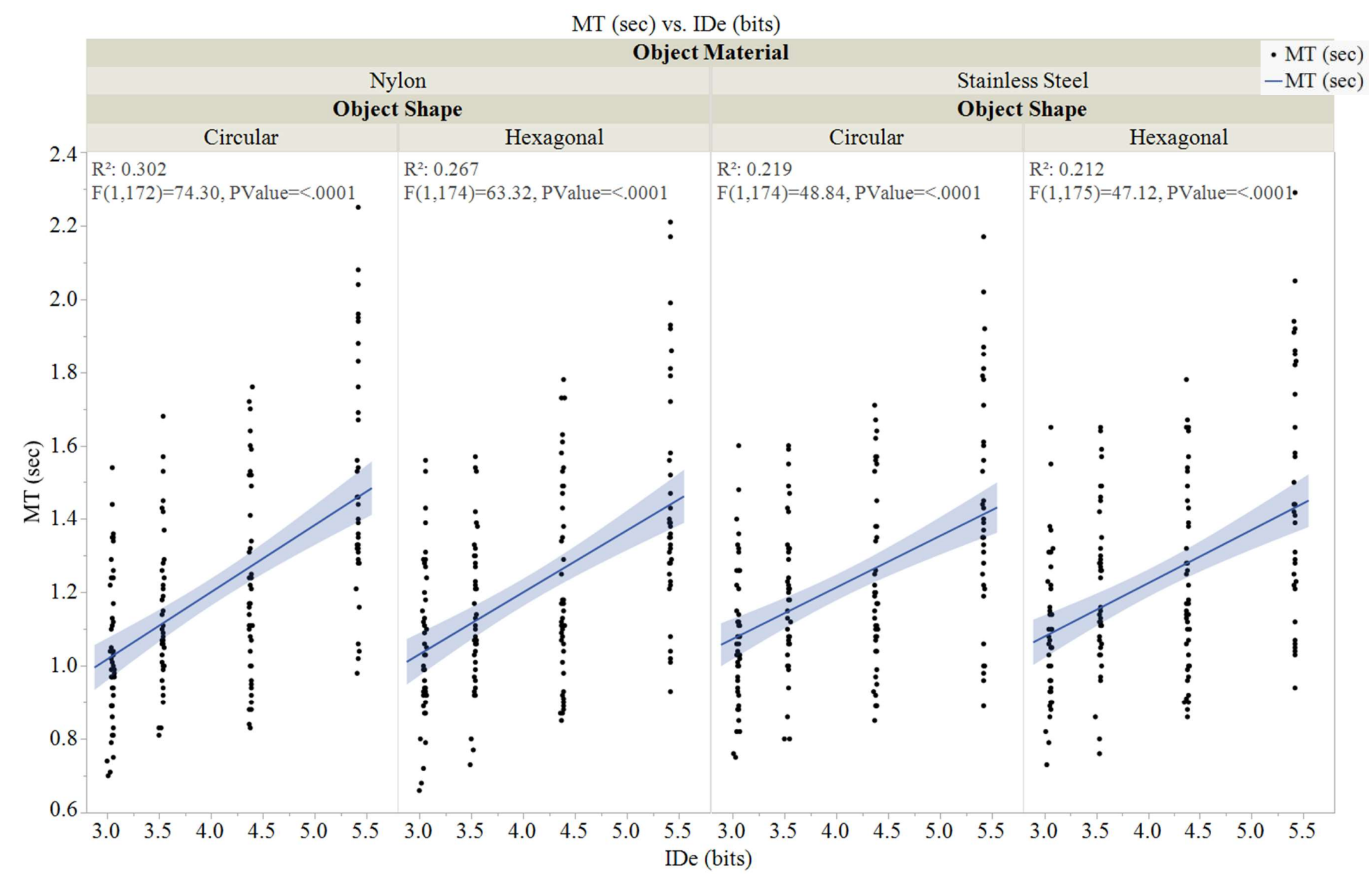

Figure 4-1: MT as a function of $\mathrm{ID}_{\mathrm{e}}$ under different combinations of object attributes 




Figure 4-2: Normalized MT as a function of $\mathrm{ID}_{\mathrm{e}}$ under different combinations of object attributes 


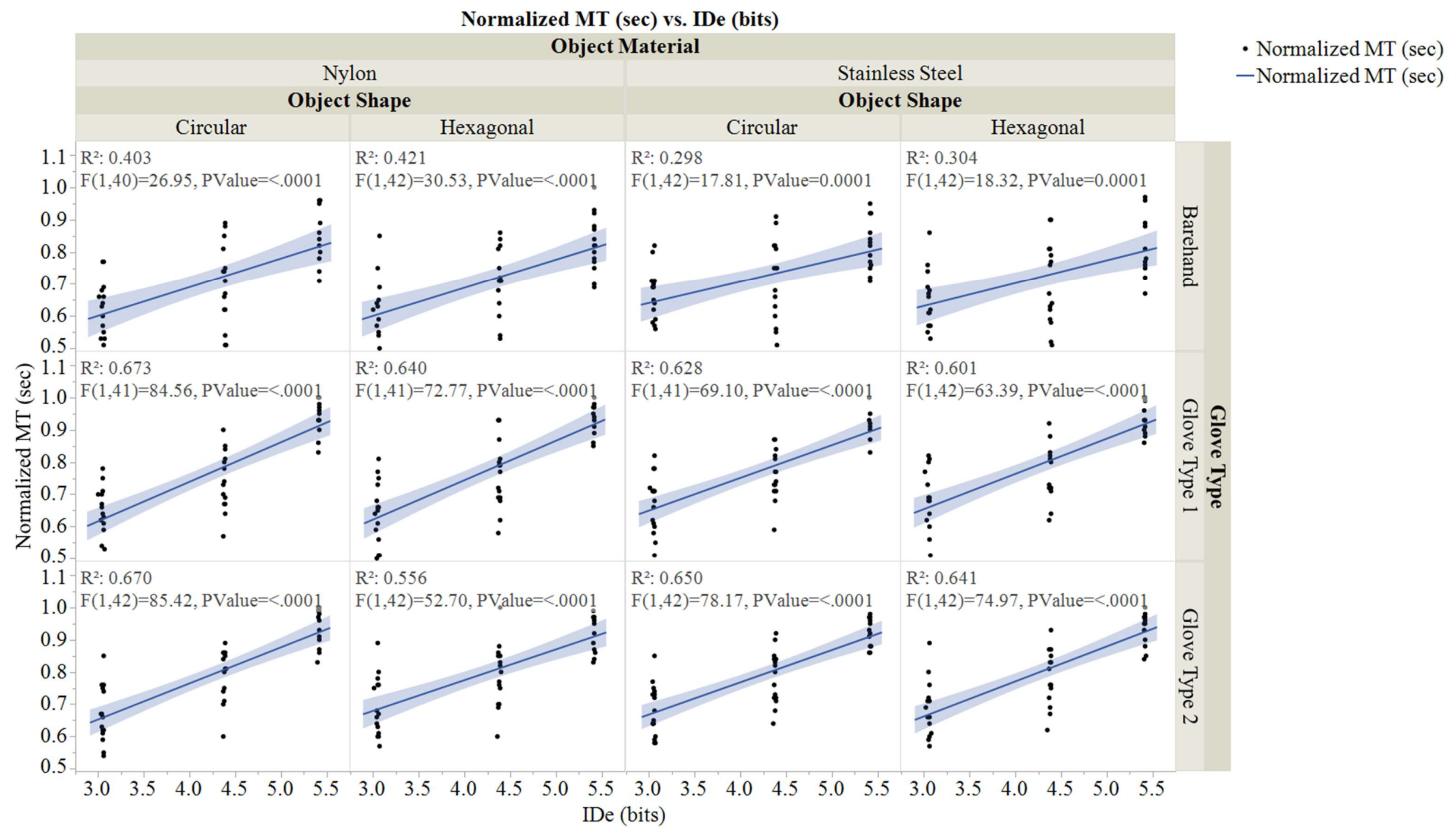

Figure 4-3: Linear fit between IDe and Normalized MT under different combinations of independent variables 


\subsection{Analysis of variance (ANOVA)}

\subsubsection{Throughput}

General linear ANOVA was used to study the effect of glove condition, object attributes (height, material and shape) and their interaction on throughput (TP). Descriptive statistics for the main effects on throughput is shown in Table 4-2. The main effects of glove condition $(p<0.0001)$, object height $(p<0.0001)$ and object material $(p=0.0022)$ were found to be statistically significant. Object shape $(p=0.5217)$ and its interactions had no statistically significant effect on throughput (Table 4-2). The throughput data for all participants is given in Appendix V (Column 11).

Tukey-HSD pairwise comparison test was used to compare the different levels of treatment factors. Tukey-HSD test for glove condition revealed that throughput for barehand was significantly greater than both glove types. However, there was no statistically significant difference between the two glove types. The mean throughput for the barehand was 3.61 bits/sec. Glove type 1 had a mean throughput of $3.36 \mathrm{bits} / \mathrm{sec}$ and glove type 2 had a mean throughput of $3.31 \mathrm{bits} / \mathrm{sec}$, slightly lower than glove type 1 .

Tukey-HSD test for object heights revealed that there was no significant statistical difference between object heights of $0.28^{\prime \prime}$ and 0.43 ". The object height of $0.88^{\prime \prime}$ was significantly different from the other two heights.

Tukey-HSD test for object material showed that the nylon and stainless-steel are significantly different from each other. The mean throughput for nylon objects was 3.45 bits/sec and for stainless-steel objects was $3.40 \mathrm{bits} / \mathrm{sec}$. Both circular and hexagonal shaped objects had a similar TP of $3.43 \mathrm{bits} / \mathrm{sec}$. 
Table 4-1: ANOVA and Mean Pairwise Comparison Result of Throughput

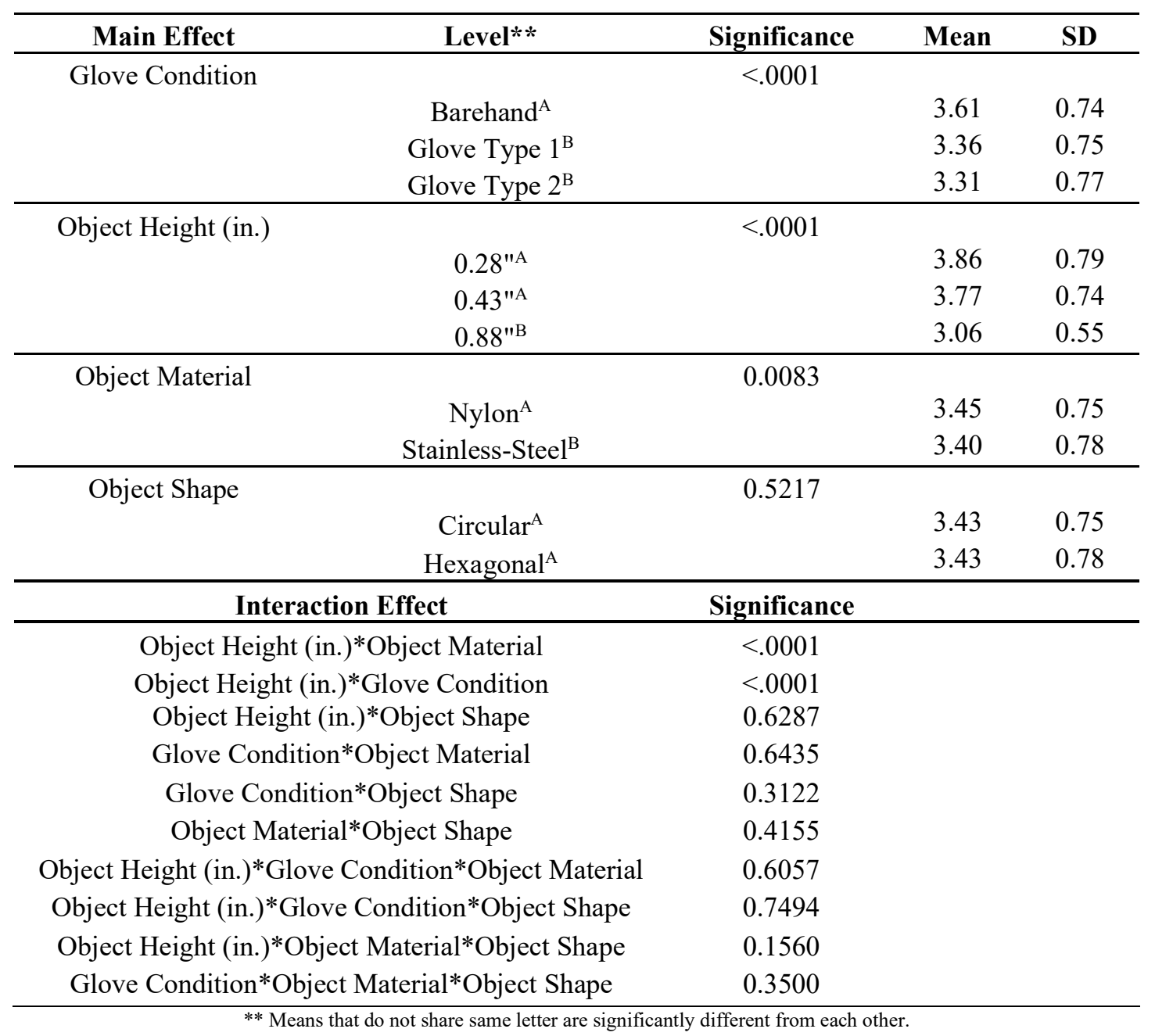

Interaction effects of object height with object material $(p<0.0001)$ and object height with glove condition $(p<0.0001)$ were found to be statistically significant (Table 4-2). Figure 4-4 shows the mean and 95\% confidence interval of TP for all combinations of object height and object material. The throughput for $0.88^{\prime \prime}$ stainless-steel objects ( $\left.2.99 \mathrm{bits} / \mathrm{sec}\right)$ was significantly different from 0.88 " nylon objects $(3.13 \mathrm{bits} / \mathrm{sec})$. The throughputs of 0.28 " and 0.43 "objects were not different from each other but were significantly higher than 0.88 "objects. 


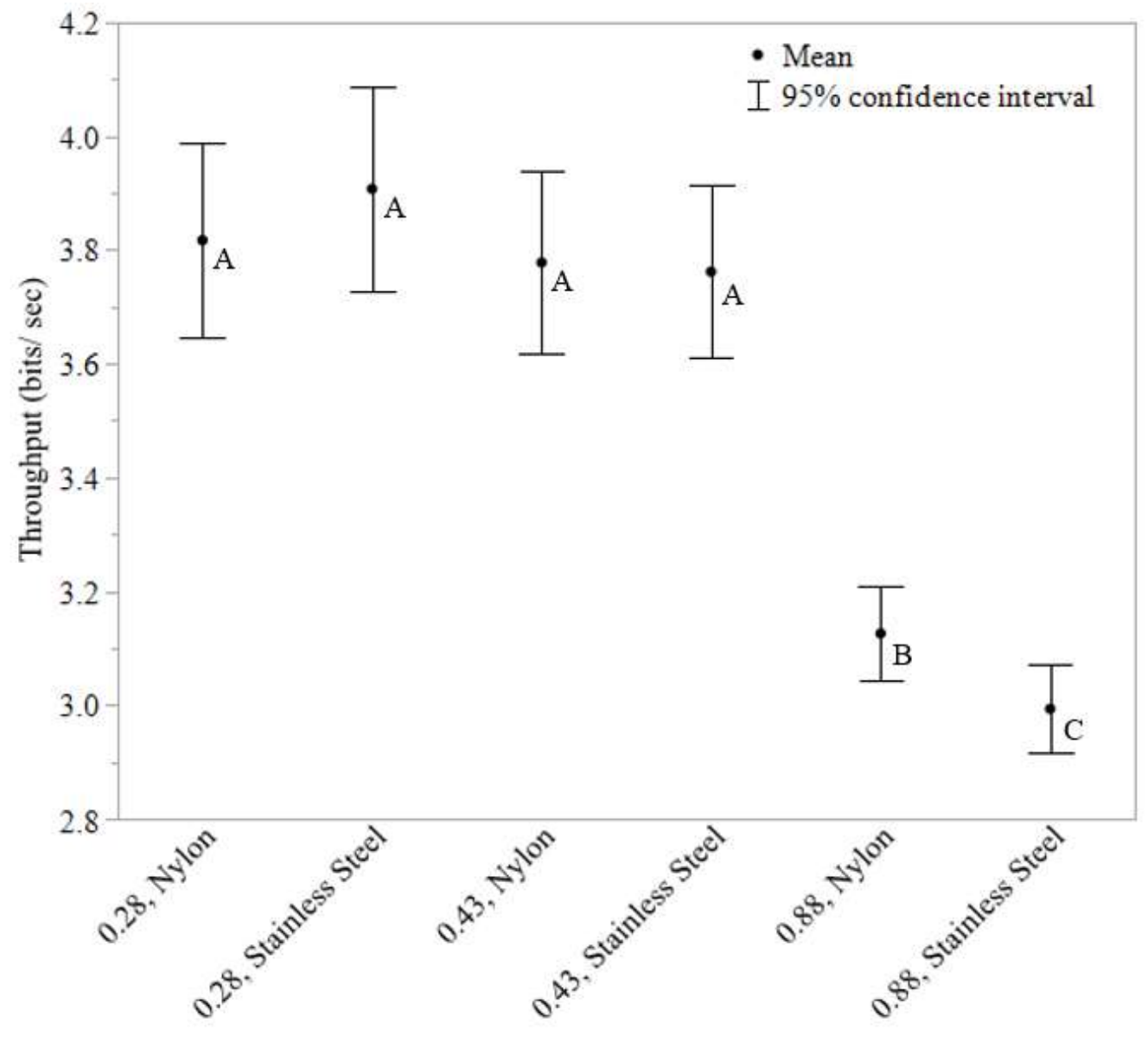

Combinations of Object Height and Object Material*

* Means that do not share same letter are significantly different from each other.

Figure 4-4: Mean and 95\% Confidence Interval of Throughput for all combinations of Object Height and Object Material

Figure 4-5 shows the mean and 95\% confidence interval of TP for all combinations of object height and glove condition. The plot shows that the decrease in throughput for glove type 1 and glove type 2 is more pronounced for objects with heights of 0.28 " and $0.43 "$. 


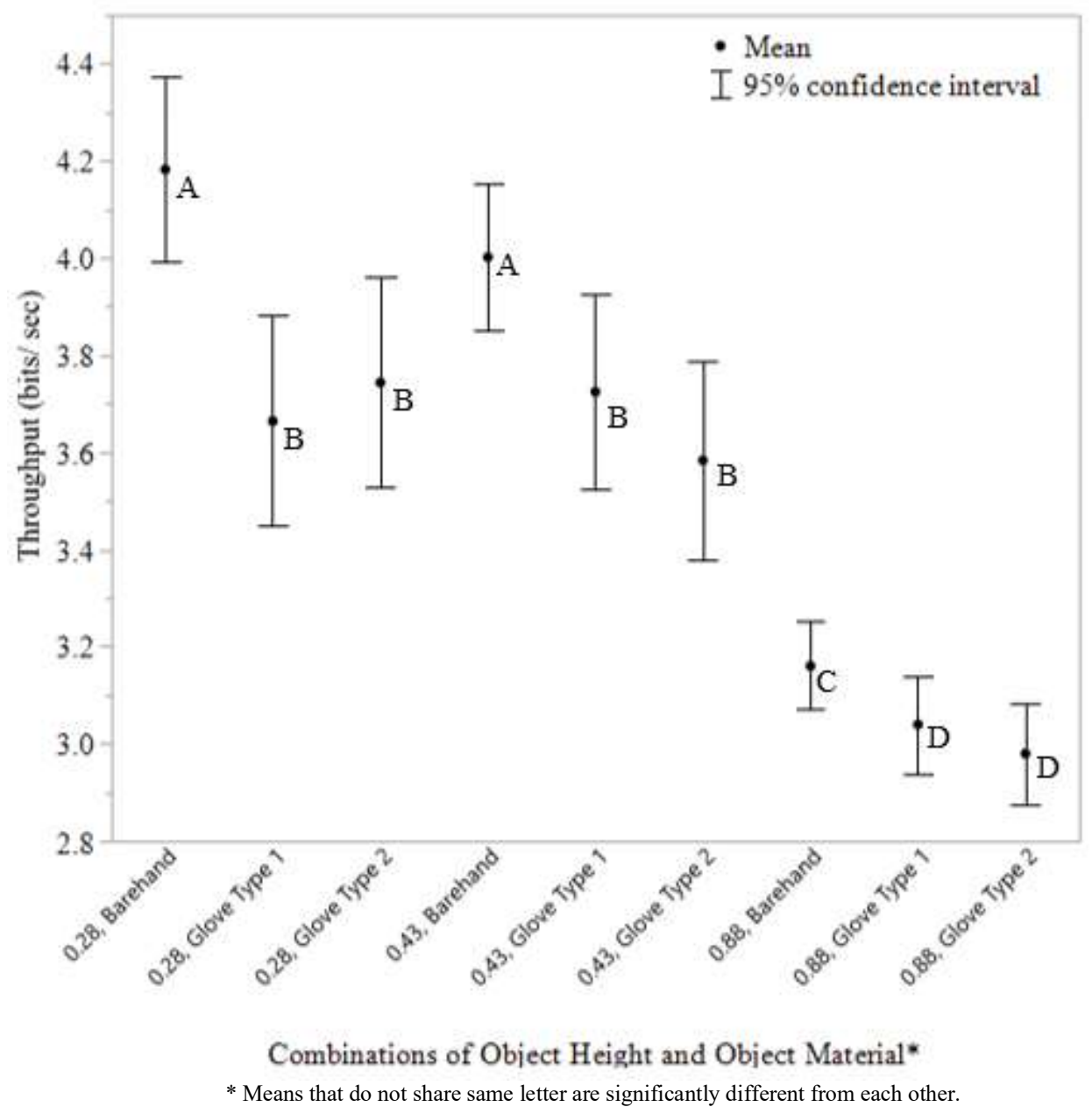

Figure 4-5: Mean and 95\% Confidence Interval of Throughput for all combinations of Object Height*Glove Condition

\subsubsection{Recommended Object Attributes}

The ANOVA based three-way interaction effect of object height, object material and object shape on the throughput for different glove condition was statistically insignificant, suggesting that the object attributes (and their combination) were unable to clearly distinguish the glove conditions. A few two-way interaction effects were statistically significant, indicating that in some cases the mean throughput for barehand condition was different compared to gloved conditions. In order to identify the objects attributes (height, material and shape) that can best distinguish the different glove conditions, we performed additional analysis by carefully evaluating measures such as variance for object attributes, statistical p-values for main (and interaction) effect as well as results of pair-wise Tukey-HSD comparison test. 
The variance for different experimental conditions tested in this study is shown in Figure 4-6. In general, a lower variance was observed for the conditions with the object height of 0.88 " (plates $1 \& 2$ ) compared to the other object heights. To identify the object attributes with overall low variance which were able to generate significant effect of glove condition, the variance was summed (i.e., to obtain the true spread of the data about the individual means of the glove conditions) and compared with the corresponding p-values and the results of pairwise Tukey-HSD comparison test (Table 4-2).

Using this information, cases IV, VI and VII do not distinguish between any glove conditions at all. Other cases, where Tukey HSD result is $\mathrm{AAB}$ or $\mathrm{ABB}$ or $\mathrm{A} \mathrm{A} / \mathrm{B} \mathrm{B}$, help in distinguishing barehand from glove type 1/ 2 conditions. In Table 4-3, these cases are sorted in the increasing order of the Total variance in TP. Cases with lower variance values perform better than the ones with higher variance values. Case III - Task plate 1 with SS-Circular objects was the best out of the available experimental conditions for distinguishing glove conditions (barehand from glove type 1/2) based on Fitts' law. 


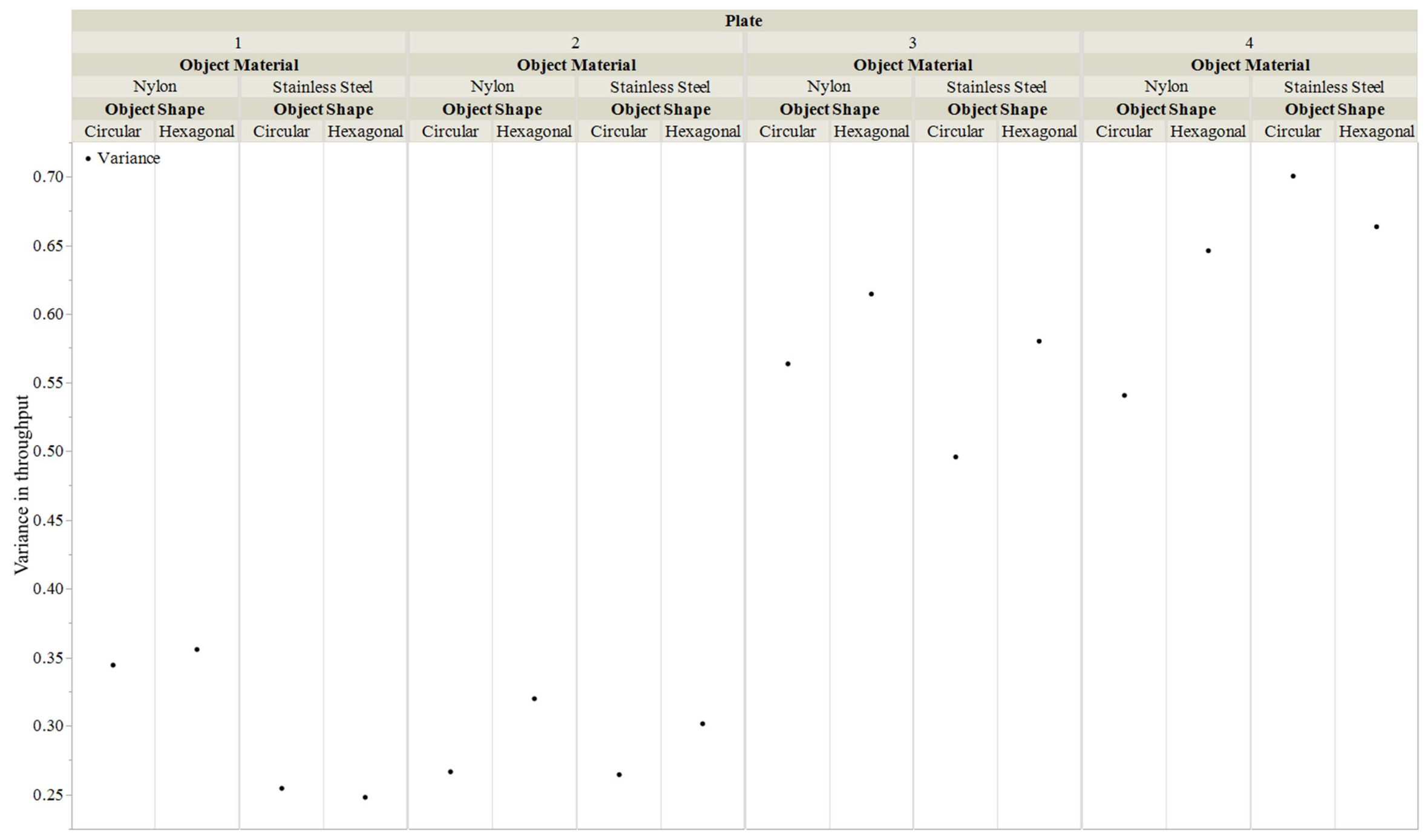

Figure 4-6: Variance of different experimental conditions tested in this study 
Table 4-2: Summary information of Cases I to XVI

\begin{tabular}{|c|c|c|c|c|c|c|c|}
\hline Cases & $\begin{array}{c}\text { Task } \\
\text { Plate }\end{array}$ & $\begin{array}{c}\text { Object } \\
\text { Height }\end{array}$ & $\begin{array}{c}\text { Object } \\
\text { Material }\end{array}$ & $\begin{array}{c}\text { Object } \\
\text { Shape }\end{array}$ & $\begin{array}{c}\text { Total } \\
\text { variance in } \\
\text { TP }\end{array}$ & $\begin{array}{c}\text { p-value of } \\
\text { Glove } \\
\text { Condition }\end{array}$ & $\begin{array}{c}\text { Tukey HSD } \\
\text { result }\end{array}$ \\
\hline I & 1 & 0.88 & Nylon & Circle & 1.05 & 0.0014 & A A/B B \\
\hline II & 1 & 0.88 & Nylon & Hexagon & 1.04 & $<0.0001$ & AAB \\
\hline III & 1 & 0.88 & SS & Circle & 0.79 & 0.0210 & A A/B B \\
\hline IV & 1 & 0.88 & SS & Hexagon & 0.77 & 0.0404 & AAA \\
\hline V & 2 & 0.88 & Nylon & Circle & 0.82 & 0.0224 & A A/B B \\
\hline VI & 2 & 0.88 & Nylon & Hexagon & 0.99 & 0.0848 & AAA \\
\hline VII & 2 & 0.88 & SS & Circle & 0.82 & 0.0829 & AAA \\
\hline VIII & 2 & 0.88 & SS & Hexagon & 0.92 & 0.0011 & ABB \\
\hline IX & 3 & 0.43 & Nylon & Circle & 1.67 & 0.0020 & A A/B B \\
\hline X & 3 & 0.43 & Nylon & Hexagon & 1.83 & 0.0024 & ABB \\
\hline XI & 3 & 0.43 & SS & Circle & 1.49 & 0.0106 & A A/B B \\
\hline XII & 3 & 0.43 & SS & Hexagon & 1.70 & 0.0003 & ABB \\
\hline XIII & 4 & 0.28 & Nylon & Circle & 1.60 & 0.0007 & ABB \\
\hline XIV & 4 & 0.28 & Nylon & Hexagon & 1.83 & $<0.0001$ & ABB \\
\hline XV & 4 & 0.28 & SS & Circle & 2.05 & $<0.0001$ & ABB \\
\hline XVI & 4 & 0.28 & SS & Hexagon & 1.89 & $<0.0001$ & ABB \\
\hline
\end{tabular}

Table 4-3: Cases of experimental conditions sorted according to increasing variance

\begin{tabular}{|c|c|c|c|c|c|}
\hline Cases & $\begin{array}{c}\text { Task } \\
\text { Plate }\end{array}$ & $\begin{array}{c}\text { Object } \\
\text { Height }\end{array}$ & $\begin{array}{c}\text { Object } \\
\text { Material }\end{array}$ & $\begin{array}{c}\text { Object } \\
\text { Shape }\end{array}$ & $\begin{array}{c}\text { Total variance in } \\
\text { TP }\end{array}$ \\
\hline III & 1 & 0.88 & SS & Circle & 0.79 \\
\hline V & 2 & 0.88 & Nylon & Circle & 0.82 \\
\hline VIII & 2 & 0.88 & SS & Hexagon & 0.92 \\
\hline II & 1 & 0.88 & Nylon & Hexagon & 1.04 \\
\hline I & 1 & 0.88 & Nylon & Circle & 1.05 \\
\hline XI & 3 & 0.43 & SS & Circle & 1.49 \\
\hline XIII & 4 & 0.28 & Nylon & Circle & 1.6 \\
\hline IX & 3 & 0.43 & Nylon & Circle & 1.67 \\
\hline XII & 3 & 0.43 & SS & Hexagon & 1.7 \\
\hline XIV & 4 & 0.28 & Nylon & Hexagon & 1.83 \\
\hline X & 3 & 0.43 & Nylon & Hexagon & 1.83 \\
\hline XVI & 4 & 0.28 & SS & Hexagon & 1.89 \\
\hline XV & 4 & 0.28 & SS & Circle & 2.05 \\
\hline
\end{tabular}




\section{Chapter 5 : Discussion and Conclusion}

During industrial assembly or maintenance tasks, workers are often required to carry out the tasks with accuracy under time pressure. Gloves provide protection against hand injuries in the workplace, but they also increase task completion times and the number of errors. Thus, the workers are reluctant to wear safety gloves, and this leads to millions of hand injuries annually. Consequently, there is a decline in productivity and loss of millions of dollars in medical and compensation costs to the employer. The objective of this study was to develop new guidelines to estimate glove performance based on speed-accuracy trade-off. Using the ISO 9241-411 standard based on Fitts' Law in 3-D physical world, throughput for different types of gloves was evaluated. Interaction effects between glove condition and object attributes of shape, height and material were studied. Object attributes that produced a significant effect on throughput were identified. The object attributes were ranked by combing different statistical measures to identify the attributes that can differentiate the glove conditions in terms of throughput.

Movement time as a function of effective index of difficulty was plotted for different combinations of Object Material (Nylon/ SS) and Object Shape (Circular/ Hexagonal). The linear relationship was found to be the strongest for Nylon-Circular objects $\left(r^{2}=0.55\right)$. A further breakdown of plots for each glove condition showed that for barehand, the strongest relationship was found for Nylon Hexagonal objects $\left(r^{2}=0.42\right)$. For Glove Type 1 , the strongest relationship was found for Nylon Circular objects $\left(r^{2}=0.67\right)$ and for Glove Type 2, the strongest relationship was found for Nylon Circular objects $\left(r^{2}=0.67\right)$. For application of Fitts' Law in virtual environment, higher $r^{2}$ values ranging from 0.82 to 0.98 have been found in literature $[12,15,16]$. Bootsma et al. [20] studied the effect of varying object dimensions and amplitude in manual prehension tasks using Fitts' Law. The coefficient of determination between movement time and $\mathrm{ID}_{\mathrm{e}}$ was $\mathrm{r}^{2}=0.68$ and based on this value it was suggested that the speed-accuracy of Fitts' Law holds good for complex prehension tasks as well. In our study, $r^{2}$ values for some glove conditions, such as gloves types 1 and 2 are closer to this value.

The slope of the least-squares regression line between ID and MT is called throughput. The throughput values are same for all values of ID (slope of line is independent of $x$ values). This is true if there is a change in only task amplitude and target width in the study. In our study, object height is changing across the range of ID. In our study, same objects were used 
for plates 1 and 2. However, object heights were different for plates 3 and 4. So, object heights varied across the plates. As is seen in ANOVA results, object height has a significant effect on throughput. This maybe another reason for lower $r^{2}$ values. For barehand, the weaker relationship may be due to high variability between the subjects. This is expected as the barehand condition is the easiest for the participants to carry out the object transfer tasks. In gloved condition, the ability to maneuver objects is adversely affected. The range of index of difficulty in our study is from 3.06 to 5.43 bits and is narrower than the range of 4.25 to 7 bits used by Bootsma et al. [20]. In our study, the range of ID may not be sufficiently wide enough to distinguish the plates for barehand condition.

Throughput statistical analysis revealed that object height, object material and glove condition had a significant effect on throughput. Interaction effects of glove condition with object height and object height with object weight were found to be statistically significant. The experiment data rejects the null hypothesis that "Glove condition, object attributes (height, shape and weight) and their interaction will have no effect on throughput". The mean throughput for the barehand was the highest (3.61 bits/sec) and it was significantly different from the two glove types tested in this study. The difference between mean throughput values of Glove Type 1 (3.36 bits/sec) and Glove Type 2 (3.31 bits/sec) was statistically insignificant. The performance time is expected to increase with glove thickness when the participants are asked to perform the tasks at their fastest speed [29]. However, the difference in throughput of Glove Type 1 and Glove Type 2 was very small. Both leather gloves had larger widths at fingertips, as is the case with most leather gloves. In Glove Type 1, leather bunches at the fingertips while grasping the objects. This posed additional unexpected constraint on the grasping abilities with this glove. In Glove Type 2, the sturdier TPR material made the glove less flexible and it did not bunch while grasping the objects (Figure 5-1). Therefore, despite having a difference in thickness, both gloves posed similar constraints on the grasping abilities. This maybe the reason that no significant difference in their performance was observed.

The mean throughput for nylon objects ( $3.45 \mathrm{bits} / \mathrm{sec}$ ) was significantly higher than the mean throughput for stainless-steel objects ( $3.40 \mathrm{bits} / \mathrm{sec})$. This is expected since lighter objects are easier to move and maneuver than heavier objects.

The mean throughput for objects with height of 0.88 " was the lowest $(3.06 \mathrm{bits} / \mathrm{sec})$ and was significantly different from the other two heights. However, there was no significant difference between object heights of 0.28 " (3.86 bits/sec) and $0.43 "$ ( $3.77 \mathrm{bits} / \mathrm{sec})$. This is 
because weights of $0.28 "$ and $0.43^{\prime \prime}$ objects was very less in comparison to 0.88 " objects. Although 0.88" objects were associated with lower accuracy constraints, the decrease in movement time was not enough. This may be explained due to additional time involved in grasping and moving the larger and heavier objects. Since object height had a significant effect on throughput, this may be another reason for a slightly poor fit between $\mathrm{ID}_{\mathrm{e}}$ and MT.
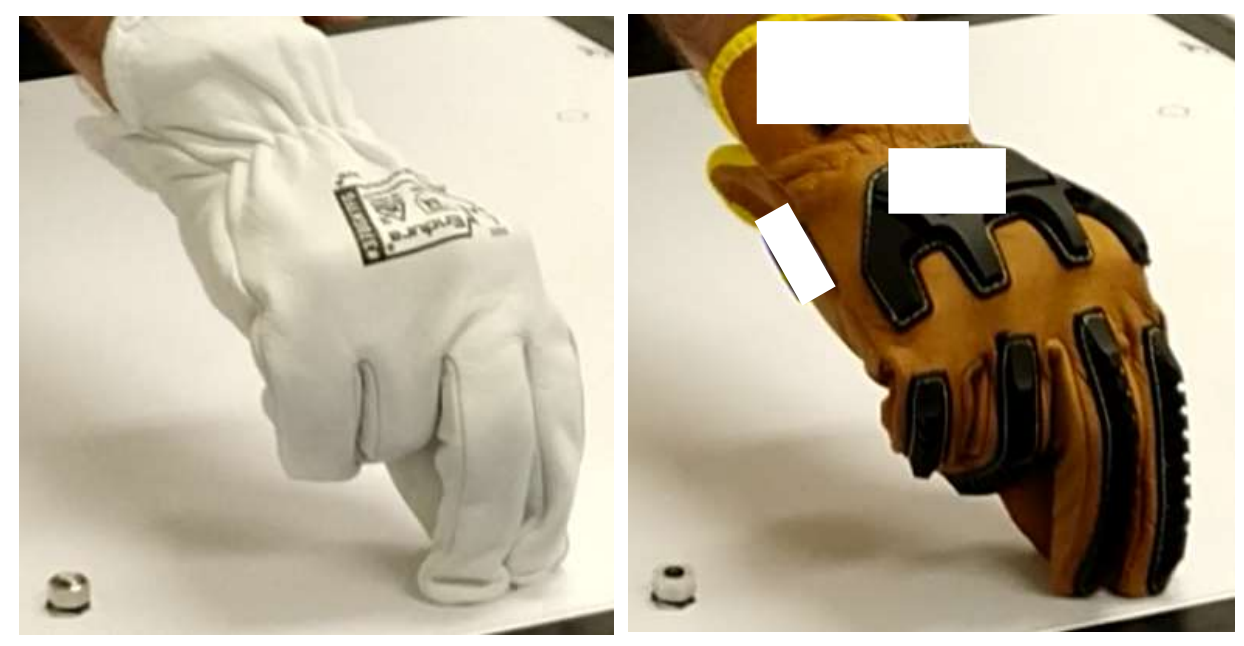

Figure 5-1: Comparison of gloves while lifting smallest 0.28 " objects

The mean throughput for 0.88 " stainless-steel objects ( $2.99 \mathrm{bits} / \mathrm{sec})$ was significantly lower than the 0.88 " nylon weights ( $3.13 \mathrm{bits} / \mathrm{sec})$, but there was no difference in TP for 0.28 " and $0.43 "$ objects due to difference in material. In the former case, there was a huge weight difference between object types. The weight of 0.88 " stainless-steel object was $205 \mathrm{~g}$ while that of 0.88 " nylon object was $\sim 30 \mathrm{~g}$. However, weights of 0.28 " and 0.43 " objects were low and similar to each other. Their throughput was higher than $0.88^{\prime \prime}$ objects, but they were not significantly different from each other.

The interaction effect of glove condition with object height showed that for smaller height objects $\left(0.28\right.$ " and $\left.0.43^{\prime \prime}\right)$, the mean throughput for barehand was significantly higher than the two glove types. However, there was little significant difference in throughput for $0.88^{\prime \prime}$ height objects due to glove conditions. While picking up smaller objects, fingers came in contact with the task plate and the ability to lift the objects off the task plate was seriously affected with gloves. For larger objects, more surface of the object to be lifted was accessible to the fingers. Therefore, glove condition did not severely affect the throughput for larger objects as it did for smaller objects. 
This is the first study which aims at determination of throughput of gloves and studies the effect of object attributes (material, shape and height) and its' interaction with gloves. Most of the studies in literature have studied the effect of changing object dimensions on MT. In our study, with the change in object heights, width also changed. And MT is a function of target width as well. Therefore, in our study, it was difficult to make direct correlations of object height with movement time. McIntosh et al. [21] studied the impact of changing object dimensions in three directions on movement time. The study revealed that the time taken to grasp objects is inversely proportional to object height due to reduced accuracy constraints. Therefore, the movement time should decrease for larger objects. However, McIntosh et al. [21] has stated that the dimensional effects of the object on MT depends on grasping strategy of the fingers. In their study, objects were mounted in the air and they were grasped between finger and thumb, across the width. They stated that beyond object width of $4 \mathrm{~cm}$, there is a linear relationship between MT and object width. In our study, the object was approached along the reach axis and the hand grasped the object from the top using thumb, index finger and middle finger. Since we used cylindrical/ hexagonal objects and the fingers grasped the area around the diameter, it was difficult to ascertain independent effects of the two dimensions (one along the reach axis and the other orthogonal to reach axis). The object widths/diameter of 0.88 " height objects were closer to this $4 \mathrm{~cm}$ threshold $(3.81 \mathrm{~cm})$. Bootsma et al. [20] stated that the object size - the dimension of object orthogonal to reach axis, does not influence the movement time until it reaches the maximum size that can be grasped. After that size is reached, movement time increases with the object size. In the study by Bootsma et al. [20], range of object size was from $3 \mathrm{~cm}$ to $9 \mathrm{~cm}$ with linear effect between object size and MT visible only after $7 \mathrm{~cm}$ size. In our study, object width had lower limits, from $1.27 \mathrm{~cm}$ to $3.81 \mathrm{~cm}$. The high variation in hand/palm size and flexibility among participants may result in variation of results [20]. Therefore, for larger objects (taller in this study), reduced safety clearance between the fingers and object may have caused an incremental increase in MT, despite having lower accuracy constraints. Higher object weights of these objects may be another possible cause of lower throughput values.

Finally, various statistical measures (variance, p-values, pair-wise Tukey-HSD comparison) were used to identify the objects attributes (height, material and shape) that can best distinguish the different glove conditions. It was found that a task plate with an amplitude of 11" with SS-Circular objects performed the best for distinguishing glove conditions based on speed-accuracy trade-off. 


\subsection{Study Limitations}

In this study, the participants were asked to perform simple object transfer tasks for a small range of index of difficulty. But in practice, the workers perform a wide range of tasks of varying difficulty and different object weight/ size. The range of ID used in this study was 3.06 to 5.43. To get higher ID, either task amplitude can be increased, or object width can be reduced. The task amplitude cannot be exceeded beyond $21 "$ as it will go beyond the comfortable reaching envelope of the human arm. Furthermore, in this study the length of the digitizer arm also posed additional constraint on the task amplitude. The object size could not be reduced below $0.5^{\prime \prime}$ as such dimensions may not be practically relevant. To get lower ID, task amplitude can be decreased along with an increase in the object width. But such arrangement will put the objects in close proximity with respect to each other leaving insufficient space around the objects for grasping. In virtual environment, only clicking is involved and so it is possible to have larger and wider range of IDs. But, in 3-D physical world, the application of ISO 9241-411 standard is restricted to the narrow range of IDs. The narrower range of IDs is perhaps one of the reasons for not seeing a stronger relationship between MT and $\mathrm{ID}_{\mathrm{e}}$ which restricted the spread of data points.

The gloves used in this study were expected to impose different levels of constraint during object transfer tasks due to different levels of thickness. However, while carrying out the tasks, the structure of Glove Type 1 changed, and it resulted in similar constraint as Glove Type 2. This is a probable reason that we did not see any difference in their throughput values. The shapes and material of objects used in this study are the most commonly used in industrial operations. However, it was difficult to replicate exact operation/ objects used in an industrial process. Finally, the COVID-19 pandemic significantly affected the participant recruitment efforts resulting in unequal number of men (12) and women (3) participants. It was originally intended to have equal number of male and female participants.

\subsection{Practical Implications}

This study showed that glove condition, physical attributes of objects used during industrial tasks and their interaction influence speed accuracy trade-off. ISO 9241-411 standard can be used in the 3-D physical world to compare barehanded exertions with gloved exertions based on speed-accuracy trade-off. Based on this study, task amplitude of 11" with target width of $1.5^{\prime \prime}$, and stainless-steel object with a circular shape and 0.88 " height, can be used to compare barehanded exertions with gloved exertions. Selection of high-performance gloves will reduce 
operation time/ reduce the number of errors. In addition to safety standards available for the glove selection process, employers can also conduct speed-accuracy trade-off analysis to improve overall productivity of workers. The gloves tested in this study did not impose increasing levels of constraints based on the assumptions of thickness and additional padding. Therefore, it cannot be said conclusively that the standard can be used for comparing different gloves. Future studies should consider careful selection of gloves such that they impose different levels of constraints on the task performance.

\subsection{Final Conclusions}

In conclusion, the data from this study seem to indicate that ISO 9241-411 standard can be used in the 3-D physical environment to compare barehanded exertions with gloved exertions. Barehanded exertions were found to be different when compared with gloved exertions under various object attributes such as height, material and shape. On the other hand, the gloved conditions were found not to be different from each other when compared using the ISO 9241-411 standard. A "limited range of IDs (3-5.4)" was found to be one of the limiting factors with the implementation of ISO 9241-411 standard in the 3D physical environment. Such a limited range of IDs restricted the spread of data points which further affected the relationship between the MT and IDs. Furthermore, the gloves tested in this study (although intended to be quite different from each other due to incremental thickness and padding) imposed quite similar levels of constraints for very reasons. Thus, based on the data from this study it cannot be conclusively stated that the ISO 9241-411 standard can be used in the 3-D physical environment to compare safety gloves. 


\section{References}

1. Occupational Safety and Health Administration. Personal Protective Equipment. 2004; Available from: https://www.osha.gov/Publications/osha3151.pdf.

2. Electronic Code of Federal Regulations. $\$ 1910.138$ Hand protection. 1994; Available from: https://gov.ecfr.io/cgi-bin/text$\underline{\mathrm{idx}}$ ?SID $=16 \mathrm{cbe} 2 \mathrm{fcbabde} 3 \mathrm{bfe} 99185870520 \mathrm{~d} 9 \mathrm{cc} \& \mathrm{mc}=$ true $\&$ node $=$ se29.5.1910 11 $38 \& \operatorname{rgn}=\operatorname{div} 8$

3. SuperiorGlove. Everything You Need To Know About ANSI/ISEA 138 - The New Impact Standard.2019; Available from:

https://www.superiorglove.com/blog/everything-you-need-to-know-about-ansiisea-138-the-new-impact-standard

4. Grainger. Glove Selection: Using ANSI/ISEA 105-2016 American National Standard for Hand Protection Classification. 2018; Available from: https://www.grainger.com/content/qt-glove-selection-using-ansi-isea-105-2016396.

5. Drury, C.G., The speed - accuracy trade-off in industry. Ergonomics, 1994. 37(4): p. $747-763$.

6. Woodworth, R.S., Accuracy of voluntary movement. The Psychological Review: Monograph Supplements, 1899. 3(3): p. i.

7. Plamondon, R. and A.M. Alimi, Speed/accuracy trade-offs in target-directed movements. Behavioral and brain sciences, 1997. 20(2): p. 279-303.

8. Fitts, P.M., The information capacity of the human motor system in controlling the amplitude of movement. Journal of experimental psychology, 1954. 47(6): p. 381.

9. MacKenzie, I.S., A note on the validity of the shannon formulation for fitts' index of difficulty. Open Journal of Applied Sciences, 2013. 3(06): p. 360.

10. Hoffmann, E.R., C.G. Drury, and C.J. Romanowski, Performance in one-, twoand three-dimensional terminal aiming tasks. Ergonomics, 2011. 54(12): p. 11751185 .

11. MacKenzie, I.S., Fitts' law. Handbook of human-computer interaction, 2018. 1: p. 349-370. 
12. Hassan, M., J. Magee, and I.S. MacKenzie. A Fitts' Law Evaluation of HandsFree and Hands-On Input on a Laptop Computer. in International Conference on Human-Computer Interaction. 2019. Springer.

13. List, C. and M. Kipp. Is Bigger Better? A Fitts' Law Study on the Impact of Display Size on Touch Performance. in IFIP Conference on Human-Computer Interaction. 2019. Springer.

14. Zhuang, Q., et al. Modeling Pilots' Operation Error Based on Fitts' Law. in International Conference on Human-Computer Interaction. 2019. Springer.

15. Roig-Maimó, M.F., et al., Head-tracking interfaces on mobile devices: Evaluation using Fitts' law and a new multi-directional corner task for small displays. International Journal of Human-Computer Studies, 2018. 112: p. 1-15.

16. Bachynskyi, M., et al. Performance and ergonomics of touch surfaces: A comparative study using biomechanical simulation. in Proceedings of the 33rd Annual ACM Conference on Human Factors in Computing Systems. 2015.

17. Drury, C.G., Application of Fitts' law to foot-pedal design. Human factors, 1975. 17(4): p. 368-373.

18. Glaser, H.J. and C.G. Halcomb. Foot placement and response latency: A test of Fitts' law. in Proceedings of the Human Factors Society Annual Meeting. 1980. SAGE Publications Sage CA: Los Angeles, CA.

19. Drury, C., A note on Fitts' Law and assembly order. Ergonomics, 1993. 36(7): p. 801-806.

20. Bootsma, R.J., et al., The speed-accuracy trade-off in manual prehension: effects of movement amplitude, object size and object width on kinematic characteristics. Experimental brain research, 1994. 98(3): p. 535-541.

21. McIntosh, R.D., M. Mon-Williams, and J.R. Tresilian, Grasping at laws: Speedaccuracy trade-offs in manual prehension. Journal of experimental psychology: human perception and performance, 2018. 44(7): p. 1022.

22. Murata, A. and H. Iwase, Extending Fitts' law to a three-dimensional pointing task. Human movement science, 2001. 20(6): p. 791-805.

23. Cha, Y. and R. Myung. Extended Fitts' law in three-dimensional pointing tasks. in Proceedings of the Human Factors and Ergonomics Society Annual Meeting. 2010. SAGE Publications Sage CA: Los Angeles, CA.

24. Crossman, E.R., The measurement of perceptual load in manual operations. 1956, University of Birmingham. 
25. Accot, J. and S. Zhai. Refining Fitts' law models for bivariate pointing. in Proceedings of the SIGCHI conference on Human factors in computing systems. 2003.

26. Moore, D. and N. Campbell-Kyureghyan, User Experience and Task Completion Time Evaluation of Impact Protective Gloves. 2017.

27. Dianat, I., C.M. Haslegrave, and A.W. Stedmon, Methodology for evaluating gloves in relation to the effects on hand performance capabilities: a literature review. Ergonomics, 2012. 55(11): p. 1429-1451.

28. Gauvin, C., et al. Mechanical and Biomechanical Approaches for Measuring Protective Glove Adherence. in Proceedings of the Human Factors and Ergonomics Society Annual Meeting. 2008. SAGE Publications Sage CA: Los Angeles, CA.

29. Kinoshita, H., Effect of gloves on prehensile forces during lifting and holding tasks. Ergonomics, 1999. 42(10): p. 1372-1385.

30. Polechoński, J. and D. Olex-Zarychta, The influence of tactile feedback on hand movement accuracy. Human Movement, 2012. 13(3): p. 236-241.

31. Bronkema-Orr, L. and R.R. Bishu. The effects of glove frictional characteristics and load on grasp force and grasp control. in Proceedings of the Human Factors and Ergonomics Society Annual Meeting. 1996. SAGE Publications Sage CA: Los Angeles, CA.

32. Bishu, R.R., et al., Tactility as a function of grasp force: effects of glove, orientation, pressure, load, and handle. 1994.

33. Padron, M., Safety Professionals, 'We've Got a Problem'. 2018; Available from https://ohsonline.com/Articles/2018/06/01/Safety-Professionals-Weve-Got-aProblem.aspx?Page $=1$

34. Montgomery, D. C., Design and analysis of experiments, 2017. New York: John Wiley. 


\section{Appendix I: Anthropometric Measurements Of Participants}

\begin{tabular}{|c|c|c|c|c|}
\hline Participant & Age (years) & Weight (pounds) & Height (feet) & $\begin{array}{c}\text { KnuckleWidth } \\
\text { (inches) }\end{array}$ \\
\hline 1 & 26 & 135 & 5.4 & 3.5 \\
\hline 2 & 25 & 165 & 6.0 & 3.5 \\
\hline 3 & 24 & 156 & 5.7 & 3 \\
\hline 4 & 23 & 117 & 5.3 & 3 \\
\hline 5 & 32 & 136 & 5.6 & 3.25 \\
\hline 6 & 23 & 150 & 5.6 & 3 \\
\hline 7 & 29 & 120 & 5.2 & 2.7 \\
\hline 8 & 30 & 115 & 5.0 & 2.3 \\
\hline 9 & 25 & 150 & 5.8 & 3.2 \\
\hline 10 & 29 & 123 & 5.3 & 3.3 \\
\hline 11 & 29 & 120 & 5.5 & 3.4 \\
\hline 12 & 24 & 119 & 5.6 & 3.45 \\
\hline 13 & 29 & 165 & 5.9 & 3.5 \\
\hline 14 & 34 & 198 & 6.0 & 3.6 \\
\hline 15 & 30 & 150 & 5.6 & 3.6 \\
\hline
\end{tabular}




\title{
Appendix II: WVU IRB Consent Form
}

\section{WestVirginiaUniversity.}

OFFICE OF HUMAN RESEARCH PROTECTION

\author{
Key Information for: \\ A New Method to Determine Speed-Accuracy Trade-Off of Safety Gloves \\ Based on ISO 9241-411 Standard
}

You are being asked to participate in the research described below. This page provides key information that may help you to make this decision; more detailed information can be found after this section.

Why is this research being done and what is involved?

- The purpose of this study is to evaluate performance of safety gloves in terms of speed and accuracy. New guidelines will be developed for glove selection on the basis of the object to be handled and the glove performance.

- You will be asked to perform object transfer tasks from one point to another point on a circle using different glove conditions.

- The study will take four hours to complete.

Do I have to participate and what are the risks involved?

Participation in this research study is completely voluntary and you are free to withdraw from the research at any time. If you do not wish to participate, please discuss alternatives with the researcher or refer to the "Alternatives" section in the consent form. You may or may not directly benefit from participating in this research.

Risks from participation in this study include slight discomfort in the hand since this study will take 4 hours to complete.

Who can I talk to if I have questions or concerns?

If you have any questions or concems about this research or would want to withdrawal from the study, you can contact Isha Gaut at (681)-285-0201 from the Dept. of Department of Industrial \& Management Systems Engineering at West Virginia University.

For more information, please see the Informed Consent Form. 


\title{
WestVirginiaUniversity
}

OFFICE OF HUMAN RESEARCH PROTECTION

\section{Informed Consent for Research | Minimal Risk}

\author{
Principal Investigator (PI) \\ Ashish Nimbarte \\ Department \\ Industrial \& Management Systems Engineering \\ Co-Investigator(s) \\ Isha Gaut \\ Sponsor or Funding Source \\ Public/Non-Profit \\ WVU IRB Protocol \# \\ 2001848881 \\ Study Title \\ Using ISO 9241-411 Standard \\ A New Method to Determine Speed-Accuracy Trade-Off of Gloves \\ Introduction \\ You, , have been asked to participate in this research study, which has been \\ explained to you by _. This research is being conducted to fulfill the requirements for \\ a Master's of Science in Industrial Engineering from the Department of Industrial \& Management Systems \\ Engineering at West Virginia University. This research is being conducted under the supervision of Ashish \\ Nimbarte, $\mathrm{PhD}$. \\ Purpose
}

The purpose of this study is to evaluate performance of safety gloves in terms of speed and accuracy. New guidelines will be developed for glove selection on the basis of the object to be handled and the glove performance. WVU expects to enroll approximately 15 subjects. A total of approximately 15 subjects, at all sites, are expected to participate in this study.

\section{Description of Procedures}

1. First, the objective and experimental procedure of this study will be explained to you. You will not be allowed to participate if you suffer from any type of musculoskeletal, degenerative, or neurological disorder or if you have a history of hand or fingertip pain or any current pain. Then, you will be asked to read and sign the IRB consent form.

2. Then, your anthropometric data such as age, body weight, height will be recorded. Hand measurement knuckle width will be taken to provide appropriate glove size for the participant.

3. You will be given some time to get familiarized with the equipment and data collection procedure. You will be allowed to practice for some time before beginning with the actual data collection.

4. You will perform object transfer tasks along a circle (maximum diameter of circle is 21 inches). Object size varies from 0.5 inches to 1.5 inches. Object weight varies from $1 \mathrm{~g}$ to $200 \mathrm{~g}$. Circular and hexagonal object shapes will be used. Three different glove conditions will be used.

5. There will be six objects at positions " 1 " to " 6 ". The experiment will begin with you lifting the object at position " 1 " and moving it along a straight line to position " 7 " and so on.

vะยงหล.2ง 


\section{WestVirginiaUniversity.}

OFFICE OF HUMAN RESEARCH PROTECTION

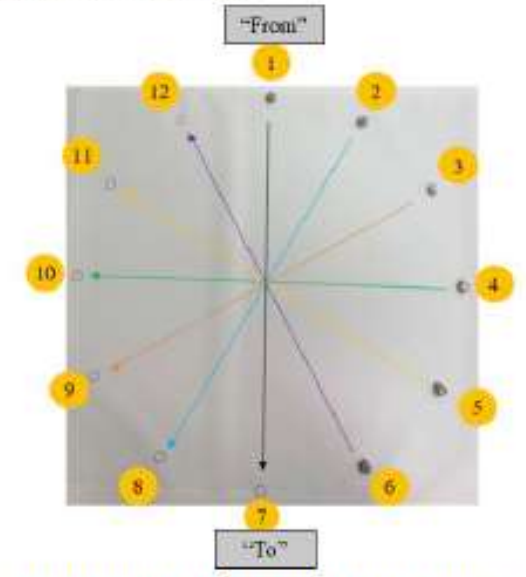

6. You will perform a total of 180 experimental trials. Each trial takes about $10-15$ seconds to complete. Glove conditions and object specifications will be randomized in the experiment. A rest period of 2 minutes will be given after every ten trials.

7. After every trial, the researcher will use Microscribe 3D Digitizer to record the coordinates of the center of the object at the "Select" position. "Select" position represents the final position (position where the object is actually placed). This will serve as an additional rest period after every trial.

8. The trial will be recorded with a video camera with focus on the circle used in the experiment equipment. Your face and body except hand will not be captured in the video. Recording is done to obtain movement time for each trial.

This study involves use of safety gloves for transferring circular or hexagonal shaped objects from one point to another point and will take approximately four hours to complete.

\section{Risks and Discomforts}

You may feel slight discomfort in the hand since this study will take 4 hours to complete. Appropriate rest period will be given to overcome fatigue.

In addition, there is always the risk of uncommon or previously unknown side effect(s) or event.

\section{Alternatives}

You do not have to participate in this study.

Benefits

You may or may not directly benefit from participating in this research. The knowledge gained from this study may eventually benefit others.

\section{Financial Considerations}

You will be paid $\$ 0$ for each visit. You can eam up to $\$ 0$.

Your information may be provided to the appropriate parties for billing and/or payment purposes. Please be advised that any compensation received for participation in a research study, including a gift card, is considered taxable income and must be reported to the Internal Revenue Service (IRS). 


\section{WestVirginiaUniversity.}

\section{OFFICE OF HUMAN RESEARCH PROTECTION}

If you are a WVU employee or a WVU student-employee, you are required to report the total amount of compensation received for your participation in a research study to the WVU Tax Services Office upon receipt of payment.

Your data, health information, research results, specimens, genomic data or any and all other information related to this research study used in this research study may contribute to a new discovery or treatment. In some instances, your data, your health information, your research results, your specimens, these discoveries or treatments, or any other information related to this research study, even if identifiers are removed, may be of commercial value and may be sold, patented, or licensed by the investigators and West Virginia University for use in other research or the development of new products. You will not retain any property rights nor will you share in any money or commercial profit that the investigators, West Virginia University, or their agents may realize.

Confidentiality

The identifiable data are names and videotapes (only your hand will be visible). All direct identifiers (i.e. names) about you will be removed after the data collection procedure. Any link between you and your data will be disconnected. Substitute codes will be used for identification. Data files will be kept in separate secure locations. Computer passwords will be used to protect information. The data will be stored on secure WVU servers. Aggregate reporting will be used, and misleading identifiers will be used in articles or presentations.

Any information about you that is obtained as a result of your participation in this research will be kept as confidential as legally possible. Your research records and test results, just like hospital records, may be subpoenaed by court order or may be inspected by the study sponsor or federal regulatory authorities without your additional consent.

In addition, there are certain instances where the researcher is legally required to give information to the appropriate authorities. These would include mandatory reporting of infectious diseases, mandatory reporting of information about behavior that is imminently dangerous to you or to others, such as suicide, child abuse, etc.

Audiotapes or videotapes will be kept locked up and will be destroyed as soon as possible after the research is finished.

In any publications that result from this research, neither your name nor any information from which you might be identified will be published without your consent.

Any information about you collected in this research, even if identifiers are removed, will not be used for future studies.

\section{Voluntary Participation}

Participation in this study is voluntary. You are free to withdraw your consent to participate in this study at any time. If you choose to withdraw your participation from the study, the data collected on you up until that time remains a part of the study database and may not be removed. No additional information will be added to the study database after your withdrawal

Refusal to participate or withdraw will not affect your class standing or grades and will involve no penalty to you. Refusal to participate or withdraw will not affect your employee status at West Virginia University.

Refusal to participate or withdraw will not affect your future care or status at West Virginia University.

In the event new information becomes available that may affect your willingness to participate in this study, this information will be given to you so that you can make an informed decision about whether or not to continue your participation.

vaneas 2 
If you have any questions, concerns, or complaints about this research, you can contact Ashish Nimbarte at Ashish_Nimbarte@mail.wvu.edu or (304)-293-9473. You can also contact Isha Gaut at ig0009@mix.wvu.edu or (681)-285-0201

If you are hurt from being in this research, you should contact Ashish Nimbarte at Ashish.Nimbarte@ mail.wvu.edu (304)-293-9473. If injury occurs outside of business hours and is related to your participation in this research, please contact Isha Gaut at (681)-285-0201.

For information regarding your rights as a participant in research or to talk about the research, contact the WVU Office of Human Research Protection (OHRP) at (304) 293-7073 or by email at IRB@mail.wvu.edu.

\section{Signatures}

You have been given the opportunity to ask questions about the research, and you have received answers concerning areas you did not understand. Upon signing this form, you will receive a copy.

Participant Signature

I willingly consent to participate in this research.

\begin{tabular}{ll}
\hline Signature of Subject or Subject's Legal Representative & \\
\hline Printed Name & Date
\end{tabular}

Consenting Individual Signature

The participant has had the opportunity to have questions addressed. The participant willingly agrees to be in the study.

\begin{tabular}{lc}
\hline Signature of Person Obtaining Informed Consent & \\
\hline Printed Name & Date
\end{tabular}




\section{Appendix III: Glove Sizing Charts}

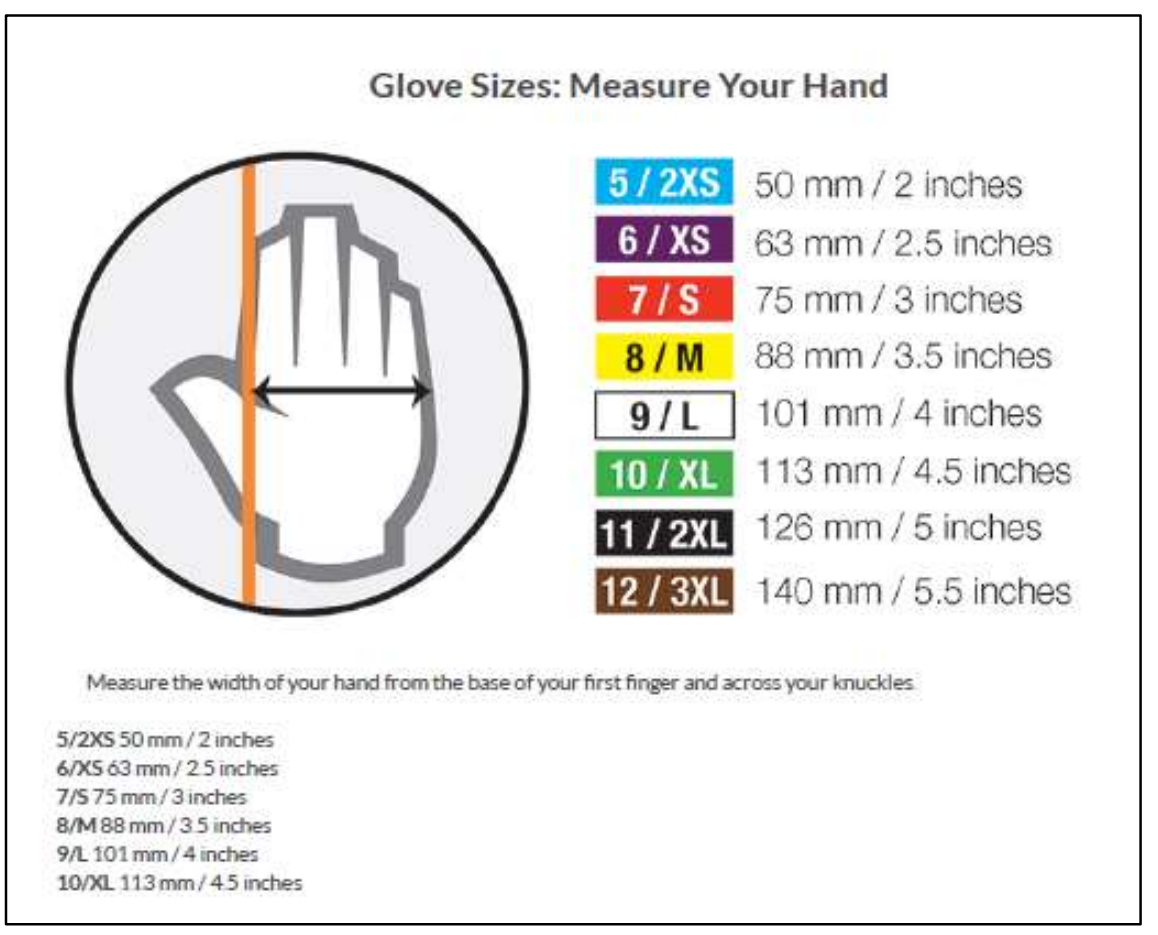

Glove Sizing Chart For Glove Type 1

\section{Glove Sizes: Measure Your Hand}

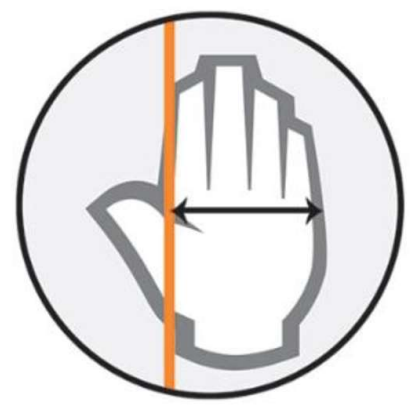

\begin{tabular}{|c|c|}
\hline $5 / 2 \times S$ & 50 mm / 2 inches \\
\hline $6 / X S$ & $63 \mathrm{~mm} / 2.5$ inches \\
\hline $7 / S$ & $75 \mathrm{~mm} / 3$ inches \\
\hline $8 / M$ & 88 mm / 3.5 inches \\
\hline $9 / \mathrm{L}$ & $101 \mathrm{~mm} / 4$ inches \\
\hline $10 / X L$ & $113 \mathrm{~mm} / 4.5$ inches \\
\hline 18 & $126 \mathrm{~mm} / 5$ inches \\
\hline & $.0 \mathrm{~mm} / 5.5 \mathrm{inch}$ \\
\hline
\end{tabular}

Measure the width of your hand from the base of your first finger and across your knuckles.

$5 / 2 X S 50 \mathrm{~mm} / 2$ inches $6 / \mathrm{XS} 63 \mathrm{~mm} / 2.5$ inches 7/S $75 \mathrm{~mm} / 3$ inches $8 / \mathrm{M} 88 \mathrm{~mm} / 3.5$ inches 9/L $101 \mathrm{~mm} / 4$ inches 10/XL $113 \mathrm{~mm} / 4.5$ inches 11/2XL $126 \mathrm{~mm} / 5$ inches $12 / 3 X \mathrm{~L} 140 \mathrm{~mm} / 5.5$ inches

Glove Sizing Chat For Glove Type 2 


\section{Appendix IV: Test for normality and equality of variance of throughput}

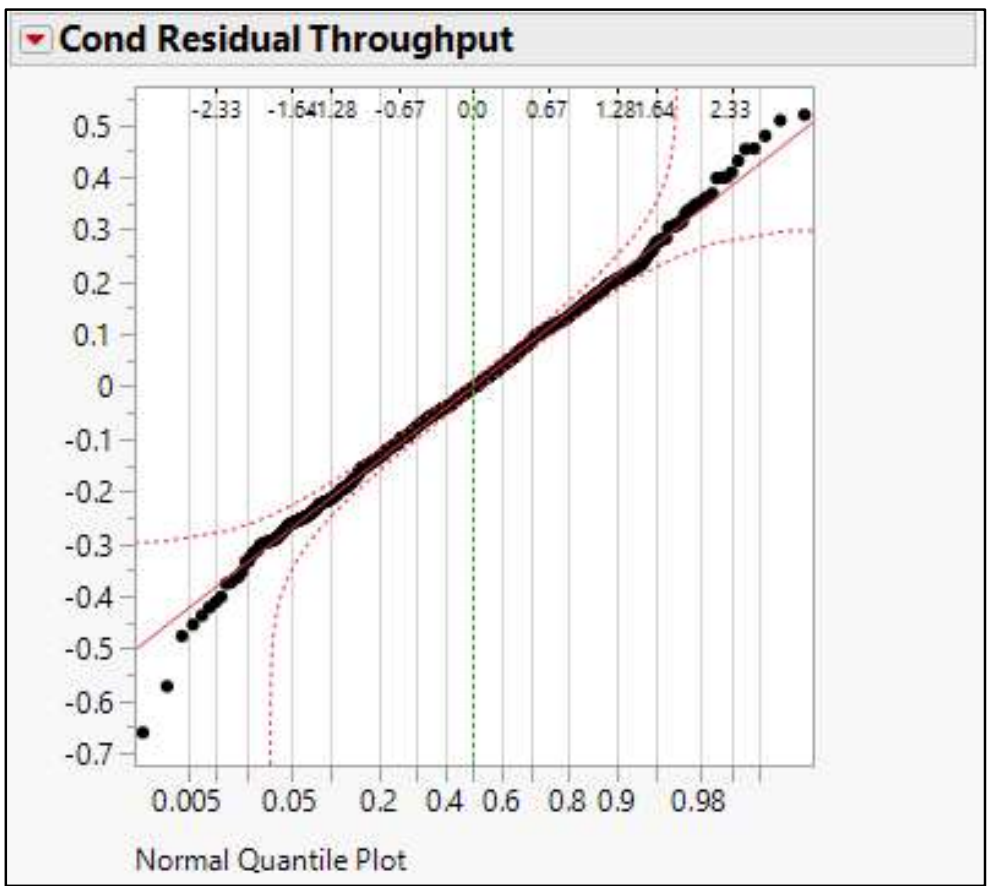

Normal quantile plot of conditional residuals of throughput

\begin{tabular}{|c|c|}
\hline$\triangle$ Goodness & f-Fit Test \\
\hline Shapiro-Wilk & Test \\
\hline w & Prob $<W$ \\
\hline 0.996753 & 0.1668 \\
\hline $\begin{array}{l}\text { Note: } \mathrm{Ho}=\mathrm{TH} \\
\text { reject Ho. }\end{array}$ & data is from the Normal distribution. Small p-values \\
\hline
\end{tabular}

Goodness of fit test showing that the data is from a normal distribution

Tests for equality of variance

\begin{tabular}{|l|r|r|r|r|}
\hline Test & F Ratio & DFNum & DFDen & Prob > F \\
\hline O'Brien[.5] & 1.6003 & 35 & 667 & 0.0166 \\
\hline Levene & 1.5116 & 35 & 667 & 0.0311 \\
\hline Bartlett & 1.4743 & 35 &. & 0.0349 \\
\hline
\end{tabular}




\section{Appendix V: Experiment Data}

\begin{tabular}{|c|c|c|c|c|c|c|c|c|c|c|}
\hline Participant & $\begin{array}{l}\text { Task } \\
\text { Plate }\end{array}$ & $\begin{array}{l}\text { Object } \\
\text { Height }\end{array}$ & $\begin{array}{l}\text { Glove } \\
\text { Condition }\end{array}$ & $\begin{array}{l}\text { Object } \\
\text { Material }\end{array}$ & $\begin{array}{l}\text { Object } \\
\text { Shape }\end{array}$ & ID & IDe & MT & $\begin{array}{l}\text { Normalized } \\
\text { MT }\end{array}$ & TP \\
\hline 1 & 1 & 0.88 & Barehand & Nylon & Circular & 3.06 & 3.05 & 0.89 & 0.57 & 3.46 \\
\hline 1 & 1 & 0.88 & Barehand & Nylon & Hexagonal & 3.06 & 3.04 & 0.89 & 0.57 & 3.45 \\
\hline 1 & 1 & 0.88 & Barehand & SS & Circular & 3.06 & 3.06 & 1.00 & 0.64 & 3.06 \\
\hline 1 & 1 & 0.88 & Barehand & SS & Hexagonal & 3.06 & 3.06 & 0.94 & 0.61 & 3.26 \\
\hline 1 & 1 & 0.88 & Glove Type 1 & Nylon & Circular & 3.06 & 3.06 & 0.94 & 0.61 & 3.26 \\
\hline 1 & 1 & 0.88 & Glove Type 1 & Nylon & Hexagonal & 3.06 & 3.05 & 0.94 & 0.61 & 3.26 \\
\hline 1 & 1 & 0.88 & Glove Type 1 & SS & Circular & 3.06 & 3.05 & 0.94 & 0.61 & 3.25 \\
\hline 1 & 1 & 0.88 & Glove Type 1 & SS & Hexagonal & 3.06 & 3.06 & 1.00 & 0.64 & 3.06 \\
\hline 1 & 1 & 0.88 & Glove Type 2 & Nylon & Circular & 3.06 & 3.05 & 0.94 & 0.61 & 3.25 \\
\hline 1 & 1 & 0.88 & Glove Type 2 & Nylon & Hexagonal & 3.06 & 3.04 & 1.00 & 0.64 & 3.04 \\
\hline 1 & 1 & 0.88 & Glove Type 2 & SS & Circular & 3.06 & 3.06 & 1.06 & 0.68 & 2.91 \\
\hline 1 & 1 & 0.88 & Glove Type 2 & SS & Hexagonal & 3.06 & 3.06 & 1.00 & 0.64 & 3.12 \\
\hline 1 & 2 & 0.88 & Barehand & Nylon & Circular & 3.54 & 3.55 & 1.00 & 0.64 & 3.55 \\
\hline 1 & 2 & 0.88 & Barehand & Nylon & Hexagonal & 3.54 & 3.54 & 1.06 & 0.68 & 3.37 \\
\hline 1 & 2 & 0.88 & Barehand & SS & Circular & 3.54 & 3.55 & 1.06 & 0.68 & 3.38 \\
\hline 1 & 2 & 0.88 & Barehand & SS & Hexagonal & 3.54 & 3.55 & 1.00 & 0.64 & 3.55 \\
\hline 1 & 2 & 0.88 & Glove Type 1 & Nylon & Circular & 3.54 & 3.54 & 1.11 & 0.71 & 3.20 \\
\hline 1 & 2 & 0.88 & Glove Type 1 & Nylon & Hexagonal & 3.54 & 3.54 & 0.94 & 0.61 & 3.77 \\
\hline 1 & 2 & 0.88 & Glove Type 1 & SS & Circular & 3.54 & 3.54 & 1.00 & 0.64 & 3.54 \\
\hline 1 & 2 & 0.88 & Glove Type 1 & SS & Hexagonal & 3.54 & 3.55 & 1.11 & 0.71 & 3.21 \\
\hline 1 & 2 & 0.88 & Glove Type 2 & Nylon & Circular & 3.54 & 3.54 & 1.00 & 0.64 & 3.54 \\
\hline 1 & 2 & 0.88 & Glove Type 2 & Nylon & Hexagonal & 3.54 & 3.54 & 1.06 & 0.68 & 3.37 \\
\hline 1 & 2 & 0.88 & Glove Type 2 & SS & Circular & 3.54 & 3.54 & 1.06 & 0.68 & 3.37 \\
\hline 1 & 2 & 0.88 & Glove Type 2 & SS & Hexagonal & 3.54 & 3.55 & 1.06 & 0.68 & 3.38 \\
\hline 1 & 3 & 0.43 & Barehand & Nylon & Circular & 4.39 & 4.39 & 1.11 & 0.71 & 3.98 \\
\hline 1 & 3 & 0.43 & Barehand & Nylon & Hexagonal & 4.39 & 4.40 & 1.11 & 0.71 & 3.98 \\
\hline 1 & 3 & 0.43 & Barehand & SS & Circular & 4.39 & 4.40 & 1.17 & 0.75 & 3.77 \\
\hline 1 & 3 & 0.43 & Barehand & SS & Hexagonal & 4.39 & 4.40 & 1.00 & 0.64 & 4.48 \\
\hline 1 & 3 & 0.43 & Glove Type 1 & Nylon & Circular & 4.39 & 4.39 & 1.00 & 0.64 & 4.39 \\
\hline 1 & 3 & 0.43 & Glove Type 1 & Nylon & Hexagonal & 4.39 & 4.39 & 1.06 & 0.68 & 4.19 \\
\hline 1 & 3 & 0.43 & Glove Type 1 & SS & Circular & 4.39 & 4.39 & 1.11 & 0.71 & 3.97 \\
\hline 1 & 3 & 0.43 & Glove Type 1 & SS & Hexagonal & 4.39 & 4.39 & 1.00 & 0.64 & 4.39 \\
\hline 1 & 3 & 0.43 & Glove Type 2 & Nylon & Circular & 4.39 & 4.38 & 1.17 & 0.75 & 3.75 \\
\hline 1 & 3 & 0.43 & Glove Type 2 & Nylon & Hexagonal & 4.39 & 4.39 & 1.17 & 0.75 & 3.77 \\
\hline 1 & 3 & 0.43 & Glove Type 2 & SS & Circular & 4.39 & 4.39 & 1.11 & 0.71 & 3.97 \\
\hline 1 & 3 & 0.43 & Glove Type 2 & SS & Hexagonal & 4.39 & 4.39 & 1.17 & 0.75 & 3.76 \\
\hline 1 & 4 & 0.28 & Barehand & Nylon & Circular & 5.43 & 5.42 & 1.33 & 0.86 & 4.13 \\
\hline 1 & 4 & 0.28 & Barehand & Nylon & Hexagonal & 5.43 & 5.42 & 1.28 & 0.82 & 4.26 \\
\hline
\end{tabular}




\begin{tabular}{|c|c|c|c|c|c|c|c|c|c|c|}
\hline Participant & $\begin{array}{l}\text { Task } \\
\text { Plate } \\
\end{array}$ & $\begin{array}{l}\text { Object } \\
\text { Height }\end{array}$ & $\begin{array}{l}\text { Glove } \\
\text { Condition }\end{array}$ & $\begin{array}{l}\text { Object } \\
\text { Material }\end{array}$ & $\begin{array}{l}\text { Object } \\
\text { Shape }\end{array}$ & ID & IDe & MT & $\begin{array}{l}\text { Normalized } \\
\text { MT } \\
\end{array}$ & TP \\
\hline 1 & 4 & 0.28 & Barehand & SS & Circular & 5.43 & 5.42 & 1.33 & 0.86 & 4.06 \\
\hline 1 & 4 & 0.28 & Barehand & SS & Hexagonal & 5.43 & 5.42 & 1.39 & 0.89 & 3.84 \\
\hline 1 & 4 & 0.28 & Glove Type 1 & Nylon & Circular & 5.43 & 5.41 & 1.33 & 0.86 & 3.84 \\
\hline 1 & 4 & 0.28 & Glove Type 1 & Nylon & Hexagonal & 5.43 & 5.42 & 1.39 & 0.89 & 3.84 \\
\hline 1 & 4 & 0.28 & Glove Type 1 & $\mathrm{SS}$ & Circular & 5.43 & 5.41 & 1.44 & 0.93 & 3.61 \\
\hline 1 & 4 & 0.28 & Glove Type 1 & $\mathrm{SS}$ & Hexagonal & 5.43 & 5.41 & 1.50 & 0.96 & 3.61 \\
\hline 1 & 4 & 0.28 & Glove Type 2 & Nylon & Circular & 5.43 & 5.41 & 1.56 & 1.00 & 3.52 \\
\hline 1 & 4 & 0.28 & Glove Type 2 & Nylon & Hexagonal & 5.43 & 5.41 & 1.39 & 0.89 & 3.61 \\
\hline 1 & 4 & 0.28 & Glove Type 2 & SS & Circular & 5.43 & 5.41 & 1.44 & 0.93 & 3.83 \\
\hline 1 & 4 & 0.28 & Glove Type 2 & SS & Hexagonal & 5.43 & 5.41 & 1.44 & 0.93 & 3.61 \\
\hline 2 & 1 & 0.88 & Barehand & Nylon & Circular & 3.06 & 3.01 & 0.70 & 0.66 & 4.30 \\
\hline 2 & 1 & 0.88 & Barehand & Nylon & Hexagonal & 3.06 & 3.00 & 0.66 & 0.62 & 4.54 \\
\hline 2 & 1 & 0.88 & Barehand & SS & Circular & 3.06 & 3.03 & 0.75 & 0.71 & 4.02 \\
\hline 2 & 1 & 0.88 & Barehand & SS & Hexagonal & 3.06 & 3.04 & 0.79 & 0.74 & 3.88 \\
\hline 2 & 1 & 0.88 & Glove Type 1 & Nylon & Circular & 3.06 & 3.00 & 0.74 & 0.70 & 4.09 \\
\hline 2 & 1 & 0.88 & Glove Type 1 & Nylon & Hexagonal & 3.06 & 3.02 & 0.68 & 0.64 & 4.48 \\
\hline 2 & 1 & 0.88 & Glove Type 1 & $\mathrm{SS}$ & Circular & 3.06 & 3.01 & 0.76 & 0.72 & 3.96 \\
\hline 2 & 1 & 0.88 & Glove Type 1 & SS & Hexagonal & 3.06 & 3.01 & 0.82 & 0.77 & 3.69 \\
\hline 2 & 1 & 0.88 & Glove Type 2 & Nylon & Circular & 3.06 & 3.03 & 0.71 & 0.67 & 4.28 \\
\hline 2 & 1 & 0.88 & Glove Type 2 & Nylon & Hexagonal & 3.06 & 3.01 & 0.80 & 0.75 & 3.78 \\
\hline 2 & 1 & 0.88 & Glove Type 2 & SS & Circular & 3.06 & 3.04 & 0.82 & 0.77 & 3.75 \\
\hline 2 & 1 & 0.88 & Glove Type 2 & SS & Hexagonal & 3.06 & 3.02 & 0.73 & 0.69 & 4.13 \\
\hline 2 & 2 & 0.88 & Barehand & Nylon & Circular & 3.54 & 3.52 & 0.83 & 0.78 & 4.25 \\
\hline 2 & 2 & 0.88 & Barehand & Nylon & Hexagonal & 3.54 & 3.50 & 0.80 & 0.75 & 4.40 \\
\hline 2 & 2 & 0.88 & Barehand & $\mathrm{SS}$ & Circular & 3.54 & 3.55 & 0.80 & 0.76 & 4.42 \\
\hline 2 & 2 & 0.88 & Barehand & SS & Hexagonal & 3.54 & 3.53 & 0.76 & 0.71 & 4.67 \\
\hline 2 & 2 & 0.88 & Glove Type 1 & Nylon & Circular & 3.54 & 3.50 & 0.83 & 0.78 & 4.21 \\
\hline 2 & 2 & 0.88 & Glove Type 1 & Nylon & Hexagonal & 3.54 & 3.49 & 0.73 & 0.68 & 4.81 \\
\hline 2 & 2 & 0.88 & Glove Type 1 & SS & Circular & 3.54 & 3.50 & 0.80 & 0.75 & 4.37 \\
\hline 2 & 2 & 0.88 & Glove Type 1 & SS & Hexagonal & 3.54 & 3.49 & 0.86 & 0.81 & 4.07 \\
\hline 2 & 2 & 0.88 & Glove Type 2 & Nylon & Circular & 3.54 & 3.50 & 0.81 & 0.76 & 4.34 \\
\hline 2 & 2 & 0.88 & Glove Type 2 & Nylon & Hexagonal & 3.54 & 3.52 & 0.77 & 0.73 & 4.57 \\
\hline 2 & 2 & 0.88 & Glove Type 2 & SS & Circular & 3.54 & 3.53 & 0.86 & 0.81 & 4.11 \\
\hline 2 & 2 & 0.88 & Glove Type 2 & SS & Hexagonal & 3.54 & 3.53 & 0.80 & 0.75 & 4.42 \\
\hline 2 & 3 & 0.43 & Barehand & Nylon & Circular & 4.39 & 4.39 & 0.94 & 0.88 & 4.74 \\
\hline 2 & 3 & 0.43 & Barehand & Nylon & Hexagonal & 4.39 & 4.39 & 0.89 & 0.84 & 4.96 \\
\hline 2 & 3 & 0.43 & Barehand & SS & Circular & 4.39 & 4.39 & 0.95 & 0.89 & 4.69 \\
\hline 2 & 3 & 0.43 & Barehand & SS & Hexagonal & 4.39 & 4.38 & 0.96 & 0.90 & 4.61 \\
\hline 2 & 3 & 0.43 & Glove Type 1 & Nylon & Circular & 4.39 & 4.38 & 0.83 & 0.78 & 4.60 \\
\hline 2 & 3 & 0.43 & Glove Type 1 & Nylon & Hexagonal & 4.39 & 4.38 & 0.92 & 0.87 & 4.76 \\
\hline 2 & 3 & 0.43 & Glove Type 1 & SS & Circular & 4.39 & 4.39 & 0.89 & 0.84 & 4.93 \\
\hline
\end{tabular}




\begin{tabular}{|c|c|c|c|c|c|c|c|c|c|c|}
\hline Participant & $\begin{array}{l}\text { Task } \\
\text { Plate } \\
\end{array}$ & $\begin{array}{l}\text { Object } \\
\text { Height }\end{array}$ & $\begin{array}{l}\text { Glove } \\
\text { Condition }\end{array}$ & $\begin{array}{l}\text { Object } \\
\text { Material }\end{array}$ & $\begin{array}{l}\text { Object } \\
\text { Shape }\end{array}$ & ID & IDe & MT & $\begin{array}{l}\text { Normalized } \\
\text { MT } \\
\end{array}$ & TP \\
\hline 2 & 3 & 0.43 & Glove Type 1 & $\mathrm{SS}$ & Hexagonal & 4.39 & 4.38 & 0.88 & 0.83 & 5.03 \\
\hline 2 & 3 & 0.43 & Glove Type 2 & Nylon & Circular & 4.39 & 4.39 & 0.95 & 0.89 & 4.64 \\
\hline 2 & 3 & 0.43 & Glove Type 2 & Nylon & Hexagonal & 4.39 & 4.39 & 0.91 & 0.85 & 4.85 \\
\hline 2 & 3 & 0.43 & Glove Type 2 & SS & Circular & 4.39 & 4.39 & 0.89 & 0.84 & 4.94 \\
\hline 2 & 3 & 0.43 & Glove Type 2 & $\mathrm{SS}$ & Hexagonal & 4.39 & 4.39 & 0.92 & 0.87 & 4.78 \\
\hline 2 & 4 & 0.28 & Barehand & Nylon & Hexagonal & 5.43 & 5.42 & 0.93 & 0.87 & 5.89 \\
\hline 2 & 4 & 0.28 & Barehand & SS & Circular & 5.43 & 5.42 & 0.89 & 0.83 & 6.11 \\
\hline 2 & 4 & 0.28 & Barehand & SS & Hexagonal & 5.43 & 5.42 & 0.94 & 0.88 & 5.87 \\
\hline 2 & 4 & 0.28 & Glove Type 1 & Nylon & Circular & 5.43 & 5.41 & 0.98 & 0.93 & 5.55 \\
\hline 2 & 4 & 0.28 & Glove Type 1 & SS & Circular & 5.43 & 5.42 & 0.96 & 0.90 & 5.45 \\
\hline 2 & 4 & 0.28 & Glove Type 1 & SS & Hexagonal & 5.43 & 5.42 & 1.06 & 1.00 & 5.02 \\
\hline 2 & 4 & 0.28 & Glove Type 2 & Nylon & Circular & 5.43 & 5.42 & 1.02 & 0.96 & 4.64 \\
\hline 2 & 4 & 0.28 & Glove Type 2 & Nylon & Hexagonal & 5.43 & 5.42 & 1.02 & 0.96 & 5.31 \\
\hline 2 & 4 & 0.28 & Glove Type 2 & SS & Circular & 5.43 & 5.42 & 0.98 & 0.92 & 5.44 \\
\hline 2 & 4 & 0.28 & Glove Type 2 & SS & Hexagonal & 5.43 & 5.42 & 1.03 & 0.97 & 5.27 \\
\hline 3 & 1 & 0.88 & Barehand & Nylon & Circular & 3.06 & 3.04 & 0.99 & 0.68 & 3.11 \\
\hline 3 & 1 & 0.88 & Barehand & Nylon & Hexagonal & 3.06 & 3.04 & 0.93 & 0.64 & 3.27 \\
\hline 3 & 1 & 0.88 & Barehand & SS & Circular & 3.06 & 3.05 & 1.01 & 0.70 & 3.01 \\
\hline 3 & 1 & 0.88 & Barehand & SS & Hexagonal & 3.06 & 3.04 & 1.00 & 0.69 & 3.04 \\
\hline 3 & 1 & 0.88 & Glove Type 1 & Nylon & Circular & 3.06 & 3.04 & 1.02 & 0.70 & 3.00 \\
\hline 3 & 1 & 0.88 & Glove Type 1 & Nylon & Hexagonal & 3.06 & 3.05 & 1.06 & 0.73 & 2.89 \\
\hline 3 & 1 & 0.88 & Glove Type 1 & SS & Circular & 3.06 & 3.04 & 1.03 & 0.71 & 2.97 \\
\hline 3 & 1 & 0.88 & Glove Type 1 & SS & Hexagonal & 3.06 & 3.04 & 1.06 & 0.73 & 2.88 \\
\hline 3 & 1 & 0.88 & Glove Type 2 & Nylon & Circular & 3.06 & 3.04 & 0.97 & 0.67 & 3.13 \\
\hline 3 & 1 & 0.88 & Glove Type 2 & Nylon & Hexagonal & 3.06 & 3.04 & 0.99 & 0.68 & 3.10 \\
\hline 3 & 1 & 0.88 & Glove Type 2 & SS & Circular & 3.06 & 3.04 & 1.06 & 0.73 & 2.89 \\
\hline 3 & 1 & 0.88 & Glove Type 2 & $\mathrm{SS}$ & Hexagonal & 3.06 & 3.04 & 1.03 & 0.71 & 2.96 \\
\hline 3 & 2 & 0.88 & Barehand & Nylon & Circular & 3.54 & 3.53 & 1.03 & 0.71 & 3.43 \\
\hline 3 & 2 & 0.88 & Barehand & Nylon & Hexagonal & 3.54 & 3.53 & 1.03 & 0.71 & 3.44 \\
\hline 3 & 2 & 0.88 & Barehand & SS & Circular & 3.54 & 3.54 & 1.07 & 0.74 & 3.31 \\
\hline 3 & 2 & 0.88 & Barehand & $\mathrm{SS}$ & Hexagonal & 3.54 & 3.53 & 1.03 & 0.71 & 3.46 \\
\hline 3 & 2 & 0.88 & Glove Type 1 & Nylon & Circular & 3.54 & 3.53 & 1.10 & 0.76 & 3.22 \\
\hline 3 & 2 & 0.88 & Glove Type 1 & Nylon & Hexagonal & 3.54 & 3.53 & 1.17 & 0.81 & 3.03 \\
\hline 3 & 2 & 0.88 & Glove Type 1 & SS & Circular & 3.54 & 3.53 & 1.10 & 0.76 & 3.22 \\
\hline 3 & 2 & 0.88 & Glove Type 1 & SS & Hexagonal & 3.54 & 3.53 & 1.14 & 0.79 & 3.15 \\
\hline 3 & 2 & 0.88 & Glove Type 2 & Nylon & Circular & 3.54 & 3.53 & 1.07 & 0.74 & 3.32 \\
\hline 3 & 2 & 0.88 & Glove Type 2 & Nylon & Hexagonal & 3.54 & 3.54 & 1.07 & 0.74 & 3.31 \\
\hline 3 & 2 & 0.88 & Glove Type 2 & SS & Circular & 3.54 & 3.54 & 1.08 & 0.75 & 3.26 \\
\hline 3 & 2 & 0.88 & Glove Type 2 & $\mathrm{SS}$ & Hexagonal & 3.54 & 3.54 & 1.11 & 0.77 & 3.18 \\
\hline 3 & 3 & 0.43 & Barehand & Nylon & Circular & 4.39 & 4.38 & 1.22 & 0.85 & 3.60 \\
\hline 3 & 3 & 0.43 & Barehand & Nylon & Hexagonal & 4.39 & 4.39 & 1.18 & 0.82 & 3.71 \\
\hline
\end{tabular}




\begin{tabular}{|c|c|c|c|c|c|c|c|c|c|c|}
\hline Participant & $\begin{array}{l}\text { Task } \\
\text { Plate } \\
\end{array}$ & $\begin{array}{l}\text { Object } \\
\text { Height }\end{array}$ & $\begin{array}{l}\text { Glove } \\
\text { Condition }\end{array}$ & $\begin{array}{l}\text { Object } \\
\text { Material }\end{array}$ & $\begin{array}{l}\text { Object } \\
\text { Shape }\end{array}$ & ID & IDe & MT & $\begin{array}{l}\text { Normalized } \\
\text { MT } \\
\end{array}$ & TP \\
\hline 3 & 3 & 0.43 & Barehand & $\mathrm{SS}$ & Circular & 4.39 & 4.39 & 1.17 & 0.81 & 3.76 \\
\hline 3 & 3 & 0.43 & Barehand & SS & Hexagonal & 4.39 & 4.39 & 1.14 & 0.79 & 3.87 \\
\hline 3 & 3 & 0.43 & Glove Type 1 & Nylon & Circular & 4.39 & 4.39 & 1.21 & 0.84 & 3.65 \\
\hline 3 & 3 & 0.43 & Glove Type 1 & Nylon & Hexagonal & 4.39 & 4.38 & 1.35 & 0.93 & 3.30 \\
\hline 3 & 3 & 0.43 & Glove Type 1 & $\mathrm{SS}$ & Circular & 4.39 & 4.38 & 1.26 & 0.87 & 3.49 \\
\hline 3 & 3 & 0.43 & Glove Type 1 & $\mathrm{SS}$ & Hexagonal & 4.39 & 4.38 & 1.26 & 0.88 & 3.48 \\
\hline 3 & 3 & 0.43 & Glove Type 2 & Nylon & Circular & 4.39 & 4.39 & 1.25 & 0.86 & 3.52 \\
\hline 3 & 3 & 0.43 & Glove Type 2 & Nylon & Hexagonal & 4.39 & 4.39 & 1.18 & 0.82 & 3.72 \\
\hline 3 & 3 & 0.43 & Glove Type 2 & SS & Circular & 4.39 & 4.38 & 1.20 & 0.83 & 3.67 \\
\hline 3 & 3 & 0.43 & Glove Type 2 & SS & Hexagonal & 4.39 & 4.39 & 1.22 & 0.85 & 3.59 \\
\hline 3 & 4 & 0.28 & Barehand & Nylon & Circular & 5.43 & 5.42 & 1.39 & 0.96 & 3.91 \\
\hline 3 & 4 & 0.28 & Barehand & Nylon & Hexagonal & 5.43 & 5.42 & 1.33 & 0.92 & 4.07 \\
\hline 3 & 4 & 0.28 & Barehand & SS & Circular & 5.43 & 5.42 & 1.33 & 0.92 & 4.09 \\
\hline 3 & 4 & 0.28 & Barehand & $\mathrm{SS}$ & Hexagonal & 5.43 & 5.42 & 1.28 & 0.89 & 4.24 \\
\hline 3 & 4 & 0.28 & Glove Type 1 & Nylon & Circular & 5.43 & 5.42 & 1.44 & 1.00 & 3.72 \\
\hline 3 & 4 & 0.28 & Glove Type 1 & Nylon & Hexagonal & 5.43 & 5.42 & 1.36 & 0.94 & 3.88 \\
\hline 3 & 4 & 0.28 & Glove Type 1 & $\mathrm{SS}$ & Circular & 5.43 & 5.42 & 1.31 & 0.91 & 4.15 \\
\hline 3 & 4 & 0.28 & Glove Type 1 & SS & Hexagonal & 5.43 & 5.42 & 1.44 & 1.00 & 3.77 \\
\hline 3 & 4 & 0.28 & Glove Type 2 & Nylon & Circular & 5.43 & 5.42 & 1.31 & 0.91 & 4.13 \\
\hline 3 & 4 & 0.28 & Glove Type 2 & Nylon & Hexagonal & 5.43 & 5.42 & 1.38 & 0.95 & 3.93 \\
\hline 3 & 4 & 0.28 & Glove Type 2 & SS & Circular & 5.43 & 5.42 & 1.40 & 0.97 & 3.88 \\
\hline 3 & 4 & 0.28 & Glove Type 2 & SS & Hexagonal & 5.43 & 5.42 & 1.41 & 0.98 & 3.85 \\
\hline 4 & 1 & 0.88 & Barehand & Nylon & Circular & 3.06 & 3.06 & 0.75 & 0.51 & 4.11 \\
\hline 4 & 1 & 0.88 & Barehand & Nylon & Hexagonal & 3.06 & 3.06 & 0.79 & 0.54 & 3.87 \\
\hline 4 & 1 & 0.88 & Barehand & $\mathrm{SS}$ & Circular & 3.06 & 3.07 & 0.82 & 0.56 & 3.75 \\
\hline 4 & 1 & 0.88 & Barehand & $\mathrm{SS}$ & Hexagonal & 3.06 & 3.07 & 0.90 & 0.62 & 3.41 \\
\hline 4 & 1 & 0.88 & Glove Type 1 & Nylon & Circular & 3.06 & 3.04 & 0.79 & 0.54 & 3.85 \\
\hline 4 & 1 & 0.88 & Glove Type 1 & Nylon & Hexagonal & 3.06 & 3.04 & 0.72 & 0.50 & 4.21 \\
\hline 4 & 1 & 0.88 & Glove Type 1 & SS & Circular & 3.06 & 3.06 & 0.88 & 0.60 & 3.50 \\
\hline 4 & 1 & 0.88 & Glove Type 1 & SS & Hexagonal & 3.06 & 3.06 & 0.88 & 0.60 & 3.49 \\
\hline 4 & 1 & 0.88 & Glove Type 2 & Nylon & Circular & 3.06 & 3.06 & 0.81 & 0.55 & 3.80 \\
\hline 4 & 1 & 0.88 & Glove Type 2 & Nylon & Hexagonal & 3.06 & 3.05 & 0.87 & 0.60 & 3.49 \\
\hline 4 & 1 & 0.88 & Glove Type 2 & SS & Circular & 3.06 & 3.06 & 0.85 & 0.58 & 3.63 \\
\hline 4 & 1 & 0.88 & Glove Type 2 & SS & Hexagonal & 3.06 & 3.05 & 0.86 & 0.59 & 3.55 \\
\hline 4 & 2 & 0.88 & Barehand & Nylon & Circular & 3.54 & 3.54 & 0.99 & 0.68 & 3.63 \\
\hline 4 & 2 & 0.88 & Barehand & Nylon & Hexagonal & 3.54 & 3.54 & 0.99 & 0.68 & 3.61 \\
\hline 4 & 2 & 0.88 & Barehand & SS & Circular & 3.54 & 3.54 & 1.08 & 0.74 & 3.27 \\
\hline 4 & 2 & 0.88 & Barehand & SS & Hexagonal & 3.54 & 3.54 & 1.05 & 0.72 & 3.40 \\
\hline 4 & 2 & 0.88 & Glove Type 1 & Nylon & Circular & 3.54 & 3.53 & 1.01 & 0.70 & 3.52 \\
\hline 4 & 2 & 0.88 & Glove Type 1 & Nylon & Hexagonal & 3.54 & 3.53 & 0.93 & 0.64 & 3.82 \\
\hline 4 & 2 & 0.88 & Glove Type 1 & SS & Circular & 3.54 & 3.53 & 1.00 & 0.69 & 3.53 \\
\hline
\end{tabular}




\begin{tabular}{|c|c|c|c|c|c|c|c|c|c|c|}
\hline Participant & $\begin{array}{l}\text { Task } \\
\text { Plate }\end{array}$ & $\begin{array}{l}\text { Object } \\
\text { Height }\end{array}$ & $\begin{array}{l}\text { Glove } \\
\text { Condition }\end{array}$ & $\begin{array}{l}\text { Object } \\
\text { Material }\end{array}$ & $\begin{array}{l}\text { Object } \\
\text { Shape } \\
\end{array}$ & ID & IDe & MT & $\begin{array}{l}\text { Normalized } \\
\text { MT } \\
\end{array}$ & TP \\
\hline 4 & 2 & 0.88 & Glove Type 1 & $\mathrm{SS}$ & Hexagonal & 3.54 & 3.53 & 1.07 & 0.73 & 3.31 \\
\hline 4 & 2 & 0.88 & Glove Type 2 & Nylon & Circular & 3.54 & 3.54 & 0.92 & 0.63 & 3.87 \\
\hline 4 & 2 & 0.88 & Glove Type 2 & Nylon & Hexagonal & 3.54 & 3.53 & 0.97 & 0.67 & 3.64 \\
\hline 4 & 2 & 0.88 & Glove Type 2 & SS & Circular & 3.54 & 3.53 & 1.03 & 0.71 & 3.48 \\
\hline 4 & 2 & 0.88 & Glove Type 2 & $\mathrm{SS}$ & Hexagonal & 3.54 & 3.53 & 1.07 & 0.73 & 3.30 \\
\hline 4 & 3 & 0.43 & Barehand & Nylon & Circular & 4.39 & 4.39 & 0.90 & 0.62 & 4.86 \\
\hline 4 & 3 & 0.43 & Barehand & Nylon & Hexagonal & 4.39 & 4.38 & 0.87 & 0.60 & 5.01 \\
\hline 4 & 3 & 0.43 & Barehand & SS & Circular & 4.39 & 4.38 & 0.92 & 0.63 & 4.79 \\
\hline 4 & 3 & 0.43 & Barehand & SS & Hexagonal & 4.39 & 4.38 & 0.86 & 0.59 & 5.16 \\
\hline 4 & 3 & 0.43 & Glove Type 1 & Nylon & Circular & 4.39 & 4.37 & 0.84 & 0.57 & 5.23 \\
\hline 4 & 3 & 0.43 & Glove Type 1 & Nylon & Hexagonal & 4.39 & 4.37 & 0.85 & 0.58 & 5.18 \\
\hline 4 & 3 & 0.43 & Glove Type 1 & SS & Circular & 4.39 & 4.37 & 0.85 & 0.59 & 4.99 \\
\hline 4 & 3 & 0.43 & Glove Type 1 & SS & Hexagonal & 4.39 & 4.37 & 0.91 & 0.62 & 4.86 \\
\hline 4 & 3 & 0.43 & Glove Type 2 & Nylon & Circular & 4.39 & 4.37 & 0.88 & 0.60 & 4.99 \\
\hline 4 & 3 & 0.43 & Glove Type 2 & Nylon & Hexagonal & 4.39 & 4.36 & 0.87 & 0.60 & 4.99 \\
\hline 4 & 3 & 0.43 & Glove Type 2 & $\mathrm{SS}$ & Circular & 4.39 & 4.36 & 0.93 & 0.64 & 4.76 \\
\hline 4 & 3 & 0.43 & Glove Type 2 & SS & Hexagonal & 4.39 & 4.35 & 0.90 & 0.62 & 4.89 \\
\hline 4 & 4 & 0.28 & Barehand & Nylon & Circular & 5.43 & 5.43 & 1.16 & 0.80 & 4.67 \\
\hline 4 & 4 & 0.28 & Barehand & Nylon & Hexagonal & 5.43 & 5.42 & 1.22 & 0.84 & 4.48 \\
\hline 4 & 4 & 0.28 & Barehand & $\mathrm{SS}$ & Circular & 5.43 & 5.42 & 1.19 & 0.82 & 4.55 \\
\hline 4 & 4 & 0.28 & Barehand & SS & Hexagonal & 5.43 & 5.42 & 1.12 & 0.77 & 4.84 \\
\hline 4 & 4 & 0.28 & Glove Type 1 & Nylon & Circular & 5.43 & 5.41 & 1.46 & 1.00 & 3.71 \\
\hline 4 & 4 & 0.28 & Glove Type 1 & Nylon & Hexagonal & 5.43 & 5.41 & 1.25 & 0.86 & 4.33 \\
\hline 4 & 4 & 0.28 & Glove Type 1 & SS & Hexagonal & 5.43 & 5.41 & 1.25 & 0.86 & 4.33 \\
\hline 4 & 4 & 0.28 & Glove Type 2 & Nylon & Circular & 5.43 & 5.40 & 1.21 & 0.83 & 4.46 \\
\hline 4 & 4 & 0.28 & Glove Type 2 & Nylon & Hexagonal & 5.43 & 5.41 & 1.21 & 0.83 & 4.48 \\
\hline 4 & 4 & 0.28 & Glove Type 2 & $\mathrm{SS}$ & Circular & 5.43 & 5.41 & 1.25 & 0.86 & 4.33 \\
\hline 4 & 4 & 0.28 & Glove Type 2 & $\mathrm{SS}$ & Hexagonal & 5.43 & 5.41 & 1.22 & 0.84 & 4.47 \\
\hline 5 & 1 & 0.88 & Barehand & Nylon & Circular & 3.06 & 3.06 & 0.83 & 0.77 & 3.70 \\
\hline 5 & 1 & 0.88 & Barehand & Nylon & Hexagonal & 3.06 & 3.07 & 0.92 & 0.85 & 3.38 \\
\hline 5 & 1 & 0.88 & Barehand & $\mathrm{SS}$ & Circular & 3.06 & 3.06 & 0.89 & 0.82 & 3.48 \\
\hline 5 & 1 & 0.88 & Barehand & SS & Hexagonal & 3.06 & 3.06 & 0.93 & 0.86 & 3.29 \\
\hline 5 & 1 & 0.88 & Glove Type 1 & Nylon & Circular & 3.06 & 3.05 & 0.81 & 0.75 & 3.76 \\
\hline 5 & 1 & 0.88 & Glove Type 1 & Nylon & Hexagonal & 3.06 & 3.06 & 0.87 & 0.81 & 3.50 \\
\hline 5 & 1 & 0.88 & Glove Type 1 & SS & Circular & 3.06 & 3.06 & 0.89 & 0.82 & 3.45 \\
\hline 5 & 1 & 0.88 & Glove Type 1 & $\mathrm{SS}$ & Hexagonal & 3.06 & 3.05 & 0.89 & 0.82 & 3.44 \\
\hline 5 & 1 & 0.88 & Glove Type 2 & Nylon & Circular & 3.06 & 3.06 & 0.92 & 0.85 & 3.35 \\
\hline 5 & 1 & 0.88 & Glove Type 2 & Nylon & Hexagonal & 3.06 & 3.05 & 0.96 & 0.89 & 3.20 \\
\hline 5 & 1 & 0.88 & Glove Type 2 & $\mathrm{SS}$ & Circular & 3.06 & 3.06 & 0.92 & 0.85 & 3.36 \\
\hline 5 & 1 & 0.88 & Glove Type 2 & SS & Hexagonal & 3.06 & 3.06 & 0.96 & 0.89 & 3.20 \\
\hline 5 & 2 & 0.88 & Barehand & Nylon & Circular & 3.54 & 3.54 & 0.90 & 0.83 & 3.93 \\
\hline
\end{tabular}




\begin{tabular}{|c|c|c|c|c|c|c|c|c|c|c|}
\hline Participant & $\begin{array}{l}\text { Task } \\
\text { Plate } \\
\end{array}$ & $\begin{array}{l}\text { Object } \\
\text { Height }\end{array}$ & $\begin{array}{l}\text { Glove } \\
\text { Condition }\end{array}$ & $\begin{array}{l}\text { Object } \\
\text { Material }\end{array}$ & $\begin{array}{l}\text { Object } \\
\text { Shape }\end{array}$ & ID & IDe & MT & $\begin{array}{l}\text { Normalized } \\
\text { MT } \\
\end{array}$ & TP \\
\hline 5 & 2 & 0.88 & Barehand & Nylon & Hexagonal & 3.54 & 3.54 & 0.96 & 0.89 & 3.69 \\
\hline 5 & 2 & 0.88 & Barehand & SS & Circular & 3.54 & 3.54 & 0.99 & 0.91 & 3.61 \\
\hline 5 & 2 & 0.88 & Barehand & SS & Hexagonal & 3.54 & 3.54 & 0.97 & 0.90 & 3.65 \\
\hline 5 & 2 & 0.88 & Glove Type 1 & Nylon & Circular & 3.54 & 3.53 & 0.96 & 0.89 & 3.70 \\
\hline 5 & 2 & 0.88 & Glove Type 1 & Nylon & Hexagonal & 3.54 & 3.53 & 0.92 & 0.85 & 3.88 \\
\hline 5 & 2 & 0.88 & Glove Type 1 & $\mathrm{SS}$ & Circular & 3.54 & 3.54 & 0.99 & 0.91 & 3.59 \\
\hline 5 & 2 & 0.88 & Glove Type 1 & SS & Hexagonal & 3.54 & 3.54 & 0.96 & 0.88 & 3.71 \\
\hline 5 & 2 & 0.88 & Glove Type 2 & Nylon & Circular & 3.54 & 3.54 & 0.94 & 0.87 & 3.78 \\
\hline 5 & 2 & 0.88 & Glove Type 2 & Nylon & Hexagonal & 3.54 & 3.54 & 0.92 & 0.85 & 3.86 \\
\hline 5 & 2 & 0.88 & Glove Type 2 & SS & Circular & 3.54 & 3.54 & 0.94 & 0.87 & 3.75 \\
\hline 5 & 2 & 0.88 & Glove Type 2 & SS & Hexagonal & 3.54 & 3.54 & 1.03 & 0.95 & 3.44 \\
\hline 5 & 3 & 0.43 & Barehand & Nylon & Circular & 4.39 & 4.39 & 0.96 & 0.89 & 4.60 \\
\hline 5 & 3 & 0.43 & Barehand & Nylon & Hexagonal & 4.39 & 4.39 & 0.93 & 0.86 & 4.74 \\
\hline 5 & 3 & 0.43 & Barehand & SS & Circular & 4.39 & 4.39 & 0.99 & 0.91 & 4.46 \\
\hline 5 & 3 & 0.43 & Barehand & SS & Hexagonal & 4.39 & 4.39 & 0.97 & 0.90 & 4.60 \\
\hline 5 & 3 & 0.43 & Glove Type 1 & Nylon & Circular & 4.39 & 4.39 & 0.88 & 0.81 & 5.03 \\
\hline 5 & 3 & 0.43 & Glove Type 1 & Nylon & Hexagonal & 4.39 & 4.39 & 0.88 & 0.81 & 5.02 \\
\hline 5 & 3 & 0.43 & Glove Type 1 & SS & Circular & 4.39 & 4.38 & 0.89 & 0.82 & 4.94 \\
\hline 5 & 3 & 0.43 & Glove Type 1 & SS & Hexagonal & 4.39 & 4.38 & 0.88 & 0.81 & 5.01 \\
\hline 5 & 3 & 0.43 & Glove Type 2 & Nylon & Circular & 4.39 & 4.39 & 0.92 & 0.85 & 4.79 \\
\hline 5 & 3 & 0.43 & Glove Type 2 & Nylon & Hexagonal & 4.39 & 4.39 & 0.90 & 0.83 & 4.88 \\
\hline 5 & 3 & 0.43 & Glove Type 2 & SS & Circular & 4.39 & 4.38 & 0.97 & 0.90 & 4.51 \\
\hline 5 & 3 & 0.43 & Glove Type 2 & SS & Hexagonal & 4.39 & 4.39 & 0.90 & 0.83 & 4.86 \\
\hline 5 & 4 & 0.28 & Barehand & Nylon & Circular & 5.43 & 5.43 & 1.04 & 0.96 & 5.30 \\
\hline 5 & 4 & 0.28 & Barehand & Nylon & Hexagonal & 5.43 & 5.42 & 1.01 & 0.93 & 5.38 \\
\hline 5 & 4 & 0.28 & Barehand & $\mathrm{SS}$ & Circular & 5.43 & 5.43 & 1.00 & 0.92 & 5.32 \\
\hline 5 & 4 & 0.28 & Barehand & $\mathrm{SS}$ & Hexagonal & 5.43 & 5.42 & 1.05 & 0.97 & 5.16 \\
\hline 5 & 4 & 0.28 & Glove Type 1 & Nylon & Hexagonal & 5.43 & 5.42 & 1.08 & 1.00 & 5.00 \\
\hline 5 & 4 & 0.28 & Glove Type 1 & SS & Circular & 5.43 & 5.42 & 1.00 & 0.92 & 5.21 \\
\hline 5 & 4 & 0.28 & Glove Type 1 & SS & Hexagonal & 5.43 & 5.42 & 1.07 & 0.99 & 5.01 \\
\hline 5 & 4 & 0.28 & Glove Type 2 & Nylon & Circular & 5.43 & 5.42 & 1.06 & 0.98 & 5.14 \\
\hline 5 & 4 & 0.28 & Glove Type 2 & Nylon & Hexagonal & 5.43 & 5.42 & 1.04 & 0.96 & 5.22 \\
\hline 5 & 4 & 0.28 & Glove Type 2 & SS & Circular & 5.43 & 5.42 & 1.06 & 0.98 & 5.14 \\
\hline 5 & 4 & 0.28 & Glove Type 2 & SS & Hexagonal & 5.43 & 5.42 & 1.04 & 0.96 & 5.21 \\
\hline 6 & 1 & 0.88 & Barehand & Nylon & Circular & 3.06 & 3.05 & 0.86 & 0.64 & 3.54 \\
\hline 6 & 1 & 0.88 & Barehand & Nylon & Hexagonal & 3.06 & 3.06 & 0.87 & 0.65 & 3.50 \\
\hline 6 & 1 & 0.88 & Barehand & SS & Circular & 3.06 & 3.05 & 0.93 & 0.69 & 3.28 \\
\hline 6 & 1 & 0.88 & Barehand & SS & Hexagonal & 3.06 & 3.05 & 0.89 & 0.66 & 3.42 \\
\hline 6 & 1 & 0.88 & Glove Type 1 & Nylon & Circular & 3.06 & 3.04 & 0.89 & 0.66 & 3.45 \\
\hline 6 & 1 & 0.88 & Glove Type 1 & Nylon & Hexagonal & 3.06 & 3.04 & 0.92 & 0.68 & 3.33 \\
\hline 6 & 1 & 0.88 & Glove Type 1 & SS & Circular & 3.06 & 3.05 & 0.96 & 0.71 & 3.18 \\
\hline
\end{tabular}




\begin{tabular}{|c|c|c|c|c|c|c|c|c|c|c|}
\hline Participant & $\begin{array}{l}\text { Task } \\
\text { Plate }\end{array}$ & $\begin{array}{l}\text { Object } \\
\text { Height }\end{array}$ & $\begin{array}{l}\text { Glove } \\
\text { Condition }\end{array}$ & $\begin{array}{l}\text { Object } \\
\text { Material }\end{array}$ & $\begin{array}{l}\text { Object } \\
\text { Shape }\end{array}$ & ID & IDe & MT & $\begin{array}{l}\text { Normalized } \\
\text { MT }\end{array}$ & TP \\
\hline 6 & 1 & 0.88 & Glove Type 1 & SS & Hexagonal & 3.06 & 3.05 & 0.93 & 0.69 & 3.29 \\
\hline 6 & 1 & 0.88 & Glove Type 2 & Nylon & Circular & 3.06 & 3.05 & 0.89 & 0.66 & 3.44 \\
\hline 6 & 1 & 0.88 & Glove Type 2 & Nylon & Hexagonal & 3.06 & 3.06 & 0.90 & 0.67 & 3.40 \\
\hline 6 & 1 & 0.88 & Glove Type 2 & SS & Circular & 3.06 & 3.05 & 0.88 & 0.65 & 3.47 \\
\hline 6 & 1 & 0.88 & Glove Type 2 & SS & Hexagonal & 3.06 & 3.06 & 0.90 & 0.66 & 3.43 \\
\hline 6 & 2 & 0.88 & Barehand & Nylon & Circular & 3.54 & 3.54 & 0.99 & 0.73 & 3.60 \\
\hline 6 & 2 & 0.88 & Barehand & Nylon & Hexagonal & 3.54 & 3.55 & 1.07 & 0.79 & 3.32 \\
\hline 6 & 2 & 0.88 & Barehand & SS & Circular & 3.54 & 3.55 & 1.06 & 0.78 & 3.37 \\
\hline 6 & 2 & 0.88 & Barehand & SS & Hexagonal & 3.54 & 3.55 & 1.06 & 0.78 & 3.37 \\
\hline 6 & 2 & 0.88 & Glove Type 1 & Nylon & Circular & 3.54 & 3.53 & 1.03 & 0.76 & 3.44 \\
\hline 6 & 2 & 0.88 & Glove Type 1 & Nylon & Hexagonal & 3.54 & 3.54 & 1.10 & 0.81 & 3.22 \\
\hline 6 & 2 & 0.88 & Glove Type 1 & SS & Circular & 3.54 & 3.53 & 1.10 & 0.81 & 3.23 \\
\hline 6 & 2 & 0.88 & Glove Type 1 & SS & Hexagonal & 3.54 & 3.54 & 1.13 & 0.83 & 3.15 \\
\hline 6 & 2 & 0.88 & Glove Type 2 & Nylon & Circular & 3.54 & 3.54 & 1.06 & 0.78 & 3.37 \\
\hline 6 & 2 & 0.88 & Glove Type 2 & Nylon & Hexagonal & 3.54 & 3.54 & 1.04 & 0.77 & 3.40 \\
\hline 6 & 2 & 0.88 & Glove Type 2 & SS & Circular & 3.54 & 3.54 & 1.07 & 0.79 & 3.31 \\
\hline 6 & 2 & 0.88 & Glove Type 2 & SS & Hexagonal & 3.54 & 3.54 & 1.12 & 0.83 & 3.17 \\
\hline 6 & 3 & 0.43 & Barehand & Nylon & Circular & 4.39 & 4.38 & 1.00 & 0.74 & 4.39 \\
\hline 6 & 3 & 0.43 & Barehand & Nylon & Hexagonal & 4.39 & 4.38 & 1.01 & 0.75 & 4.33 \\
\hline 6 & 3 & 0.43 & Barehand & SS & Circular & 4.39 & 4.38 & 1.11 & 0.82 & 4.00 \\
\hline 6 & 3 & 0.43 & Barehand & SS & Hexagonal & 4.39 & 4.38 & 1.10 & 0.81 & 4.11 \\
\hline 6 & 3 & 0.43 & Glove Type 1 & Nylon & Circular & 4.39 & 4.38 & 1.08 & 0.80 & 4.04 \\
\hline 6 & 3 & 0.43 & Glove Type 1 & Nylon & Hexagonal & 4.39 & 4.38 & 1.08 & 0.80 & 4.04 \\
\hline 6 & 3 & 0.43 & Glove Type 1 & SS & Circular & 4.39 & 4.38 & 1.10 & 0.81 & 4.01 \\
\hline 6 & 3 & 0.43 & Glove Type 1 & $\mathrm{SS}$ & Hexagonal & 4.39 & 4.38 & 1.10 & 0.82 & 3.98 \\
\hline 6 & 3 & 0.43 & Glove Type 2 & Nylon & Circular & 4.39 & 4.38 & 1.08 & 0.80 & 4.05 \\
\hline 6 & 3 & 0.43 & Glove Type 2 & Nylon & Hexagonal & 4.39 & 4.38 & 1.18 & 0.88 & 3.72 \\
\hline 6 & 3 & 0.43 & Glove Type 2 & SS & Circular & 4.39 & 4.38 & 1.08 & 0.80 & 4.06 \\
\hline 6 & 3 & 0.43 & Glove Type 2 & SS & Hexagonal & 4.39 & 4.38 & 1.12 & 0.83 & 3.90 \\
\hline 6 & 4 & 0.28 & Barehand & Nylon & Circular & 5.43 & 5.42 & 1.28 & 0.95 & 4.25 \\
\hline 6 & 4 & 0.28 & Barehand & Nylon & Hexagonal & 5.43 & 5.42 & 1.35 & 1.00 & 4.03 \\
\hline 6 & 4 & 0.28 & Barehand & SS & Circular & 5.43 & 5.42 & 1.28 & 0.95 & 4.24 \\
\hline 6 & 4 & 0.28 & Barehand & SS & Hexagonal & 5.43 & 5.42 & 1.29 & 0.96 & 4.20 \\
\hline 6 & 4 & 0.28 & Glove Type 1 & Nylon & Circular & 5.43 & 5.42 & 1.29 & 0.96 & 4.21 \\
\hline 6 & 4 & 0.28 & Glove Type 1 & Nylon & Hexagonal & 5.43 & 5.41 & 1.28 & 0.95 & 4.24 \\
\hline 6 & 4 & 0.28 & Glove Type 1 & SS & Circular & 5.43 & 5.41 & 1.35 & 1.00 & 4.02 \\
\hline 6 & 4 & 0.28 & Glove Type 1 & SS & Hexagonal & 5.43 & 5.41 & 1.25 & 0.93 & 4.34 \\
\hline 6 & 4 & 0.28 & Glove Type 2 & Nylon & Circular & 5.43 & 5.41 & 1.33 & 0.99 & 4.09 \\
\hline 6 & 4 & 0.28 & Glove Type 2 & Nylon & Hexagonal & 5.43 & 5.41 & 1.31 & 0.97 & 4.16 \\
\hline 6 & 4 & 0.28 & Glove Type 2 & SS & Circular & 5.43 & 5.41 & 1.25 & 0.93 & 4.33 \\
\hline 6 & 4 & 0.28 & Glove Type 2 & SS & Hexagonal & 5.43 & 5.42 & 1.28 & 0.95 & 4.24 \\
\hline
\end{tabular}




\begin{tabular}{|c|c|c|c|c|c|c|c|c|c|c|}
\hline Participant & $\begin{array}{l}\text { Task } \\
\text { Plate }\end{array}$ & $\begin{array}{l}\text { Object } \\
\text { Height }\end{array}$ & \begin{tabular}{|l|l} 
Glove \\
Condition
\end{tabular} & $\begin{array}{l}\text { Object } \\
\text { Material }\end{array}$ & $\begin{array}{l}\text { Object } \\
\text { Shape }\end{array}$ & ID & IDe & MT & $\begin{array}{l}\text { Normalized } \\
\text { MT } \\
\end{array}$ & TP \\
\hline 7 & 1 & 0.88 & Barehand & Nylon & Circular & 3.06 & 3.03 & 1.04 & 0.53 & 2.91 \\
\hline 7 & 1 & 0.88 & Barehand & Nylon & Hexagonal & 3.06 & 3.04 & 1.12 & 0.57 & 2.73 \\
\hline 7 & 1 & 0.88 & Barehand & SS & Circular & 3.06 & 3.04 & 1.15 & 0.58 & 2.65 \\
\hline 7 & 1 & 0.88 & Barehand & SS & Hexagonal & 3.06 & 3.04 & 1.08 & 0.55 & 2.81 \\
\hline 7 & 1 & 0.88 & Glove Type 1 & Nylon & Circular & 3.06 & 3.03 & 1.22 & 0.62 & 2.49 \\
\hline 7 & 1 & 0.88 & Glove Type 1 & Nylon & Hexagonal & 3.06 & 3.03 & 1.15 & 0.59 & 2.63 \\
\hline 7 & 1 & 0.88 & Glove Type 1 & SS & Circular & 3.06 & 3.04 & 1.22 & 0.62 & 2.49 \\
\hline 7 & 1 & 0.88 & Glove Type 1 & SS & Hexagonal & 3.06 & 3.03 & 1.23 & 0.62 & 2.47 \\
\hline 7 & 1 & 0.88 & Glove Type 2 & Nylon & Circular & 3.06 & 3.04 & 1.24 & 0.63 & 2.46 \\
\hline 7 & 1 & 0.88 & Glove Type 2 & Nylon & Hexagonal & 3.06 & 3.04 & 1.29 & 0.66 & 2.36 \\
\hline 7 & 1 & 0.88 & Glove Type 2 & SS & Circular & 3.06 & 3.04 & 1.26 & 0.64 & 2.41 \\
\hline 7 & 1 & 0.88 & Glove Type 2 & SS & Hexagonal & 3.06 & 3.04 & 1.31 & 0.66 & 2.33 \\
\hline 7 & 2 & 0.88 & Barehand & Nylon & Circular & 3.54 & 3.55 & 1.24 & 0.63 & 2.87 \\
\hline 7 & 2 & 0.88 & Barehand & Nylon & Hexagonal & 3.54 & 3.55 & 1.14 & 0.58 & 3.12 \\
\hline 7 & 2 & 0.88 & Barehand & SS & Circular & 3.54 & 3.55 & 1.21 & 0.62 & 2.94 \\
\hline 7 & 2 & 0.88 & Barehand & $\mathrm{SS}$ & Hexagonal & 3.54 & 3.55 & 1.26 & 0.64 & 2.82 \\
\hline 7 & 2 & 0.88 & Glove Type 1 & Nylon & Circular & 3.54 & 3.54 & 1.28 & 0.65 & 2.79 \\
\hline 7 & 2 & 0.88 & Glove Type 1 & Nylon & Hexagonal & 3.54 & 3.54 & 1.30 & 0.66 & 2.73 \\
\hline 7 & 2 & 0.88 & Glove Type 1 & SS & Circular & 3.54 & 3.54 & 1.32 & 0.67 & 2.69 \\
\hline 7 & 2 & 0.88 & Glove Type 1 & $\mathrm{SS}$ & Hexagonal & 3.54 & 3.54 & 1.29 & 0.66 & 2.74 \\
\hline 7 & 2 & 0.88 & Glove Type 2 & Nylon & Circular & 3.54 & 3.55 & 1.37 & 0.70 & 2.60 \\
\hline 7 & 2 & 0.88 & Glove Type 2 & Nylon & Hexagonal & 3.54 & 3.55 & 1.39 & 0.71 & 2.56 \\
\hline 7 & 2 & 0.88 & Glove Type 2 & SS & Circular & 3.54 & 3.55 & 1.47 & 0.75 & 2.41 \\
\hline 7 & 2 & 0.88 & Glove Type 2 & SS & Hexagonal & 3.54 & 3.55 & 1.57 & 0.80 & 2.27 \\
\hline 7 & 3 & 0.43 & Barehand & Nylon & Circular & 4.39 & 4.39 & 1.00 & 0.51 & 4.39 \\
\hline 7 & 3 & 0.43 & Barehand & Nylon & Hexagonal & 4.39 & 4.39 & 1.04 & 0.53 & 4.21 \\
\hline 7 & 3 & 0.43 & Barehand & $\mathrm{SS}$ & Circular & 4.39 & 4.39 & 1.08 & 0.55 & 4.06 \\
\hline 7 & 3 & 0.43 & Barehand & $\mathrm{SS}$ & Hexagonal & 4.39 & 4.39 & 1.03 & 0.52 & 4.28 \\
\hline 7 & 3 & 0.43 & Glove Type 1 & Nylon & Circular & 4.39 & 4.38 & 1.32 & 0.67 & 3.34 \\
\hline 7 & 3 & 0.43 & Glove Type 1 & Nylon & Hexagonal & 4.39 & 4.39 & 1.54 & 0.79 & 2.85 \\
\hline 7 & 3 & 0.43 & Glove Type 1 & $\mathrm{SS}$ & Circular & 4.39 & 4.39 & 1.45 & 0.74 & 3.07 \\
\hline 7 & 3 & 0.43 & Glove Type 1 & SS & Hexagonal & 4.39 & 4.39 & 1.39 & 0.71 & 3.20 \\
\hline 7 & 3 & 0.43 & Glove Type 2 & Nylon & Circular & 4.39 & 4.39 & 1.59 & 0.81 & 2.78 \\
\hline 7 & 3 & 0.43 & Glove Type 2 & Nylon & Hexagonal & 4.39 & 4.38 & 1.49 & 0.76 & 2.95 \\
\hline 7 & 3 & 0.43 & Glove Type 2 & SS & Circular & 4.39 & 4.38 & 1.62 & 0.82 & 2.72 \\
\hline 7 & 3 & 0.43 & Glove Type 2 & $\mathrm{SS}$ & Hexagonal & 4.39 & 4.38 & 1.49 & 0.76 & 2.97 \\
\hline 7 & 4 & 0.28 & Barehand & Nylon & Circular & 5.43 & 5.42 & 1.39 & 0.71 & 3.91 \\
\hline 7 & 4 & 0.28 & Barehand & Nylon & Hexagonal & 5.43 & 5.42 & 1.36 & 0.69 & 3.98 \\
\hline 7 & 4 & 0.28 & Barehand & $\mathrm{SS}$ & Circular & 5.43 & 5.42 & 1.39 & 0.71 & 3.91 \\
\hline 7 & 4 & 0.28 & Barehand & $\mathrm{SS}$ & Hexagonal & 5.43 & 5.42 & 1.31 & 0.67 & 4.15 \\
\hline 7 & 4 & 0.28 & Glove Type 1 & Nylon & Circular & 5.43 & 5.42 & 1.96 & 1.00 & 3.10 \\
\hline
\end{tabular}




\begin{tabular}{|c|c|c|c|c|c|c|c|c|c|c|}
\hline Participant & $\begin{array}{l}\text { Task } \\
\text { Plate } \\
\end{array}$ & $\begin{array}{l}\text { Object } \\
\text { Height }\end{array}$ & $\begin{array}{l}\text { Glove } \\
\text { Condition }\end{array}$ & $\begin{array}{l}\text { Object } \\
\text { Material }\end{array}$ & $\begin{array}{l}\text { Object } \\
\text { Shape }\end{array}$ & ID & IDe & MT & $\begin{array}{l}\text { Normalized } \\
\text { MT } \\
\end{array}$ & TP \\
\hline 7 & 4 & 0.28 & Glove Type 1 & Nylon & Hexagonal & 5.43 & 5.42 & 1.93 & 0.98 & 2.85 \\
\hline 7 & 4 & 0.28 & Glove Type 1 & SS & Circular & 5.43 & 5.42 & 1.78 & 0.91 & 3.07 \\
\hline 7 & 4 & 0.28 & Glove Type 1 & SS & Hexagonal & 5.43 & 5.42 & 1.82 & 0.93 & 2.99 \\
\hline 7 & 4 & 0.28 & Glove Type 2 & Nylon & Circular & 5.43 & 5.42 & 1.76 & 0.90 & 3.09 \\
\hline 7 & 4 & 0.28 & Glove Type 2 & Nylon & Hexagonal & 5.43 & 5.42 & 1.81 & 0.92 & 3.02 \\
\hline 7 & 4 & 0.28 & Glove Type 2 & $\mathrm{SS}$ & Circular & 5.43 & 5.41 & 1.79 & 0.91 & 3.02 \\
\hline 7 & 4 & 0.28 & Glove Type 2 & SS & Hexagonal & 5.43 & 5.41 & 1.91 & 0.97 & 2.87 \\
\hline 8 & 1 & 0.88 & Barehand & Nylon & Circular & 3.06 & 3.07 & 0.98 & 0.45 & 3.13 \\
\hline 8 & 1 & 0.88 & Barehand & Nylon & Hexagonal & 3.06 & 3.06 & 0.93 & 0.43 & 3.29 \\
\hline 8 & 1 & 0.88 & Barehand & SS & Circular & 3.06 & 3.07 & 1.02 & 0.47 & 3.03 \\
\hline 8 & 1 & 0.88 & Barehand & SS & Hexagonal & 3.06 & 3.07 & 1.14 & 0.53 & 2.70 \\
\hline 8 & 1 & 0.88 & Glove Type 1 & Nylon & Circular & 3.06 & 3.06 & 1.03 & 0.47 & 2.99 \\
\hline 8 & 1 & 0.88 & Glove Type 1 & Nylon & Hexagonal & 3.06 & 3.07 & 1.10 & 0.51 & 2.80 \\
\hline 8 & 1 & 0.88 & Glove Type 1 & SS & Circular & 3.06 & 3.06 & 1.11 & 0.51 & 2.76 \\
\hline 8 & 1 & 0.88 & Glove Type 1 & SS & Hexagonal & 3.06 & 3.07 & 1.10 & 0.51 & 2.79 \\
\hline 8 & 1 & 0.88 & Glove Type 2 & Nylon & Circular & 3.06 & 3.06 & 1.34 & 0.62 & 2.34 \\
\hline 8 & 1 & 0.88 & Glove Type 2 & Nylon & Hexagonal & 3.06 & 3.06 & 1.31 & 0.60 & 2.35 \\
\hline 8 & 1 & 0.88 & Glove Type 2 & SS & Circular & 3.06 & 3.07 & 1.26 & 0.58 & 2.43 \\
\hline 8 & 1 & 0.88 & Glove Type 2 & SS & Hexagonal & 3.06 & 3.08 & 1.32 & 0.61 & 2.34 \\
\hline 8 & 2 & 0.88 & Barehand & Nylon & Circular & 3.54 & 3.53 & 1.14 & 0.52 & 3.12 \\
\hline 8 & 2 & 0.88 & Barehand & Nylon & Hexagonal & 3.54 & 3.54 & 1.11 & 0.51 & 3.19 \\
\hline 8 & 2 & 0.88 & Barehand & SS & Circular & 3.54 & 3.54 & 1.20 & 0.55 & 2.97 \\
\hline 8 & 2 & 0.88 & Barehand & SS & Hexagonal & 3.54 & 3.54 & 1.24 & 0.57 & 2.88 \\
\hline 8 & 2 & 0.88 & Glove Type 1 & Nylon & Circular & 3.54 & 3.54 & 1.19 & 0.55 & 2.96 \\
\hline 8 & 2 & 0.88 & Glove Type 1 & Nylon & Hexagonal & 3.54 & 3.54 & 1.23 & 0.57 & 2.87 \\
\hline 8 & 2 & 0.88 & Glove Type 1 & SS & Circular & 3.54 & 3.54 & 1.29 & 0.60 & 2.75 \\
\hline 8 & 2 & 0.88 & Glove Type 1 & $\mathrm{SS}$ & Hexagonal & 3.54 & 3.55 & 1.35 & 0.62 & 2.63 \\
\hline 8 & 2 & 0.88 & Glove Type 2 & Nylon & Circular & 3.54 & 3.55 & 1.29 & 0.60 & 2.75 \\
\hline 8 & 2 & 0.88 & Glove Type 2 & Nylon & Hexagonal & 3.54 & 3.56 & 1.38 & 0.64 & 2.59 \\
\hline 8 & 2 & 0.88 & Glove Type 2 & SS & Circular & 3.54 & 3.55 & 1.32 & 0.61 & 2.70 \\
\hline 8 & 2 & 0.88 & Glove Type 2 & $\mathrm{SS}$ & Hexagonal & 3.54 & 3.55 & 1.49 & 0.69 & 2.40 \\
\hline 8 & 3 & 0.43 & Barehand & Nylon & Circular & 4.39 & 4.40 & 1.11 & 0.51 & 3.97 \\
\hline 8 & 3 & 0.43 & Barehand & Nylon & Hexagonal & 4.39 & 4.39 & 1.18 & 0.54 & 3.73 \\
\hline 8 & 3 & 0.43 & Barehand & SS & Circular & 4.39 & 4.40 & 1.10 & 0.51 & 4.00 \\
\hline 8 & 3 & 0.43 & Barehand & SS & Hexagonal & 4.39 & 4.40 & 1.10 & 0.51 & 4.01 \\
\hline 8 & 3 & 0.43 & Glove Type 1 & Nylon & Circular & 4.39 & 4.39 & 1.49 & 0.69 & 2.96 \\
\hline 8 & 3 & 0.43 & Glove Type 1 & Nylon & Hexagonal & 4.39 & 4.39 & 1.49 & 0.69 & 2.97 \\
\hline 8 & 3 & 0.43 & Glove Type 1 & SS & Circular & 4.39 & 4.39 & 1.55 & 0.71 & 2.86 \\
\hline 8 & 3 & 0.43 & Glove Type 1 & $\mathrm{SS}$ & Hexagonal & 4.39 & 4.39 & 1.57 & 0.72 & 2.80 \\
\hline 8 & 3 & 0.43 & Glove Type 2 & Nylon & Circular & 4.39 & 4.40 & 1.76 & 0.81 & 2.53 \\
\hline 8 & 3 & 0.43 & Glove Type 2 & Nylon & Hexagonal & 4.39 & 4.40 & 1.73 & 0.80 & 2.55 \\
\hline
\end{tabular}




\begin{tabular}{|c|c|c|c|c|c|c|c|c|c|c|}
\hline Participant & $\begin{array}{l}\text { Task } \\
\text { Plate }\end{array}$ & $\begin{array}{l}\text { Object } \\
\text { Height }\end{array}$ & $\begin{array}{l}\text { Glove } \\
\text { Condition }\end{array}$ & $\begin{array}{l}\text { Object } \\
\text { Material }\end{array}$ & $\begin{array}{l}\text { Object } \\
\text { Shape }\end{array}$ & ID & IDe & MT & $\begin{array}{l}\text { Normalized } \\
\text { MT }\end{array}$ & TP \\
\hline 8 & 3 & 0.43 & Glove Type 2 & SS & Circular & 4.39 & 4.39 & 1.57 & 0.72 & 2.80 \\
\hline 8 & 3 & 0.43 & Glove Type 2 & SS & Hexagonal & 4.39 & 4.39 & 1.64 & 0.76 & 2.70 \\
\hline 8 & 4 & 0.28 & Barehand & Nylon & Circular & 5.43 & 5.42 & 1.54 & 0.71 & 3.43 \\
\hline 8 & 4 & 0.28 & Barehand & Nylon & Hexagonal & 5.43 & 5.42 & 1.52 & 0.70 & 3.56 \\
\hline 8 & 4 & 0.28 & Barehand & $\mathrm{SS}$ & Circular & 5.43 & 5.42 & 1.56 & 0.72 & 3.49 \\
\hline 8 & 4 & 0.28 & Barehand & SS & Hexagonal & 5.43 & 5.42 & 1.57 & 0.72 & 3.46 \\
\hline 8 & 4 & 0.28 & Glove Type 1 & Nylon & Circular & 5.43 & 5.42 & 1.95 & 0.90 & 2.75 \\
\hline 8 & 4 & 0.28 & Glove Type 1 & Nylon & Hexagonal & 5.43 & 5.42 & 2.17 & 1.00 & 2.52 \\
\hline 8 & 4 & 0.28 & Glove Type 1 & SS & Circular & 5.43 & 5.42 & 1.81 & 0.83 & 3.00 \\
\hline 8 & 4 & 0.28 & Glove Type 1 & SS & Hexagonal & 5.43 & 5.42 & 1.92 & 0.88 & 2.83 \\
\hline 8 & 4 & 0.28 & Glove Type 2 & Nylon & Circular & 5.43 & 5.42 & 1.88 & 0.86 & 2.91 \\
\hline 8 & 4 & 0.28 & Glove Type 2 & Nylon & Hexagonal & 5.43 & 5.43 & 1.86 & 0.86 & 2.92 \\
\hline 8 & 4 & 0.28 & Glove Type 2 & SS & Circular & 5.43 & 5.43 & 1.92 & 0.88 & 2.77 \\
\hline 8 & 4 & 0.28 & Glove Type 2 & SS & Hexagonal & 5.43 & 5.43 & 1.83 & 0.85 & 2.99 \\
\hline 9 & 1 & 0.88 & Barehand & Nylon & Circular & 3.06 & 3.06 & 1.26 & 0.55 & 2.42 \\
\hline 9 & 1 & 0.88 & Barehand & Nylon & Hexagonal & 3.06 & 3.06 & 1.27 & 0.55 & 2.42 \\
\hline 9 & 1 & 0.88 & Barehand & $\mathrm{SS}$ & Circular & 3.06 & 3.06 & 1.31 & 0.57 & 2.33 \\
\hline 9 & 1 & 0.88 & Barehand & SS & Hexagonal & 3.06 & 3.05 & 1.31 & 0.57 & 2.35 \\
\hline 9 & 1 & 0.88 & Glove Type 1 & Nylon & Circular & 3.06 & 3.06 & 1.35 & 0.59 & 2.28 \\
\hline 9 & 1 & 0.88 & Glove Type 1 & Nylon & Hexagonal & 3.06 & 3.06 & 1.29 & 0.56 & 2.37 \\
\hline 9 & 1 & 0.88 & Glove Type 1 & $\mathrm{SS}$ & Circular & 3.06 & 3.05 & 1.33 & 0.58 & 2.31 \\
\hline 9 & 1 & 0.88 & Glove Type 1 & SS & Hexagonal & 3.06 & 3.06 & 1.37 & 0.60 & 2.23 \\
\hline 9 & 1 & 0.88 & Glove Type 2 & Nylon & Circular & 3.06 & 3.05 & 1.35 & 0.59 & 2.27 \\
\hline 9 & 1 & 0.88 & Glove Type 2 & Nylon & Hexagonal & 3.06 & 3.06 & 1.39 & 0.61 & 2.21 \\
\hline 9 & 1 & 0.88 & Glove Type 2 & $\mathrm{SS}$ & Circular & 3.06 & 3.06 & 1.36 & 0.59 & 2.25 \\
\hline 9 & 1 & 0.88 & Glove Type 2 & SS & Hexagonal & 3.06 & 3.06 & 1.31 & 0.57 & 2.33 \\
\hline 9 & 2 & 0.88 & Barehand & Nylon & Circular & 3.54 & 3.54 & 1.21 & 0.53 & 2.93 \\
\hline 9 & 2 & 0.88 & Barehand & Nylon & Hexagonal & 3.54 & 3.54 & 1.27 & 0.56 & 2.79 \\
\hline 9 & 2 & 0.88 & Barehand & SS & Circular & 3.54 & 3.54 & 1.31 & 0.57 & 2.72 \\
\hline 9 & 2 & 0.88 & Barehand & SS & Hexagonal & 3.54 & 3.54 & 1.32 & 0.58 & 2.68 \\
\hline 9 & 2 & 0.88 & Glove Type 1 & Nylon & Circular & 3.54 & 3.54 & 1.68 & 0.73 & 2.16 \\
\hline 9 & 2 & 0.88 & Glove Type 1 & Nylon & Hexagonal & 3.54 & 3.54 & 1.57 & 0.68 & 2.29 \\
\hline 9 & 2 & 0.88 & Glove Type 1 & $\mathrm{SS}$ & Circular & 3.54 & 3.54 & 1.55 & 0.68 & 2.29 \\
\hline 9 & 2 & 0.88 & Glove Type 1 & SS & Hexagonal & 3.54 & 3.54 & 1.64 & 0.72 & 2.20 \\
\hline 9 & 2 & 0.88 & Glove Type 2 & Nylon & Circular & 3.54 & 3.54 & 1.42 & 0.62 & 2.50 \\
\hline 9 & 2 & 0.88 & Glove Type 2 & Nylon & Hexagonal & 3.54 & 3.54 & 1.42 & 0.62 & 2.51 \\
\hline 9 & 2 & 0.88 & Glove Type 2 & SS & Circular & 3.54 & 3.54 & 1.49 & 0.65 & 2.38 \\
\hline 9 & 2 & 0.88 & Glove Type 2 & SS & Hexagonal & 3.54 & 3.54 & 1.46 & 0.64 & 2.43 \\
\hline 9 & 3 & 0.43 & Barehand & Nylon & Circular & 4.39 & 4.38 & 1.41 & 0.62 & 3.11 \\
\hline 9 & 3 & 0.43 & Barehand & Nylon & Hexagonal & 4.39 & 4.38 & 1.47 & 0.64 & 2.98 \\
\hline 9 & 3 & 0.43 & Barehand & $\mathrm{SS}$ & Circular & 4.39 & 4.38 & 1.38 & 0.60 & 3.18 \\
\hline
\end{tabular}




\begin{tabular}{|c|c|c|c|c|c|c|c|c|c|c|}
\hline Participant & $\begin{array}{l}\text { Task } \\
\text { Plate }\end{array}$ & $\begin{array}{l}\text { Object } \\
\text { Height }\end{array}$ & $\begin{array}{l}\text { Glove } \\
\text { Condition }\end{array}$ & $\begin{array}{l}\text { Object } \\
\text { Material }\end{array}$ & $\begin{array}{l}\text { Object } \\
\text { Shape }\end{array}$ & ID & IDe & MT & $\begin{array}{l}\text { Normalized } \\
\text { MT }\end{array}$ & $\mathbf{T P}$ \\
\hline 9 & 3 & 0.43 & Barehand & SS & Hexagonal & 4.39 & 4.38 & 1.45 & 0.63 & 3.04 \\
\hline 9 & 3 & 0.43 & Glove Type 1 & Nylon & Circular & 4.39 & 4.38 & 1.70 & 0.74 & 2.57 \\
\hline 9 & 3 & 0.43 & Glove Type 1 & Nylon & Hexagonal & 4.39 & 4.38 & 1.63 & 0.71 & 2.70 \\
\hline 9 & 3 & 0.43 & Glove Type 1 & $\mathrm{SS}$ & Circular & 4.39 & 4.38 & 1.67 & 0.73 & 2.63 \\
\hline 9 & 3 & 0.43 & Glove Type 1 & SS & Hexagonal & 4.39 & 4.37 & 1.65 & 0.72 & 2.65 \\
\hline 9 & 3 & 0.43 & Glove Type 2 & Nylon & Circular & 4.39 & 4.38 & 1.64 & 0.71 & 2.68 \\
\hline 9 & 3 & 0.43 & Glove Type 2 & Nylon & Hexagonal & 4.39 & 4.37 & 1.58 & 0.69 & 2.76 \\
\hline 9 & 3 & 0.43 & Glove Type 2 & SS & Circular & 4.39 & 4.38 & 1.56 & 0.68 & 2.81 \\
\hline 9 & 3 & 0.43 & Glove Type 2 & $\mathrm{SS}$ & Hexagonal & 4.39 & 4.38 & 1.53 & 0.67 & 2.86 \\
\hline 9 & 4 & 0.28 & Barehand & Nylon & Circular & 5.43 & 5.42 & 1.69 & 0.74 & 3.21 \\
\hline 9 & 4 & 0.28 & Barehand & Nylon & Hexagonal & 5.43 & 5.42 & 1.72 & 0.75 & 3.15 \\
\hline 9 & 4 & 0.28 & Barehand & SS & Circular & 5.43 & 5.42 & 1.71 & 0.75 & 3.18 \\
\hline 9 & 4 & 0.28 & Barehand & $\mathrm{SS}$ & Hexagonal & 5.43 & 5.42 & 1.74 & 0.76 & 3.15 \\
\hline 9 & 4 & 0.28 & Glove Type 1 & Nylon & Circular & 5.43 & 5.42 & 2.25 & 0.98 & 2.41 \\
\hline 9 & 4 & 0.28 & Glove Type 1 & Nylon & Hexagonal & 5.43 & 5.42 & 2.21 & 0.97 & 2.45 \\
\hline 9 & 4 & 0.28 & Glove Type 1 & SS & Circular & 5.43 & 5.42 & 2.17 & 0.95 & 2.50 \\
\hline 9 & 4 & 0.28 & Glove Type 1 & SS & Hexagonal & 5.43 & 5.42 & 2.29 & 1.00 & 2.38 \\
\hline 9 & 4 & 0.28 & Glove Type 2 & Nylon & Circular & 5.43 & 5.42 & 2.08 & 0.91 & 2.61 \\
\hline 9 & 4 & 0.28 & Glove Type 2 & Nylon & Hexagonal & 5.43 & 5.42 & 1.99 & 0.87 & 2.73 \\
\hline 9 & 4 & 0.28 & Glove Type 2 & SS & Circular & 5.43 & 5.42 & 2.02 & 0.88 & 2.69 \\
\hline 9 & 4 & 0.28 & Glove Type 2 & SS & Hexagonal & 5.43 & 5.42 & 2.05 & 0.90 & 2.64 \\
\hline 10 & 1 & 0.88 & Barehand & Nylon & Circular & 3.06 & 3.04 & 1.29 & 0.63 & 2.35 \\
\hline 10 & 1 & 0.88 & Barehand & Nylon & Hexagonal & 3.06 & 3.05 & 1.28 & 0.63 & 2.39 \\
\hline 10 & 1 & 0.88 & Barehand & SS & Circular & 3.06 & 3.04 & 1.40 & 0.69 & 2.17 \\
\hline 10 & 1 & 0.88 & Barehand & $\mathrm{SS}$ & Hexagonal & 3.06 & 3.05 & 1.38 & 0.67 & 2.22 \\
\hline 10 & 1 & 0.88 & Glove Type 1 & Nylon & Circular & 3.06 & 3.05 & 1.44 & 0.71 & 2.12 \\
\hline 10 & 1 & 0.88 & Glove Type 1 & Nylon & Hexagonal & 3.06 & 3.06 & 1.53 & 0.75 & 2.02 \\
\hline 10 & 1 & 0.88 & Glove Type 1 & SS & Circular & 3.06 & 3.06 & 1.60 & 0.78 & 1.92 \\
\hline 10 & 1 & 0.88 & Glove Type 1 & SS & Hexagonal & 3.06 & 3.06 & 1.65 & 0.81 & 1.86 \\
\hline 10 & 1 & 0.88 & Glove Type 2 & Nylon & Circular & 3.06 & 3.05 & 1.54 & 0.75 & 2.00 \\
\hline 10 & 1 & 0.88 & Glove Type 2 & Nylon & Hexagonal & 3.06 & 3.06 & 1.56 & 0.76 & 1.96 \\
\hline 10 & 1 & 0.88 & Glove Type 2 & SS & Circular & 3.06 & 3.06 & 1.48 & 0.73 & 2.07 \\
\hline 10 & 1 & 0.88 & Glove Type 2 & $\mathrm{SS}$ & Hexagonal & 3.06 & 3.06 & 1.55 & 0.76 & 1.97 \\
\hline 10 & 2 & 0.88 & Barehand & Nylon & Circular & 3.54 & 3.54 & 1.45 & 0.71 & 2.45 \\
\hline 10 & 2 & 0.88 & Barehand & Nylon & Hexagonal & 3.54 & 3.54 & 1.32 & 0.65 & 2.68 \\
\hline 10 & 2 & 0.88 & Barehand & SS & Circular & 3.54 & 3.54 & 1.42 & 0.69 & 2.50 \\
\hline 10 & 2 & 0.88 & Barehand & SS & Hexagonal & 3.54 & 3.54 & 1.45 & 0.71 & 2.45 \\
\hline 10 & 2 & 0.88 & Glove Type 1 & Nylon & Circular & 3.54 & 3.54 & 1.57 & 0.77 & 2.26 \\
\hline 10 & 2 & 0.88 & Glove Type 1 & Nylon & Hexagonal & 3.54 & 3.55 & 1.53 & 0.75 & 2.32 \\
\hline 10 & 2 & 0.88 & Glove Type 1 & SS & Circular & 3.54 & 3.54 & 1.60 & 0.78 & 2.22 \\
\hline 10 & 2 & 0.88 & Glove Type 1 & SS & Hexagonal & 3.54 & 3.55 & 1.59 & 0.78 & 2.24 \\
\hline
\end{tabular}




\begin{tabular}{|c|c|c|c|c|c|c|c|c|c|c|}
\hline Participant & $\begin{array}{l}\text { Task } \\
\text { Plate } \\
\end{array}$ & $\begin{array}{l}\text { Object } \\
\text { Height }\end{array}$ & $\begin{array}{l}\text { Glove } \\
\text { Condition }\end{array}$ & $\begin{array}{l}\text { Object } \\
\text { Material }\end{array}$ & $\begin{array}{l}\text { Object } \\
\text { Shape }\end{array}$ & ID & IDe & MT & $\begin{array}{l}\text { Normalized } \\
\text { MT } \\
\end{array}$ & TP \\
\hline 10 & 2 & 0.88 & Glove Type 2 & Nylon & Circular & 3.54 & 3.54 & 1.53 & 0.75 & 2.32 \\
\hline 10 & 2 & 0.88 & Glove Type 2 & Nylon & Hexagonal & 3.54 & 3.54 & 1.54 & 0.76 & 2.30 \\
\hline 10 & 2 & 0.88 & Glove Type 2 & SS & Circular & 3.54 & 3.54 & 1.59 & 0.78 & 2.24 \\
\hline 10 & 2 & 0.88 & Glove Type 2 & SS & Hexagonal & 3.54 & 3.54 & 1.65 & 0.81 & 2.15 \\
\hline 10 & 3 & 0.43 & Barehand & Nylon & Circular & 4.39 & 4.37 & 1.52 & 0.74 & 2.88 \\
\hline 10 & 3 & 0.43 & Barehand & Nylon & Hexagonal & 4.39 & 4.38 & 1.53 & 0.75 & 2.86 \\
\hline 10 & 3 & 0.43 & Barehand & SS & Circular & 4.39 & 4.37 & 1.53 & 0.75 & 2.86 \\
\hline 10 & 3 & 0.43 & Barehand & SS & Hexagonal & 4.39 & 4.38 & 1.54 & 0.76 & 2.83 \\
\hline 10 & 3 & 0.43 & Glove Type 1 & Nylon & Circular & 4.39 & 4.38 & 1.60 & 0.78 & 2.74 \\
\hline 10 & 3 & 0.43 & Glove Type 1 & Nylon & Hexagonal & 4.39 & 4.38 & 1.61 & 0.79 & 2.72 \\
\hline 10 & 3 & 0.43 & Glove Type 1 & SS & Circular & 4.39 & 4.38 & 1.57 & 0.77 & 2.79 \\
\hline 10 & 3 & 0.43 & Glove Type 1 & SS & Hexagonal & 4.39 & 4.38 & 1.67 & 0.82 & 2.62 \\
\hline 10 & 3 & 0.43 & Glove Type 2 & Nylon & Circular & 4.39 & 4.37 & 1.72 & 0.84 & 2.55 \\
\hline 10 & 3 & 0.43 & Glove Type 2 & Nylon & Hexagonal & 4.39 & 4.37 & 1.73 & 0.85 & 2.53 \\
\hline 10 & 3 & 0.43 & Glove Type 2 & SS & Circular & 4.39 & 4.37 & 1.71 & 0.84 & 2.55 \\
\hline 10 & 3 & 0.43 & Glove Type 2 & $\mathrm{SS}$ & Hexagonal & 4.39 & 4.37 & 1.78 & 0.87 & 2.46 \\
\hline 10 & 4 & 0.28 & Barehand & Nylon & Circular & 5.43 & 5.42 & 1.67 & 0.82 & 3.26 \\
\hline 10 & 4 & 0.28 & Barehand & Nylon & Hexagonal & 5.43 & 5.42 & 1.58 & 0.77 & 3.45 \\
\hline 10 & 4 & 0.28 & Barehand & SS & Circular & 5.43 & 5.42 & 1.60 & 0.79 & 3.39 \\
\hline 10 & 4 & 0.28 & Barehand & $\mathrm{SS}$ & Hexagonal & 5.43 & 5.42 & 1.65 & 0.81 & 3.29 \\
\hline 10 & 4 & 0.28 & Glove Type 1 & Nylon & Circular & 5.43 & 5.42 & 1.94 & 0.95 & 2.80 \\
\hline 10 & 4 & 0.28 & Glove Type 1 & Nylon & Hexagonal & 5.43 & 5.42 & 1.92 & 0.94 & 2.83 \\
\hline 10 & 4 & 0.28 & Glove Type 1 & SS & Circular & 5.43 & 5.42 & 1.85 & 0.91 & 2.94 \\
\hline 10 & 4 & 0.28 & Glove Type 1 & SS & Hexagonal & 5.43 & 5.42 & 1.86 & 0.91 & 2.92 \\
\hline 10 & 4 & 0.28 & Glove Type 2 & Nylon & Circular & 5.43 & 5.42 & 2.04 & 1.00 & 2.70 \\
\hline 10 & 4 & 0.28 & Glove Type 2 & Nylon & Hexagonal & 5.43 & 5.42 & 1.93 & 0.95 & 2.81 \\
\hline 10 & 4 & 0.28 & Glove Type 2 & SS & Circular & 5.43 & 5.42 & 1.87 & 0.92 & 2.90 \\
\hline 10 & 4 & 0.28 & Glove Type 2 & $\mathrm{SS}$ & Hexagonal & 5.43 & 5.41 & 1.94 & 0.95 & 2.79 \\
\hline 11 & 1 & 0.88 & Barehand & Nylon & Circular & 3.06 & 3.05 & 1.11 & 0.77 & 2.74 \\
\hline 11 & 1 & 0.88 & Barehand & Nylon & Hexagonal & 3.06 & 3.05 & 1.09 & 0.75 & 2.81 \\
\hline 11 & 1 & 0.88 & Barehand & $\mathrm{SS}$ & Circular & 3.06 & 3.04 & 1.15 & 0.80 & 2.65 \\
\hline 11 & 1 & 0.88 & Barehand & SS & Hexagonal & 3.06 & 3.04 & 1.10 & 0.76 & 2.78 \\
\hline 11 & 1 & 0.88 & Glove Type 1 & Nylon & Circular & 3.06 & 3.05 & 1.13 & 0.78 & 2.71 \\
\hline 11 & 1 & 0.88 & Glove Type 1 & Nylon & Hexagonal & 3.06 & 3.05 & 1.11 & 0.77 & 2.76 \\
\hline 11 & 1 & 0.88 & Glove Type 1 & SS & Circular & 3.06 & 3.05 & 1.12 & 0.78 & 2.72 \\
\hline 11 & 1 & 0.88 & Glove Type 1 & $\mathrm{SS}$ & Hexagonal & 3.06 & 3.05 & 1.16 & 0.80 & 2.64 \\
\hline 11 & 1 & 0.88 & Glove Type 2 & Nylon & Circular & 3.06 & 3.04 & 1.10 & 0.76 & 2.77 \\
\hline 11 & 1 & 0.88 & Glove Type 2 & Nylon & Hexagonal & 3.06 & 3.05 & 1.13 & 0.78 & 2.71 \\
\hline 11 & 1 & 0.88 & Glove Type 2 & $\mathrm{SS}$ & Circular & 3.06 & 3.05 & 1.08 & 0.75 & 2.82 \\
\hline 11 & 1 & 0.88 & Glove Type 2 & $\mathrm{SS}$ & Hexagonal & 3.06 & 3.05 & 1.15 & 0.80 & 2.65 \\
\hline 11 & 2 & 0.88 & Barehand & Nylon & Circular & 3.54 & 3.54 & 1.19 & 0.83 & 2.97 \\
\hline
\end{tabular}




\begin{tabular}{|c|c|c|c|c|c|c|c|c|c|c|}
\hline Participant & $\begin{array}{l}\text { Task } \\
\text { Plate }\end{array}$ & $\begin{array}{l}\text { Object } \\
\text { Height }\end{array}$ & $\begin{array}{l}\text { Glove } \\
\text { Condition }\end{array}$ & $\begin{array}{l}\text { Object } \\
\text { Material }\end{array}$ & $\begin{array}{l}\text { Object } \\
\text { Shape }\end{array}$ & ID & IDe & MT & $\begin{array}{l}\text { Normalized } \\
\text { MT } \\
\end{array}$ & TP \\
\hline 11 & 2 & 0.88 & Barehand & Nylon & Hexagonal & 3.54 & 3.55 & 1.21 & 0.84 & 2.93 \\
\hline 11 & 2 & 0.88 & Barehand & SS & Circular & 3.54 & 3.54 & 1.24 & 0.86 & 2.85 \\
\hline 11 & 2 & 0.88 & Barehand & SS & Hexagonal & 3.54 & 3.54 & 1.29 & 0.89 & 2.75 \\
\hline 11 & 2 & 0.88 & Glove Type 1 & Nylon & Circular & 3.54 & 3.53 & 1.18 & 0.82 & 2.98 \\
\hline 11 & 2 & 0.88 & Glove Type 1 & Nylon & Hexagonal & 3.54 & 3.54 & 1.21 & 0.84 & 2.95 \\
\hline 11 & 2 & 0.88 & Glove Type 1 & $\mathrm{SS}$ & Circular & 3.54 & 3.54 & 1.22 & 0.85 & 2.90 \\
\hline 11 & 2 & 0.88 & Glove Type 1 & SS & Hexagonal & 3.54 & 3.54 & 1.27 & 0.88 & 2.79 \\
\hline 11 & 2 & 0.88 & Glove Type 2 & Nylon & Circular & 3.54 & 3.54 & 1.19 & 0.83 & 2.97 \\
\hline 11 & 2 & 0.88 & Glove Type 2 & Nylon & Hexagonal & 3.54 & 3.54 & 1.22 & 0.84 & 2.91 \\
\hline 11 & 2 & 0.88 & Glove Type 2 & SS & Circular & 3.54 & 3.54 & 1.31 & 0.91 & 2.72 \\
\hline 11 & 2 & 0.88 & Glove Type 2 & SS & Hexagonal & 3.54 & 3.54 & 1.24 & 0.86 & 2.86 \\
\hline 11 & 3 & 0.43 & Barehand & Nylon & Circular & 4.39 & 4.37 & 1.16 & 0.81 & 3.76 \\
\hline 11 & 3 & 0.43 & Barehand & Nylon & Hexagonal & 4.39 & 4.37 & 1.17 & 0.81 & 3.73 \\
\hline 11 & 3 & 0.43 & Barehand & SS & Circular & 4.39 & 4.37 & 1.19 & 0.82 & 3.69 \\
\hline 11 & 3 & 0.43 & Barehand & SS & Hexagonal & 4.39 & 4.37 & 1.17 & 0.81 & 3.75 \\
\hline 11 & 3 & 0.43 & Glove Type 1 & Nylon & Circular & 4.39 & 4.37 & 1.31 & 0.90 & 3.35 \\
\hline 11 & 3 & 0.43 & Glove Type 1 & Nylon & Hexagonal & 4.39 & 4.37 & 1.34 & 0.93 & 3.27 \\
\hline 11 & 3 & 0.43 & Glove Type 1 & SS & Circular & 4.39 & 4.37 & 1.25 & 0.87 & 3.50 \\
\hline 11 & 3 & 0.43 & Glove Type 1 & SS & Hexagonal & 4.39 & 4.37 & 1.32 & 0.92 & 3.31 \\
\hline 11 & 3 & 0.43 & Glove Type 2 & Nylon & Circular & 4.39 & 4.37 & 1.24 & 0.86 & 3.54 \\
\hline 11 & 3 & 0.43 & Glove Type 2 & Nylon & Hexagonal & 4.39 & 4.37 & 1.25 & 0.86 & 3.51 \\
\hline 11 & 3 & 0.43 & Glove Type 2 & SS & Circular & 4.39 & 4.37 & 1.22 & 0.85 & 3.57 \\
\hline 11 & 3 & 0.43 & Glove Type 2 & SS & Hexagonal & 4.39 & 4.37 & 1.25 & 0.87 & 3.49 \\
\hline 11 & 4 & 0.28 & Barehand & Nylon & Circular & 5.43 & 5.43 & 1.28 & 0.89 & 4.25 \\
\hline 11 & 4 & 0.28 & Barehand & Nylon & Hexagonal & 5.43 & 5.42 & 1.28 & 0.88 & 4.26 \\
\hline 11 & 4 & 0.28 & Barehand & SS & Circular & 5.43 & 5.42 & 1.22 & 0.84 & 4.46 \\
\hline 11 & 4 & 0.28 & Barehand & SS & Hexagonal & 5.43 & 5.42 & 1.28 & 0.89 & 4.24 \\
\hline 11 & 4 & 0.28 & Glove Type 1 & Nylon & Circular & 5.43 & 5.42 & 1.40 & 0.97 & 3.90 \\
\hline 11 & 4 & 0.28 & Glove Type 1 & Nylon & Hexagonal & 5.43 & 5.41 & 1.40 & 0.97 & 3.87 \\
\hline 11 & 4 & 0.28 & Glove Type 1 & SS & Circular & 5.43 & 5.42 & 1.37 & 0.95 & 3.98 \\
\hline 11 & 4 & 0.28 & Glove Type 1 & $\mathrm{SS}$ & Hexagonal & 5.43 & 5.41 & 1.44 & 1.00 & 3.77 \\
\hline 11 & 4 & 0.28 & Glove Type 2 & Nylon & Circular & 5.43 & 5.42 & 1.35 & 0.93 & 4.03 \\
\hline 11 & 4 & 0.28 & Glove Type 2 & Nylon & Hexagonal & 5.43 & 5.42 & 1.38 & 0.95 & 3.94 \\
\hline 11 & 4 & 0.28 & Glove Type 2 & SS & Circular & 5.43 & 5.42 & 1.37 & 0.95 & 3.95 \\
\hline 11 & 4 & 0.28 & Glove Type 2 & SS & Hexagonal & 5.43 & 5.42 & 1.39 & 0.96 & 3.92 \\
\hline 12 & 1 & 0.88 & Barehand & Nylon & Circular & 3.06 & 3.06 & 1.24 & 0.69 & 2.49 \\
\hline 12 & 1 & 0.88 & Barehand & Nylon & Hexagonal & 3.06 & 3.07 & 1.24 & 0.69 & 2.51 \\
\hline 12 & 1 & 0.88 & Barehand & SS & Circular & 3.06 & 3.06 & 1.26 & 0.71 & 2.47 \\
\hline 12 & 1 & 0.88 & Barehand & $\mathrm{SS}$ & Hexagonal & 3.06 & 3.06 & 1.22 & 0.68 & 2.52 \\
\hline 12 & 1 & 0.88 & Glove Type 1 & Nylon & Circular & 3.06 & 3.06 & 1.12 & 0.63 & 2.73 \\
\hline 12 & 1 & 0.88 & Glove Type 1 & Nylon & Hexagonal & 3.06 & 3.06 & 1.18 & 0.66 & 2.59 \\
\hline
\end{tabular}




\begin{tabular}{|c|c|c|c|c|c|c|c|c|c|c|}
\hline Participant & $\begin{array}{l}\text { Task } \\
\text { Plate }\end{array}$ & $\begin{array}{l}\text { Object } \\
\text { Height }\end{array}$ & $\begin{array}{l}\text { Glove } \\
\text { Condition }\end{array}$ & $\begin{array}{l}\text { Object } \\
\text { Material } \\
\end{array}$ & $\begin{array}{l}\text { Object } \\
\text { Shape } \\
\end{array}$ & ID & IDe & MT & $\begin{array}{l}\text { Normalized } \\
\text { MT } \\
\end{array}$ & $\mathbf{T P}$ \\
\hline 12 & 1 & 0.88 & Glove Type 1 & SS & Circular & 3.06 & 3.06 & 1.21 & 0.68 & 2.56 \\
\hline 12 & 1 & 0.88 & Glove Type 1 & $\mathrm{SS}$ & Hexagonal & 3.06 & 3.06 & 1.21 & 0.68 & 2.54 \\
\hline 12 & 1 & 0.88 & Glove Type 2 & Nylon & Circular & 3.06 & 3.06 & 1.36 & 0.76 & 2.26 \\
\hline 12 & 1 & 0.88 & Glove Type 2 & Nylon & Hexagonal & 3.06 & 3.06 & 1.43 & 0.80 & 2.15 \\
\hline 12 & 1 & 0.88 & Glove Type 2 & $\mathrm{SS}$ & Circular & 3.06 & 3.06 & 1.32 & 0.74 & 2.33 \\
\hline 12 & 1 & 0.88 & Glove Type 2 & $\mathrm{SS}$ & Hexagonal & 3.06 & 3.06 & 1.27 & 0.71 & 2.43 \\
\hline 12 & 2 & 0.88 & Barehand & Nylon & Circular & 3.54 & 3.53 & 1.14 & 0.64 & 3.10 \\
\hline 12 & 2 & 0.88 & Barehand & Nylon & Hexagonal & 3.54 & 3.54 & 1.30 & 0.73 & 2.74 \\
\hline 12 & 2 & 0.88 & Barehand & SS & Circular & 3.54 & 3.53 & 1.23 & 0.69 & 2.89 \\
\hline 12 & 2 & 0.88 & Barehand & SS & Hexagonal & 3.54 & 3.53 & 1.28 & 0.72 & 2.76 \\
\hline 12 & 2 & 0.88 & Glove Type 1 & Nylon & Circular & 3.54 & 3.53 & 1.26 & 0.70 & 2.82 \\
\hline 12 & 2 & 0.88 & Glove Type 1 & Nylon & Hexagonal & 3.54 & 3.53 & 1.30 & 0.73 & 2.73 \\
\hline 12 & 2 & 0.88 & Glove Type 1 & $\mathrm{SS}$ & Circular & 3.54 & 3.53 & 1.33 & 0.75 & 2.65 \\
\hline 12 & 2 & 0.88 & Glove Type 1 & $\mathrm{SS}$ & Hexagonal & 3.54 & 3.53 & 1.42 & 0.80 & 2.49 \\
\hline 12 & 2 & 0.88 & Glove Type 2 & Nylon & Circular & 3.54 & 3.53 & 1.43 & 0.80 & 2.47 \\
\hline 12 & 2 & 0.88 & Glove Type 2 & Nylon & Hexagonal & 3.54 & 3.53 & 1.33 & 0.75 & 2.65 \\
\hline 12 & 2 & 0.88 & Glove Type 2 & $\mathrm{SS}$ & Circular & 3.54 & 3.53 & 1.43 & 0.80 & 2.47 \\
\hline 12 & 2 & 0.88 & Glove Type 2 & SS & Hexagonal & 3.54 & 3.54 & 1.49 & 0.84 & 2.40 \\
\hline 12 & 3 & 0.43 & Barehand & Nylon & Circular & 4.39 & 4.39 & 1.34 & 0.75 & 3.30 \\
\hline 12 & 3 & 0.43 & Barehand & Nylon & Hexagonal & 4.39 & 4.39 & 1.29 & 0.72 & 3.40 \\
\hline 12 & 3 & 0.43 & Barehand & $\mathrm{SS}$ & Circular & 4.39 & 4.39 & 1.35 & 0.75 & 3.26 \\
\hline 12 & 3 & 0.43 & Barehand & SS & Hexagonal & 4.39 & 4.39 & 1.38 & 0.77 & 3.19 \\
\hline 12 & 3 & 0.43 & Glove Type 1 & Nylon & Circular & 4.39 & 4.39 & 1.52 & 0.85 & 2.95 \\
\hline 12 & 3 & 0.43 & Glove Type 1 & Nylon & Hexagonal & 4.39 & 4.39 & 1.38 & 0.77 & 3.20 \\
\hline 12 & 3 & 0.43 & Glove Type 1 & $\mathrm{SS}$ & Circular & 4.39 & 4.39 & 1.38 & 0.77 & 3.27 \\
\hline 12 & 3 & 0.43 & Glove Type 1 & SS & Hexagonal & 4.39 & 4.39 & 1.43 & 0.80 & 3.07 \\
\hline 12 & 3 & 0.43 & Glove Type 2 & Nylon & Circular & 4.39 & 4.38 & 1.53 & 0.86 & 2.86 \\
\hline 12 & 3 & 0.43 & Glove Type 2 & Nylon & Hexagonal & 4.39 & 4.39 & 1.78 & 1.00 & 2.47 \\
\hline 12 & 3 & 0.43 & Glove Type 2 & SS & Circular & 4.39 & 4.39 & 1.64 & 0.92 & 2.68 \\
\hline 12 & 3 & 0.43 & Glove Type 2 & SS & Hexagonal & 4.39 & 4.39 & 1.65 & 0.93 & 2.66 \\
\hline 13 & 1 & 0.88 & Barehand & Nylon & Circular & 3.06 & 3.07 & 0.97 & 0.53 & 3.16 \\
\hline 13 & 1 & 0.88 & Barehand & Nylon & Hexagonal & 3.06 & 3.07 & 0.92 & 0.50 & 3.35 \\
\hline 13 & 1 & 0.88 & Barehand & SS & Circular & 3.06 & 3.07 & 1.08 & 0.59 & 2.84 \\
\hline 13 & 1 & 0.88 & Barehand & SS & Hexagonal & 3.06 & 3.07 & 1.05 & 0.57 & 2.93 \\
\hline 13 & 1 & 0.88 & Glove Type 1 & Nylon & Circular & 3.06 & 3.07 & 0.99 & 0.53 & 3.12 \\
\hline 13 & 1 & 0.88 & Glove Type 1 & Nylon & Hexagonal & 3.06 & 3.06 & 0.94 & 0.51 & 3.29 \\
\hline 13 & 1 & 0.88 & Glove Type 1 & $\mathrm{SS}$ & Circular & 3.06 & 3.07 & 1.03 & 0.55 & 2.99 \\
\hline 13 & 1 & 0.88 & Glove Type 1 & $\mathrm{SS}$ & Hexagonal & 3.06 & 3.06 & 1.05 & 0.56 & 2.94 \\
\hline 13 & 1 & 0.88 & Glove Type 2 & Nylon & Circular & 3.06 & 3.06 & 1.00 & 0.54 & 3.06 \\
\hline 13 & 1 & 0.88 & Glove Type 2 & Nylon & Hexagonal & 3.06 & 3.07 & 1.05 & 0.57 & 2.92 \\
\hline 13 & 1 & 0.88 & Glove Type 2 & SS & Circular & 3.06 & 3.07 & 1.11 & 0.60 & 2.78 \\
\hline
\end{tabular}




\begin{tabular}{|c|c|c|c|c|c|c|c|c|c|c|}
\hline Participant & $\begin{array}{l}\text { Task } \\
\text { Plate } \\
\end{array}$ & $\begin{array}{l}\text { Object } \\
\text { Height }\end{array}$ & $\begin{array}{l}\text { Glove } \\
\text { Condition }\end{array}$ & $\begin{array}{l}\text { Object } \\
\text { Material }\end{array}$ & $\begin{array}{l}\text { Object } \\
\text { Shape }\end{array}$ & ID & IDe & MT & $\begin{array}{l}\text { Normalized } \\
\text { MT } \\
\end{array}$ & TP \\
\hline 13 & 1 & 0.88 & Glove Type 2 & $\mathrm{SS}$ & Hexagonal & 3.06 & 3.06 & 1.05 & 0.57 & 2.91 \\
\hline 13 & 2 & 0.88 & Barehand & Nylon & Circular & 3.54 & 3.55 & 1.05 & 0.57 & 3.40 \\
\hline 13 & 2 & 0.88 & Barehand & Nylon & Hexagonal & 3.54 & 3.55 & 1.06 & 0.57 & 3.36 \\
\hline 13 & 2 & 0.88 & Barehand & SS & Circular & 3.54 & 3.56 & 1.12 & 0.61 & 3.16 \\
\hline 13 & 2 & 0.88 & Barehand & $\mathrm{SS}$ & Hexagonal & 3.54 & 3.55 & 1.11 & 0.60 & 3.21 \\
\hline 13 & 2 & 0.88 & Glove Type 1 & Nylon & Circular & 3.54 & 3.54 & 1.09 & 0.59 & 3.26 \\
\hline 13 & 2 & 0.88 & Glove Type 1 & Nylon & Hexagonal & 3.54 & 3.55 & 1.07 & 0.58 & 3.31 \\
\hline 13 & 2 & 0.88 & Glove Type 1 & SS & Circular & 3.54 & 3.55 & 1.18 & 0.64 & 3.03 \\
\hline 13 & 2 & 0.88 & Glove Type 1 & SS & Hexagonal & 3.54 & 3.54 & 1.15 & 0.62 & 3.08 \\
\hline 13 & 2 & 0.88 & Glove Type 2 & Nylon & Circular & 3.54 & 3.54 & 1.07 & 0.58 & 3.32 \\
\hline 13 & 2 & 0.88 & Glove Type 2 & Nylon & Hexagonal & 3.54 & 3.54 & 1.08 & 0.59 & 3.29 \\
\hline 13 & 2 & 0.88 & Glove Type 2 & SS & Circular & 3.54 & 3.55 & 1.08 & 0.59 & 3.29 \\
\hline 13 & 2 & 0.88 & Glove Type 2 & SS & Hexagonal & 3.54 & 3.54 & 1.16 & 0.62 & 3.07 \\
\hline 13 & 3 & 0.43 & Barehand & Nylon & Circular & 4.39 & 4.39 & 1.00 & 0.54 & 4.42 \\
\hline 13 & 3 & 0.43 & Barehand & Nylon & Hexagonal & 4.39 & 4.39 & 0.98 & 0.53 & 4.51 \\
\hline 13 & 3 & 0.43 & Barehand & $\mathrm{SS}$ & Circular & 4.39 & 4.39 & 1.04 & 0.56 & 4.21 \\
\hline 13 & 3 & 0.43 & Barehand & $\mathrm{SS}$ & Hexagonal & 4.39 & 4.39 & 1.07 & 0.58 & 4.13 \\
\hline 13 & 3 & 0.43 & Glove Type 1 & Nylon & Circular & 4.39 & 4.39 & 1.24 & 0.67 & 3.54 \\
\hline 13 & 3 & 0.43 & Glove Type 1 & Nylon & Hexagonal & 4.39 & 4.39 & 1.15 & 0.62 & 3.82 \\
\hline 13 & 3 & 0.43 & Glove Type 1 & $\mathrm{SS}$ & Circular & 4.39 & 4.38 & 1.26 & 0.68 & 3.48 \\
\hline 13 & 3 & 0.43 & Glove Type 1 & SS & Hexagonal & 4.39 & 4.39 & 1.18 & 0.64 & 3.73 \\
\hline 13 & 3 & 0.43 & Glove Type 2 & Nylon & Circular & 4.39 & 4.38 & 1.32 & 0.71 & 3.34 \\
\hline 13 & 3 & 0.43 & Glove Type 2 & Nylon & Hexagonal & 4.39 & 4.38 & 1.43 & 0.77 & 3.09 \\
\hline 13 & 3 & 0.43 & Glove Type 2 & SS & Circular & 4.39 & 4.38 & 1.34 & 0.73 & 3.27 \\
\hline 13 & 3 & 0.43 & Glove Type 2 & $\mathrm{SS}$ & Hexagonal & 4.39 & 4.38 & 1.28 & 0.69 & 3.43 \\
\hline 13 & 4 & 0.28 & Barehand & Nylon & Circular & 5.43 & 5.42 & 1.44 & 0.78 & 3.77 \\
\hline 13 & 4 & 0.28 & Barehand & Nylon & Hexagonal & 5.43 & 5.42 & 1.47 & 0.80 & 3.70 \\
\hline 13 & 4 & 0.28 & Barehand & $\mathrm{SS}$ & Circular & 5.43 & 5.42 & 1.43 & 0.77 & 3.78 \\
\hline 13 & 4 & 0.28 & Barehand & SS & Hexagonal & 5.43 & 5.42 & 1.39 & 0.75 & 3.90 \\
\hline 13 & 4 & 0.28 & Glove Type 1 & Nylon & Circular & 5.43 & 5.42 & 1.67 & 0.90 & 3.26 \\
\hline 13 & 4 & 0.28 & Glove Type 1 & Nylon & Hexagonal & 5.43 & 5.42 & 1.72 & 0.93 & 3.16 \\
\hline 13 & 4 & 0.28 & Glove Type 1 & SS & Circular & 5.43 & 5.42 & 1.61 & 0.87 & 3.37 \\
\hline 13 & 4 & 0.28 & Glove Type 1 & SS & Hexagonal & 5.43 & 5.42 & 1.65 & 0.89 & 3.29 \\
\hline 13 & 4 & 0.28 & Glove Type 2 & Nylon & Circular & 5.43 & 5.42 & 1.83 & 0.99 & 2.97 \\
\hline 13 & 4 & 0.28 & Glove Type 2 & Nylon & Hexagonal & 5.43 & 5.42 & 1.79 & 0.97 & 3.03 \\
\hline 13 & 4 & 0.28 & Glove Type 2 & $\mathrm{SS}$ & Circular & 5.43 & 5.42 & 1.78 & 0.96 & 3.04 \\
\hline 13 & 4 & 0.28 & Glove Type 2 & SS & Hexagonal & 5.43 & 5.42 & 1.85 & 1.00 & 2.96 \\
\hline 14 & 1 & 0.88 & Barehand & Nylon & Circular & 3.06 & 3.05 & 0.94 & 0.60 & 3.23 \\
\hline 14 & 1 & 0.88 & Barehand & Nylon & Hexagonal & 3.06 & 3.06 & 0.92 & 0.59 & 3.34 \\
\hline 14 & 1 & 0.88 & Barehand & SS & Circular & 3.06 & 3.05 & 0.97 & 0.62 & 3.14 \\
\hline 14 & 1 & 0.88 & Barehand & SS & Hexagonal & 3.06 & 3.05 & 0.96 & 0.61 & 3.18 \\
\hline
\end{tabular}




\begin{tabular}{|c|c|c|c|c|c|c|c|c|c|c|}
\hline Participant & $\begin{array}{l}\text { Task } \\
\text { Plate } \\
\end{array}$ & $\begin{array}{l}\text { Object } \\
\text { Height }\end{array}$ & $\begin{array}{l}\text { Glove } \\
\text { Condition }\end{array}$ & $\begin{array}{l}\text { Object } \\
\text { Material }\end{array}$ & $\begin{array}{l}\text { Object } \\
\text { Shape }\end{array}$ & ID & IDe & MT & $\begin{array}{l}\text { Normalized } \\
\text { MT } \\
\end{array}$ & TP \\
\hline 14 & 1 & 0.88 & Glove Type 1 & Nylon & Circular & 3.06 & 3.04 & 1.05 & 0.67 & 2.89 \\
\hline 14 & 1 & 0.88 & Glove Type 1 & Nylon & Hexagonal & 3.06 & 3.05 & 1.03 & 0.66 & 2.97 \\
\hline 14 & 1 & 0.88 & Glove Type 1 & SS & Circular & 3.06 & 3.05 & 1.04 & 0.66 & 2.93 \\
\hline 14 & 1 & 0.88 & Glove Type 1 & SS & Hexagonal & 3.06 & 3.05 & 1.07 & 0.68 & 2.86 \\
\hline 14 & 1 & 0.88 & Glove Type 2 & Nylon & Circular & 3.06 & 3.05 & 0.97 & 0.62 & 3.14 \\
\hline 14 & 1 & 0.88 & Glove Type 2 & Nylon & Hexagonal & 3.06 & 3.05 & 0.99 & 0.63 & 3.10 \\
\hline 14 & 1 & 0.88 & Glove Type 2 & SS & Circular & 3.06 & 3.05 & 1.00 & 0.64 & 3.06 \\
\hline 14 & 1 & 0.88 & Glove Type 2 & SS & Hexagonal & 3.06 & 3.06 & 0.94 & 0.60 & 3.24 \\
\hline 14 & 2 & 0.88 & Barehand & Nylon & Circular & 3.54 & 3.54 & 1.08 & 0.69 & 3.27 \\
\hline 14 & 2 & 0.88 & Barehand & Nylon & Hexagonal & 3.54 & 3.54 & 1.01 & 0.65 & 3.50 \\
\hline 14 & 2 & 0.88 & Barehand & SS & Circular & 3.54 & 3.53 & 1.15 & 0.73 & 3.07 \\
\hline 14 & 2 & 0.88 & Barehand & SS & Hexagonal & 3.54 & 3.53 & 1.12 & 0.72 & 3.14 \\
\hline 14 & 2 & 0.88 & Glove Type 1 & Nylon & Circular & 3.54 & 3.53 & 1.06 & 0.68 & 3.33 \\
\hline 14 & 2 & 0.88 & Glove Type 1 & Nylon & Hexagonal & 3.54 & 3.53 & 1.07 & 0.68 & 3.30 \\
\hline 14 & 2 & 0.88 & Glove Type 1 & SS & Circular & 3.54 & 3.53 & 1.13 & 0.72 & 3.15 \\
\hline 14 & 2 & 0.88 & Glove Type 1 & $\mathrm{SS}$ & Hexagonal & 3.54 & 3.53 & 1.08 & 0.69 & 3.26 \\
\hline 14 & 2 & 0.88 & Glove Type 2 & Nylon & Circular & 3.54 & 3.54 & 1.00 & 0.64 & 3.54 \\
\hline 14 & 2 & 0.88 & Glove Type 2 & Nylon & Hexagonal & 3.54 & 3.54 & 1.06 & 0.67 & 3.35 \\
\hline 14 & 2 & 0.88 & Glove Type 2 & SS & Circular & 3.54 & 3.53 & 1.03 & 0.65 & 3.44 \\
\hline 14 & 2 & 0.88 & Glove Type 2 & $\mathrm{SS}$ & Hexagonal & 3.54 & 3.53 & 1.08 & 0.69 & 3.27 \\
\hline 14 & 3 & 0.43 & Barehand & Nylon & Circular & 4.39 & 4.38 & 1.04 & 0.66 & 4.21 \\
\hline 14 & 3 & 0.43 & Barehand & Nylon & Hexagonal & 4.39 & 4.37 & 1.07 & 0.68 & 4.09 \\
\hline 14 & 3 & 0.43 & Barehand & SS & Circular & 4.39 & 4.38 & 1.07 & 0.68 & 4.10 \\
\hline 14 & 3 & 0.43 & Barehand & SS & Hexagonal & 4.39 & 4.37 & 1.06 & 0.67 & 4.14 \\
\hline 14 & 3 & 0.43 & Glove Type 1 & Nylon & Circular & 4.39 & 4.37 & 1.14 & 0.73 & 3.85 \\
\hline 14 & 3 & 0.43 & Glove Type 1 & Nylon & Hexagonal & 4.39 & 4.37 & 1.12 & 0.72 & 3.90 \\
\hline 14 & 3 & 0.43 & Glove Type 1 & SS & Circular & 4.39 & 4.37 & 1.15 & 0.73 & 3.79 \\
\hline 14 & 3 & 0.43 & Glove Type 1 & $\mathrm{SS}$ & Hexagonal & 4.39 & 4.37 & 1.15 & 0.73 & 3.80 \\
\hline 14 & 3 & 0.43 & Glove Type 2 & Nylon & Circular & 4.39 & 4.37 & 1.10 & 0.70 & 4.01 \\
\hline 14 & 3 & 0.43 & Glove Type 2 & Nylon & Hexagonal & 4.39 & 4.38 & 1.10 & 0.70 & 4.00 \\
\hline 14 & 3 & 0.43 & Glove Type 2 & $\mathrm{SS}$ & Circular & 4.39 & 4.37 & 1.13 & 0.72 & 3.88 \\
\hline 14 & 3 & 0.43 & Glove Type 2 & SS & Hexagonal & 4.39 & 4.37 & 1.13 & 0.72 & 3.90 \\
\hline 14 & 4 & 0.28 & Barehand & Nylon & Circular & 5.43 & 5.42 & 1.32 & 0.84 & 4.12 \\
\hline 14 & 4 & 0.28 & Barehand & Nylon & Hexagonal & 5.43 & 5.42 & 1.23 & 0.78 & 4.42 \\
\hline 14 & 4 & 0.28 & Barehand & SS & Circular & 5.43 & 5.42 & 1.22 & 0.77 & 4.47 \\
\hline 14 & 4 & 0.28 & Barehand & $\mathrm{SS}$ & Hexagonal & 5.43 & 5.42 & 1.21 & 0.77 & 4.50 \\
\hline 14 & 4 & 0.28 & Glove Type 1 & Nylon & Circular & 5.43 & 5.42 & 1.46 & 0.93 & 3.72 \\
\hline 14 & 4 & 0.28 & Glove Type 1 & Nylon & Hexagonal & 5.43 & 5.42 & 1.43 & 0.91 & 3.80 \\
\hline 14 & 4 & 0.28 & Glove Type 1 & $\mathrm{SS}$ & Circular & 5.43 & 5.42 & 1.45 & 0.92 & 3.75 \\
\hline 14 & 4 & 0.28 & Glove Type 1 & $\mathrm{SS}$ & Hexagonal & 5.43 & 5.42 & 1.57 & 1.00 & 3.53 \\
\hline 14 & 4 & 0.28 & Glove Type 2 & Nylon & Circular & 5.43 & 5.42 & 1.36 & 0.87 & 4.00 \\
\hline
\end{tabular}




\begin{tabular}{|c|c|c|c|c|c|c|c|c|c|c|}
\hline Participant & $\begin{array}{l}\text { Task } \\
\text { Plate } \\
\end{array}$ & $\begin{array}{l}\text { Object } \\
\text { Height }\end{array}$ & $\begin{array}{l}\text { Glove } \\
\text { Condition }\end{array}$ & $\begin{array}{l}\text { Object } \\
\text { Material }\end{array}$ & $\begin{array}{l}\text { Object } \\
\text { Shape }\end{array}$ & ID & IDe & MT & $\begin{array}{l}\text { Normalized } \\
\text { MT } \\
\end{array}$ & TP \\
\hline 14 & 4 & 0.28 & Glove Type 2 & Nylon & Hexagonal & 5.43 & 5.42 & 1.32 & 0.84 & 4.12 \\
\hline 14 & 4 & 0.28 & Glove Type 2 & SS & Circular & 5.43 & 5.42 & 1.35 & 0.86 & 4.02 \\
\hline 14 & 4 & 0.28 & Glove Type 2 & SS & Hexagonal & 5.43 & 5.42 & 1.39 & 0.88 & 3.90 \\
\hline 15 & 1 & 0.88 & Barehand & Nylon & Circular & 3.06 & 3.06 & 1.04 & 0.66 & 2.96 \\
\hline 15 & 1 & 0.88 & Barehand & Nylon & Hexagonal & 3.06 & 3.06 & 1.03 & 0.65 & 2.98 \\
\hline 15 & 1 & 0.88 & Barehand & $\mathrm{SS}$ & Circular & 3.06 & 3.05 & 1.03 & 0.65 & 2.97 \\
\hline 15 & 1 & 0.88 & Barehand & SS & Hexagonal & 3.06 & 3.06 & 0.96 & 0.61 & 3.19 \\
\hline 15 & 1 & 0.88 & Glove Type 1 & Nylon & Circular & 3.06 & 3.05 & 1.01 & 0.64 & 3.03 \\
\hline 15 & 1 & 0.88 & Glove Type 1 & Nylon & Hexagonal & 3.06 & 3.05 & 1.03 & 0.65 & 2.96 \\
\hline 15 & 1 & 0.88 & Glove Type 1 & SS & Circular & 3.06 & 3.06 & 1.12 & 0.71 & 2.73 \\
\hline 15 & 1 & 0.88 & Glove Type 1 & SS & Hexagonal & 3.06 & 3.06 & 1.10 & 0.69 & 2.86 \\
\hline 15 & 1 & 0.88 & Glove Type 2 & Nylon & Circular & 3.06 & 3.06 & 1.17 & 0.74 & 2.64 \\
\hline 15 & 1 & 0.88 & Glove Type 2 & Nylon & Hexagonal & 3.06 & 3.05 & 1.20 & 0.76 & 2.59 \\
\hline 15 & 1 & 0.88 & Glove Type 2 & SS & Circular & 3.06 & 3.06 & 1.14 & 0.72 & 2.67 \\
\hline 15 & 1 & 0.88 & Glove Type 2 & SS & Hexagonal & 3.06 & 3.05 & 1.14 & 0.72 & 2.68 \\
\hline 15 & 2 & 0.88 & Barehand & Nylon & Circular & 3.54 & 3.54 & 1.15 & 0.73 & 3.07 \\
\hline 15 & 2 & 0.88 & Barehand & Nylon & Hexagonal & 3.54 & 3.54 & 1.11 & 0.70 & 3.19 \\
\hline 15 & 2 & 0.88 & Barehand & SS & Circular & 3.54 & 3.54 & 1.18 & 0.75 & 3.02 \\
\hline 15 & 2 & 0.88 & Barehand & SS & Hexagonal & 3.54 & 3.54 & 1.30 & 0.82 & 2.72 \\
\hline 15 & 2 & 0.88 & Glove Type 1 & Nylon & Circular & 3.54 & 3.54 & 1.09 & 0.69 & 3.26 \\
\hline 15 & 2 & 0.88 & Glove Type 1 & Nylon & Hexagonal & 3.54 & 3.54 & 1.13 & 0.71 & 3.15 \\
\hline 15 & 2 & 0.88 & Glove Type 1 & SS & Circular & 3.54 & 3.54 & 1.21 & 0.76 & 2.93 \\
\hline 15 & 2 & 0.88 & Glove Type 1 & SS & Hexagonal & 3.54 & 3.54 & 1.28 & 0.81 & 2.77 \\
\hline 15 & 2 & 0.88 & Glove Type 2 & Nylon & Circular & 3.54 & 3.54 & 1.22 & 0.77 & 2.90 \\
\hline 15 & 2 & 0.88 & Glove Type 2 & Nylon & Hexagonal & 3.54 & 3.54 & 1.28 & 0.81 & 2.77 \\
\hline 15 & 2 & 0.88 & Glove Type 2 & SS & Circular & 3.54 & 3.54 & 1.29 & 0.82 & 2.75 \\
\hline 15 & 2 & 0.88 & Glove Type 2 & SS & Hexagonal & 3.54 & 3.54 & 1.26 & 0.80 & 2.81 \\
\hline 15 & 3 & 0.43 & Barehand & Nylon & Circular & 4.39 & 4.39 & 1.07 & 0.67 & 4.11 \\
\hline 15 & 3 & 0.43 & Barehand & Nylon & Hexagonal & 4.39 & 4.38 & 1.13 & 0.71 & 3.89 \\
\hline 15 & 3 & 0.43 & Barehand & SS & Circular & 4.39 & 4.38 & 1.04 & 0.66 & 4.20 \\
\hline 15 & 3 & 0.43 & Barehand & SS & Hexagonal & 4.39 & 4.38 & 0.99 & 0.62 & 4.44 \\
\hline 15 & 3 & 0.43 & Glove Type 1 & Nylon & Circular & 4.39 & 4.37 & 1.11 & 0.70 & 3.95 \\
\hline 15 & 3 & 0.43 & Glove Type 1 & Nylon & Hexagonal & 4.39 & 4.37 & 1.09 & 0.69 & 4.00 \\
\hline 15 & 3 & 0.43 & Glove Type 1 & SS & Circular & 4.39 & 4.37 & 1.13 & 0.71 & 3.90 \\
\hline 15 & 3 & 0.43 & Glove Type 1 & SS & Hexagonal & 4.39 & 4.37 & 1.14 & 0.72 & 3.84 \\
\hline 15 & 3 & 0.43 & Glove Type 2 & Nylon & Circular & 4.39 & 4.37 & 1.17 & 0.74 & 3.75 \\
\hline 15 & 3 & 0.43 & Glove Type 2 & Nylon & Hexagonal & 4.39 & 4.37 & 1.11 & 0.70 & 3.93 \\
\hline 15 & 3 & 0.43 & Glove Type 2 & SS & Circular & 4.39 & 4.37 & 1.20 & 0.76 & 3.67 \\
\hline 15 & 3 & 0.43 & Glove Type 2 & $\mathrm{SS}$ & Hexagonal & 4.39 & 4.37 & 1.28 & 0.81 & 3.41 \\
\hline 15 & 4 & 0.28 & Barehand & Nylon & Hexagonal & 5.43 & 5.43 & 1.29 & 0.82 & 4.20 \\
\hline 15 & 4 & 0.28 & Barehand & SS & Circular & 5.43 & 5.43 & 1.21 & 0.76 & 4.49 \\
\hline
\end{tabular}




\begin{tabular}{|c|c|c|c|c|c|c|c|c|c|c|}
\hline Participant & $\begin{array}{l}\text { Task } \\
\text { Plate }\end{array}$ & $\begin{array}{l}\text { Object } \\
\text { Height }\end{array}$ & $\begin{array}{l}\text { Glove } \\
\text { Condition }\end{array}$ & $\begin{array}{l}\text { Object } \\
\text { Material }\end{array}$ & $\begin{array}{l}\text { Object } \\
\text { Shape }\end{array}$ & ID & IDe & MT & $\begin{array}{l}\text { Normalized } \\
\text { MT }\end{array}$ & TP \\
\hline 15 & 4 & 0.28 & Barehand & SS & Hexagonal & 5.43 & 5.43 & 1.23 & 0.78 & 4.45 \\
\hline 15 & 4 & 0.28 & Glove Type 1 & Nylon & Circular & 5.43 & 5.41 & 1.32 & 0.83 & 4.11 \\
\hline 15 & 4 & 0.28 & Glove Type 1 & Nylon & Hexagonal & 5.43 & 5.41 & 1.35 & 0.85 & 3.94 \\
\hline 15 & 4 & 0.28 & Glove Type 1 & SS & Circular & 5.43 & 5.42 & 1.45 & 0.91 & 3.78 \\
\hline 15 & 4 & 0.28 & Glove Type 1 & SS & Hexagonal & 5.43 & 5.41 & 1.42 & 0.90 & 3.84 \\
\hline 15 & 4 & 0.28 & Glove Type 2 & Nylon & Circular & 5.43 & 5.41 & 1.53 & 0.97 & 3.55 \\
\hline 15 & 4 & 0.28 & Glove Type 2 & Nylon & Hexagonal & 5.43 & 5.41 & 1.56 & 0.99 & 3.48 \\
\hline 15 & 4 & 0.28 & Glove Type 2 & SS & Circular & 5.43 & 5.41 & 1.53 & 0.97 & 3.57 \\
\hline 15 & 4 & 0.28 & Glove Type 2 & SS & Hexagonal & 5.43 & 5.42 & 1.58 & 1.00 & 3.43 \\
\hline
\end{tabular}

